


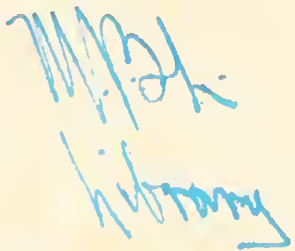




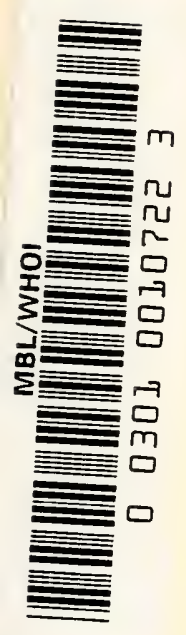



. 


\section{THE EVOLUTION OF THE EARTH AND ITS INHABITANTS}






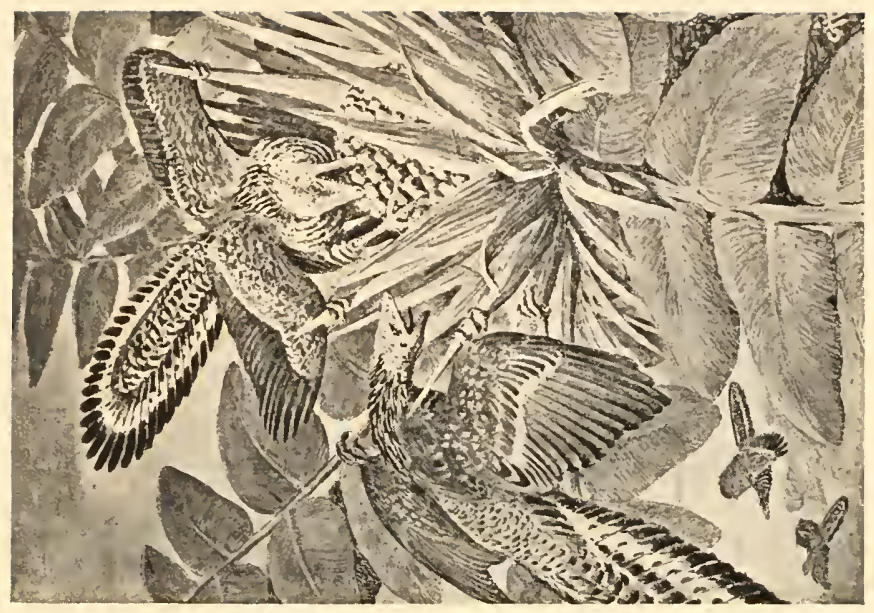

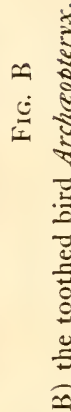
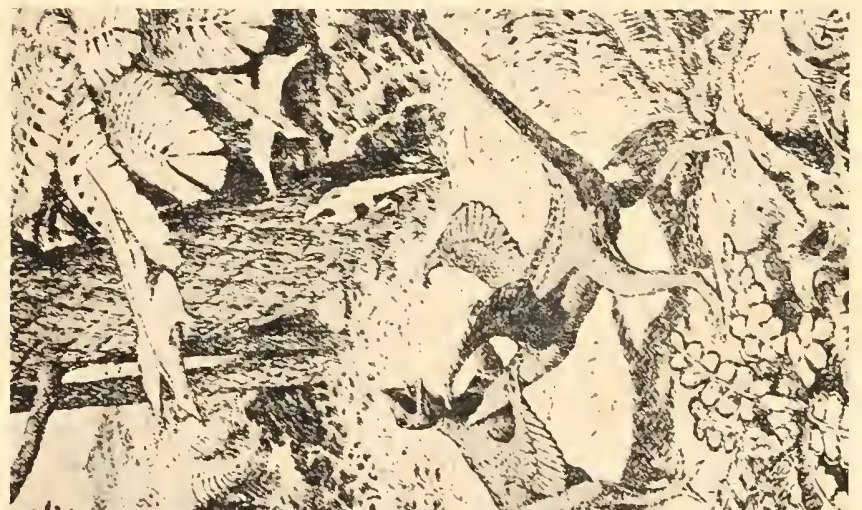

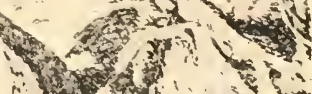
?

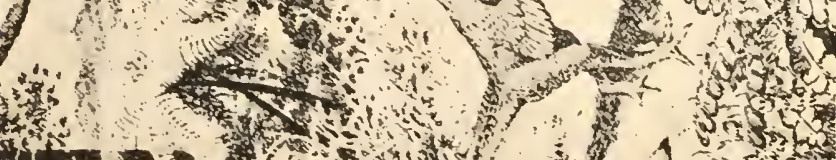

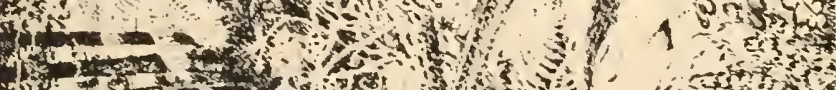

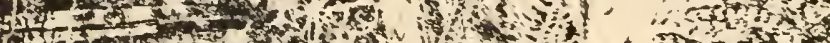
(at)

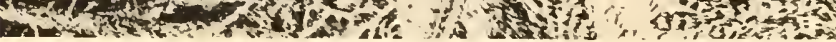




\section{The Evolution of the Earth}

\section{AND ITS INHABITANTS}

A Series of Lectures Delivered before the rale Chapter of the Sigma Xi during the Academic Year I9i6-I9I7

By

Foseph Barrell

Charles Schuchert

Lorande Loss Woodruff

Richard Swann Lull

Ellsworth Huntington

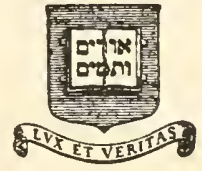

NEW HAVEN

YALE UNIVERSITY PRESS

London: Humphrey glilford: Oxford University Press

MDCCCCXIX 
COPYRIGHT, I9I 8, BY

YALE UNIVERSITY PRESS

First published, Fuly, I9I8.

Second printing, March, Igrg. 


\section{PREFACE}

DURING the collegiate year I9I6-I9I7, the conduct of the Yale Chapter of the honorary scientific society of the Sigma Xi was entrusted to my guidance, and in order to render the meetings of the chapter as profitable as possible, a symposium was proposed on the geological and biological evidences for the evolution of our planet and the earth-borne life. I therefore asked such of my colleagues as were authorities on the several subjects involved to prepare addresses to be delivered before the chapter and later to be published in the form of the present book. The course of lectures was as follows:

THE EVOLUTION OF THE EARTH AND ITS INHABITANTS

Lecture I. The Origin of the Earth, November 23, I9I6, Professor Joseph Barrell.

Lecture II. The Earth's Changing Surface and Climate, December I3, I9 16, Professor Charles Schuchert.

Lecture III. The Origin of Life, January 24, I9I7, Professor Lorande Loss Woodruff.

Lecture IV. The Pulse of Life, February 15, 19 I 7, Professor Richard Swann Lull.

Lecture V. Climate and Civilization, April 20, I9I 7, Doctor Ellsworth Huntington.

The scope of the combined essays is of necessity very broad, ranging as it does from a conception of the universe to the trend of modern civilization. Thus the first chapter deals not alone with the genesis of the earth but of the parent solar system, and, the earth having been established, its history is traced until the time of its becoming a fit environment for the abode of life. The second lecture deals with the changing lines. 
of demarcation between land and sea, the rise and growth of continents, the formation and severance of land-bridges, and the climatic changes which are recorded for geologic time. The physical environment once established, Professor Woodruff tells what we know and do not know of the origin of life. This is largely an academic discussion of the several theories which have been advanced to account for the evolution of lifeless into living matter, for from the nature of the problem evidences of direct observation are not available. The lecture on the pulse of life attempts to link up cause and effect; to find those forces which are responsible for the more or less rhythmic accelerations of evolution shown by the fossil record. The main cause is found to be climatic change, which in turn has as a chief controlling factor earth shrinkage and the consequent warping of the crust discussed in the second lecture. The pulse of life applies not alone to the evolution of animals and plants, but also to mankind. How climatic changes have influenced the growth of civilization and the formation of racial characteristics of mentality is set forth in the last lecture, that by Doctor Huntington. In so far as possible, these essays are the fruits of the original research of their several authors, which in certain instances are set forth here for the first time. The treatment of the entire subject and the marshaling of the facts thus assembled are entirely new.

I am deeply grateful to my colleagues, not only for their having accepted the tasks thus laid upon them, which in several instances implied new and extensive research, but also for the success with which the lectures were presented, as attested by the society.

Yale University,

$$
\begin{gathered}
\text { RICHARD SWANN LULL, } \\
\text { President, Yale Chapter, Sigma } X I . \\
\text { I9 } 6 \text { - 6-1 } 7 .
\end{gathered}
$$

December $1,1917$. 


\section{CONTENTS}

PAGE

Preface . . . . . . . . . RICHARD SWANN LULL V

Chapter I. The Origin of the Earth . . JOSEPH BARRELL 1

Chapter II. 'The Earth's Changing Surface and

Climate. . . . . charles Schuchert 45

Chapter III. The Origin of Life . LORANDE LOSS wOODRUFF 82

Chapter IV. The Pulse of Life . . RICHARD SWANn LULL 109

Chapter V. Climate and the Evolution of Civilization

ELLSWORTH HUNTINGTON 147

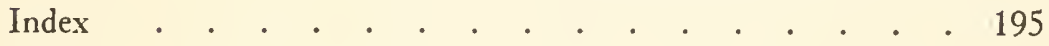





\section{ILLUSTRATIONS}

Restorations of: A. the hypothetical proavian, B. the toothed bird Archaopteryx . . . . . Frontispiece

Plate I. A. Nebulosity in the Pleiades. B. Spiral nebula in Ursa Major . . . . . . . facing page 8

Figure 1. Diagram to illustrate tidal forces . . . . . . 14

Figure 2. Origin of a spiral nebula according to Chamberlin and Moulton . . . . . . . . . 18

Plate II. The western and eastern hemispheres facing page 40

Figure 3. Diagram showing the times and probable extent of the more or less marked climatic changes in the geologic history of North America, and of its elevation into chains of mountains . . . . . . . . . 53

Figure 4. Glacially striated diabase, made in early Permian time. South Africa . . . . . facing page

Figure 5. Lower Cambrian quartzite, striated in early Permian time. South Australia . . . . facing page

Figure 6. Glacial bowlder beds beneath thick formations of dolomite on the upper Yangtse River, China. Age of till, late Proterozoic . . . . facing page

Figure 7. Eroded exposure of the oldest known glacial deposits (Lower Huronian), near Cobalt, Ontario

facing page

Figure 8. Striated bowlder taken from the oldest known glacial deposits . . . . . . . facing page

Figure 9. Generalized map of North America in Paleozoic time 62

Figure 10. The marine inundation in Pennsylvanian time . . 66

Figure 11. Earlier and maximal phases of the Silurian flood . 72

Figure 12. Great Middle Cretaceous transgression of the oceans over the lands : . . . . . . . . . .

Figure 13. Diagram showing time and extent of the known floods that have inundated North America since the close of the Proterozoic era . . . . . . 
Figure 14. Diagram of the pulse of life .

Figure 15. Squid, Loligo sp., capturing a fish . . . . . 115

Figure 16. Fish forms . . . . . . . . facing page 116

Figure 17. Laurentian peneplain as seen from the south end of Lake Michikamau, Labrador . . . facing page 118

Figure 18. Lung-fish, Neoceratodus, breathing . . . . . 121

Figure 19. African fringe-finned ganoid, Polypterus delhezi . 122

Plate III. Cast of the oldest known fossil footprint, Thinopus antiquus, from the Upper Devonian of Pennsylvania

facing page

Figure 20. Development of the hind foot of a salamander, Triton taniatus . . . . . . . . . . 124

Figure 21. Foot of a reptile, Ranodon sibericus . . . . . 124

Figure 22. Restoration of the Permian stegocephalian, Cacops aspidephorus . . . . . . . . . . .

Figure 23. Diagram showing the relation of the extra-embryonal membranes: A. bird or reptile, B. mammal

Figure 24. Skull of cynodont reptile, Nythosaurus larvatus . . 128

Figure 25. Tooth of a carnivorous dinosaur, Allosaurus, and jaw of a contemporary mammal, Diplocynodon

facing page

Plate IV. Restoration of archaic mammals: A. Phenacodus primavus, B. Coryphodon, C. Dinoceras facing page

Figure 26. Restoration of the creodont, Dromocyon . . . . 135

Figure 27. Map showing the geographical distribution of the primates, living and extinct, and their indicated dispersal from Holarctica . . . . . . . . 138

Figure 28. Gorilla, Gorilla gorilla . . . . facing page 140

Figure 29. Gibbon, Hylobates lar . . . . facing page 144

Figure 30. Photograph of a submarine, twenty feet below the surface, taken from the aeroplane whose shadow is shown in the picture . . . . . facing page 144

Figure 31. Climograph of the northeastern United States . . 159

Figure 32. Climograph of France and Italy . . . . . . 160

Figure 33. Climograph of Southern California . . . . . 161 
Figure 34. Climograph of deaths among colored people in the eastern United States, 1912-1915. Non-contagious diseases . . . . . . . . . . . . 168

Figure 35. Climograph of deaths of white people in the eastern United States, 1912-1915. Non-contagious diseases 169

Figure 36. The distribution of human energy on the basis of climate . . . . . . . . . . . 173

Figure 37. The distribution of civilization . . . . . . 173

Figure 38. Changes of climate in the subtropical zone during historic times, on the basis of the growth of trees in California . . . . . . . . . . 186 

THE EVOLUTION OF THE EARTH AND ITS INHABITANTS 



\section{CHAPTER I \\ THE ORIGIN OF THE EARTH ${ }^{1}$ \\ JOSEPH BARRELL \\ PROFESSOR OF STRUCTURAL GEOLOGY IN YALE COLLEGE}

\section{INTRODUCTION}

THE logic of all branches of science points to the existence of some system of evolution of the universe, its complete nature hidden in the vastnesses of time and space, but nevertheless developed in accordance with Nature's laws. The earth is one of the celestial host, its beginnings are bound up with that of other bodies. In the history written in the structure of the earth and in the relations of the earth to the planets, stars, and nebulæ lies concealed the story of its genesis. Two chief methods of approach, the geologic and astronomic, lead toward the solution of this fundamental problem.

The history of the earth is read in the rocks which have been thrust up by internal forces and beveled across by erosion. The nearer events are clearly recorded in the sequence and nature of the sedimentary rocks and their fossils. But the oldest formations have been folded, mashed, and crystallized out of all resemblance to their original nature, and intruded by molten masses now solidified into granite and other

1 Also presented before the Geological Society of Boston, January 19, 1917.

Some pages of the following article have been drawn from one by the writer entitled "Origin of the Solar System Under the Planetesimal Hypothesis," published as Chapter XXV in Pirsson and Schuchert's "Text-book of Geology," 1915. For permission to use this material grateful acknowledgment is made to the authors and publishers of that work. 
igneous rocks. Fossils, the time markers of geology, if once existent, have been destroyed, and, as in the dawn of human history, vast periods of time are dimly sensed through the disordered and illegible record. This crystallized and intricately distorted series of the oldest terrestrial rocks tells of an earth surface on which air and water played their parts, much as now. But it was a surface repeatedly overwhelmed by outpourings of basaltic lava on a vaster scale than those of later ages, and the crust was recurrently broken up and engulfed in the floods of rising granitic magmas. Here the geologic record begins, but the nature of its beginning points clearly to the existence of a prehistoric eon. At the farther bounds of this unrecorded time, forever hidden from direct observation, lies the origin of the earth.

But the mind of man will not be baffled. Since he may not see directly he will see by inference. Convergent lines of evidence derived from various fields of knowledge may be followed part way toward this goal, like those rays perceived through the telescope on the full moon near the margin of its visible hemisphere, which converge toward craters on the side of the moon that no eye shall ever see.

Leaving the geologic field of evidence, the problem of the origin of the earth may be approached from the astronomic side. The relationships of the earth to the stars and the planets are displayed in the depths of the heavens, and vestiges must there exist of the cosmic conditions which gave birth to our world and the other planets of our system. The forces of nature are found to obey the same laws as far as the telescope can penetrate. The spectroscope detects the familiar chemical elements in distant stars. These instruments give assurance of the unity of the cosmos, but the diversity of objects indicates various stages and various types of evolution. Which approaches nearest to that of our solar system? We must be content to study very much larger and therefore unlike 
systems, since from the distances of even the nearer stars the earth and her sister planets would be hopelessly invisible in the most powerful telescope. We cannot, then, follow into the planetary stage the evolution of other systems comparable to our own. Yet in nebulæ, in stars, and in the inherited motions and configurations of our planetary system are clues which pieced together lead up toward the origin of the earth.

The problem of the origin of the earth is within the domain of scientific investigation, but as yet the pictures which may be drawn are varied. The vague outlines shift and change but become clearer with the growth of knowledge. Where the solution of a problem is not yet definitive and certain, the method of multiple working hypotheses should be used. All facts and theories should be matched to these several hypotheses to determine which one of them shall be selected and modified, and which shall meet the fate of the unfit. At the present stage of investigation any one view should not be regarded as established beyond question, even though the assembled evidence seems strongly to support it. In a single presentation, however, all hypotheses cannot be equally treated and each investigator, while recognizing the existence of other hypotheses, may properly emphasize that one which seems to him most in accordance with the various categories of facts and more firmly established inferences.

The hypotheses of earth origin begin more especially in the astronomic field in the search for initial causes; they end in the geologic field where they dovetail into the known relations. The surviving hypothesis must give a sound explanation of those broader terrestrial conditions of atmosphere, hydrosphere, and lithosphere, of ocean basins and continental platforms, which had become established by the beginning of the geologic record. But, although much has been learned, it is still unsettled among geologists as to how far those fundamental conditions in early geologic times were different from 
those of the present. On the whole, the problem of the genesis of the earth appears to lie somewhat more in the field of the geologist than in that of the astronomer.

\section{The Place of the Earth in the Universe}

The earth, a member of the solar system. The earth is but one among the planets which together with the sun constitute the solar system. It is neither the largest nor the smallest, neither nearest to nor most remote from the sun.

The sun is a star and is but one among the millions of stars, and, though apparently so great as seen from the earth, is mediocre among them in size and brightness. The origin of the earth is obviously bound up with the origin of the other planets and all in the history of the sun. A presentation of the significant facts of magnitudes, motions, and distribution of these bodies, familiar though they are to most readers, should therefore precede the consideration of the genesis of the earth.

The planets visible to the unassisted eye are, besides the earth, five in number, distinguished by the ancients from the stars by their steady light and by their wanderings through the zodiacal path in the sky, wanderings produced as a result of the combined effect of their motions and that of the earth in nearly circular paths about the sun, their common center. The telescope has added to the number of planets two large ones, Uranus and Neptune, invisible to the naked eye because of their distance from sun and earth, and, in one zone of intermediate distance, a swarm of smaller bodies, the asteroids, better called planetoids. In size the planets sink to vanishing insignificance in comparison with the sun or any other star. Their distances from the sun and from each other are also almost infinitesimal in comparison with the distances which separate the stars. They shine by light reflected from the 
sun, and as all the planets and planetoids are attendant upon the sun, they form a common system, the solar system. The facts regarding their size, their distance from the sun, and the inclination and position of the planes of their orbits with respect to the orbit of the earth are tabulated as follows:

PRINCIPAL ELEMENTS OF THE SOLAR SYSTEM

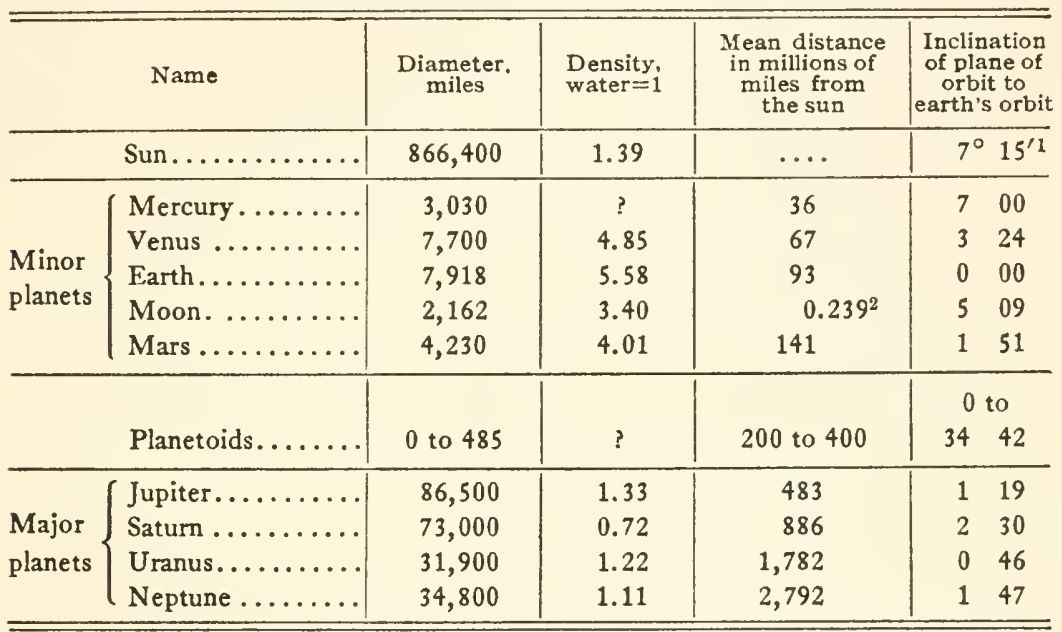

${ }^{1}$ Inclination of sun's equator to earth's orbit.

${ }^{2}$ Mean distance of moon from earth.

Notable Planetary Relations. That the orderly nature of this system implies some mode of evolution was seen by the framers of the nebular hypothesis. The more notable of these relations, following the summary by Young, are:

I. The orbits are all nearly circular.

2. They are nearly in one plane (excepting the cases of some of the little planetoids).

3. The revolution of all is in the same direction.

4. There is a curiously regular progression of distances from the sun (expressed by Bode's law, which, however, breaks down at Neptune). See foregoing table. 
5. There is a rough progression of density, increasing both ways from Saturn, the least dense of all the planets in the system.

As regards the planets themselves, we have:

6. 'The plane of the planets' rotation, the plane of their equators, roughly coinciding with those of the orbits (probably excepting Uranus).

7. The direction of the rotation of the planets about their polar axes the same as that of their revolution in their orbits (excepting probably Uranus and Neptune).

8. The plane of orbital revolution of the satellites of each planet coinciding nearly with that of the planet's rotation, its equatorial plane.

9. The direction of the satellites' revolution in their orbits also coinciding with that of the planet's rotation about its axis, with exceptions in the case of the ninth satellite of Saturn and probably the seventh of Jupiter.

I O. The largest planets rotating most swiftly.

The sun, a member of the stellar system. The sun, as has been stated, is but a star and a member of the stellar system. What are the orders of magnitude in number, in size, in distance, in speed, in duration among these countless orbs, and how do these relations enter into the problem of the origin of the earth as one of that retinue of planets which attend upon the sun?

The luminous stars of our system are estimated to be more than a hundred million in number. The number of the dark stars is unknown. Giving no ray of light to reveal their existence, they may for all we know be as numerous or more numerous than those in the radiant stages of their existence. The few stars whose sizes are known range in diameter from somewhat below a million to upward of ten million miles and more.

Many of the stars are in reality double or multiple stars, consisting of companions so close that the two or more appear as one star to the naked eye, or even under the highest power 
of the telescope, the evidence of their composite nature being revealed only through the analysis of their light by the spectroscope. These double stars revolve swiftly about each other, but such internal motions must be sharply distinguished in thought from the streaming or drifting of the stars as parts of the great stellar system. Relatively to the sun they are found to move through space with speeds averaging between IO and 30 miles per second, but ranging from less than ro to more than 200 miles per second. They do not move, however, singly and in closed orbits, but rather in broadly scattered groups whose paths are almost straight lines. These courses of the stars must slowly curve under the aggregate attraction of the millions of stars, but can never return into themselves. The paths of groups of stars intersect other groups and are to some extent interwoven among themselves. These groups have been found to be integrated into two greater groups intermeshed among each other and forming two great star streams whose average motions are in opposite directions. With the passage of millions of years, the stars thus continually enter into new relations and build new configurations in the skies: a myriad host of stellar fireflies, the living and the dead, streaming through space hundreds of millions of miles per year.

Although the stars are so great in number, their distances from each other average tens of millions of millions of miles, those in our part of the stellar system averaging between sixty and eighty trillions. The star nearest to the sun, $\alpha$ Centauri, happens, however, to be at a lesser distance of about twentysix trillions of miles.

To bring down the dimensions of the universe to finite comprehension, we must divide the scale of nature by a thousand million. Then the earth would be represented by a pebble half an inch in diameter, circling once a year about a sun 4.5 fect in diameter, at a distance of 500 feet. The nearest 
star, a Centauri, would on this same scale be seen as two spheres revolving about each other at a distance apart equal to 2 miles, and each comparable in size to the sun. This double star would be situated at a distance of about 25,000 miles from our planetary system with its sun, but the other stars in this part of the stellar system would be separated from each other on the average by more than twice this distance. The Galaxy, or Milky Way, is the cloud-like zone of faint stars which extends as a belt around the sky. The stars in it appear faint and close together because of their remoteness. They seem to constitute the outer zone of our stellar system, and its dimensions are only vaguely known. On this diminutive scale the Milky Way might be found to be encompassed by a circle of a hundred million miles diameter, or it might be more or less.

The nebula. All hypotheses of earth origin derive the planets and the sun from an antecedent nebulous or meteoritic state. The cloudy patches of light known as nebulæ, which are revealed especially by stellar photography, are, however, of several very different natures and it is a vital question as to which, if any, of these types, could have given birth to our planetary system.

First are the irregular nebulæ, diffuse clouds of luminous matter, pervading whole groups of stars as in Orion and the Pleiades, shown in Plate I, A, denser about certain stars, but nevertheless enormously attenuated. This kind of nebulosity is associated with certain regions of the Milky Way. From the characteristics of their spectra, the stars in such nebulæ are regarded as young stars and the nebulous matter may represent the remains of an antecedent stage.

The planetary nebulæ are a distinct type, comparatively few in number, and also found associated with the Milky Way. They show in the telescope faint, greenish, circular discs from which they derive their name rather than from any known 


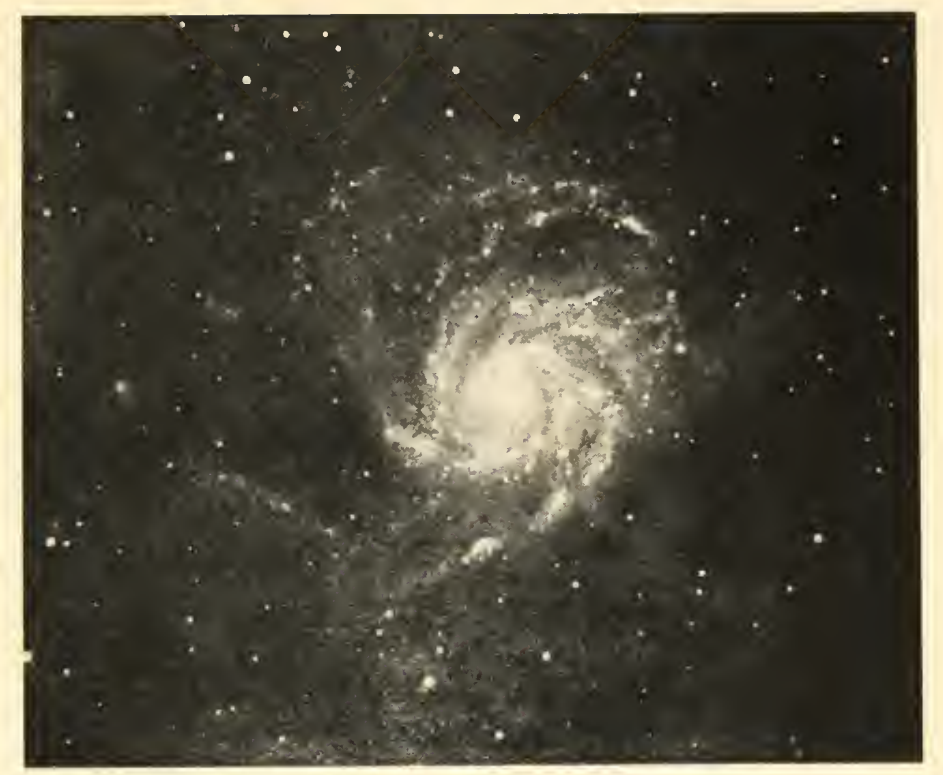



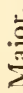

$\stackrel{8}{3}$

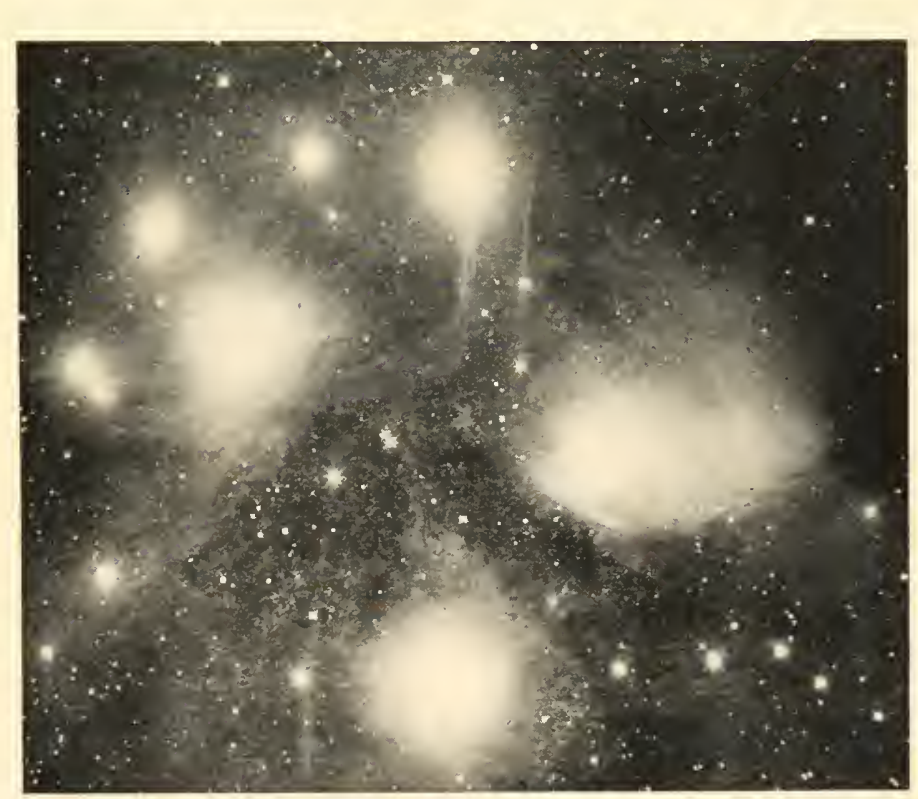

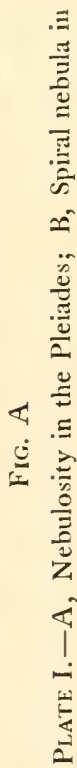



relationships to planetary systems. They seem to be related in their origin to New Stars and these in turn are thought to be produced by stars sweeping through clouds of meteoric or gaseous matter and attaining temporarily, from the swift impacts, an enormous brilliancy. The impact is so superficial, however, that the extreme brilliance is usually lost in a few days or weeks, and the star subsides through a stage like a planetary nebula into a peculiar type of star known as the Wolf-Rayet stars. The origin of the true planetary nebulæ has not, however, been observed, as they appear to possess a longer life than those which have originated in the past few centuries from new stars.

The ring nebulæ are few and special, having the form of a vortex ring.

The stellar nebulæ form another small group which look in the telescope like hazy stars.

By far the greatest number of the nebulæ are classified as spiral nebulæ, more than 120,000 of which have been made known by photography in connection with the greater telescopes. Their actual number must of course be far greater. These objects, unlike the other forms of nebulæ, avoid the Milky Way, and are scattered over regions where the stars are more widely spaced. They are very remote and may be entirely beyond the stellar system. This implies enormous magnitude. It seems probable that in general they possess high internal velocities, which implies in turn enormous masses to generate such velocities. These nebulæ possess spectra similar to those of stars rather than, like the other types of nebulæ, spectra of diffuse clouds of gas. Some astronomers look upon them, therefore, as possibly systems of stars rather than true nebulæ; systems so remote as to give the appearance of faint cloud-like spirals, even when viewed under the highest powers of the telescope. A typical spiral nebula is shown in Plate I, B. 
Hypothesis of Planets Derived from a Primal Nebula

The original hypothesis of Kant and Laplace. In 1754 and 1755 Immanuel Kant, the philosopher, published the most remarkable papers which had appeared up to that time upon the evolution of the solar system. He conceived matter to have been originally diffused and cold. From a position of rest it began to converge under the influence of gravitation and gave rise to the sun. In some manner he held that the matter in converging acquired a movement of rotation. Certain nuclei grew up independently from the center and gave rise to the planets and satellites. In 1785 he developed the idea that the contraction of the sun's mass would develop its heat, a view elaborated by Helmholtz in 1854 and generally held by astronomers at the present time. Thus Kant sought, and with a large measure of success, to evolve the present state of the universe from the simplest condition by means of mechanical laws alone.

In 1796 Laplace, one of the most eminent of French astronomers, published a general work on astronomy, and in a short note at the end of the appendix proposed a theory of the origin of the solar system which shortly became widely known as the nebular hypothesis. He was evidently unaware of Kant's work published forty-one years previously. Laplace is most noted for his mathematical work on celestial mechanics, yet he did not develop his hypothesis along such lines and apparently did not attach much importance to it. Nevertheless, it became the dominant idea in cosmic evolution throughout the next century.

Laplace postulated an original nebula as a very hot, gaseous mass extending beyond the orbit of the farthest planet and possessing a uniform rotation throughout, as if it were a solid body. Its size was the result of a balance between expansion from its heat and contraction from its gravitation. As it lost 
heat it contracted and, with the same energy of rotation that it possessed before, necessarily revolved on its axis in a shorter time. At last a stage was reached where, in the equatorial belt, centrifugal force balanced gravitation and the matter subjected to this balance of forces could sink in no further. It is thought to have existed as a ring, left behind by the condensing mass. The ring, however, was unstable; it broke up and gathered into one body. During the further shrinking of the main mass other rings were in turn abandoned. Each gathered into a subordinate nebula, passed through an independent evolution, and the whole gave rise to the system of planets and their satellites.

Modifications of the nebular hypothesis. During the first half of the nineteenth century the nebular hypothesis was accepted by astronomers almost without question, but during the second half many serious dynamical objections were developed and a process of modification began, until now not much remains of the original conception of Laplace. A rather full statement of the hypothesis and the objections to it has been given recently by Campbell. ${ }^{2}$ A briefer summary and a citation of but a few of the modifications in the general concept must here suffice.

George Darwin, Lockyer, Faye, Fouché, Poincaré, and others have taken part in this work, and in the opinion of these mathematicians and astronomers the framework of the resulting structure is still sound, though subject of course to further modification as knowledge increases. It was shown that the original nebula need not have been hot, but, as perceived by Kant, would develop heat from its self-condensation. A loose swarm of cold meteorites would suffice as well as an original gas for the initial state. The mass could never have revolved as a unit body, as if it were a solid. On the contrary, the inner

2 Campbell, W. W., "The Evolution of the Stars and the Formation of the Earth." Scientific Monthly, vol. 1, 1915, pp. 189-194. 
parts would be condensed and revolve fast while the outer parts were still diffuse and revolved slowly. The mode suggested by Laplace for the separation of the rings is also dynamically very unsatisfactory. Moulton has shown that the growth of the planets and the development of rotation in the same direction as their orbital motion could be much better attained from an initial state in which the component particles revolved in the same plane but independently and in highly elliptic orbits about the central nucleus. This is a wide departure from the idea of a circular ring revolving as a unit body.

Still more fundamental objections, emphasized by Chamberlin and Moulton, are found in certain of the existing dynamical relations of the solar system. It would be expected that in condensation the central mass would continually abandon matter from its equatorial zone, the inner planets would presumably have possessed the greater masses, and the final sun would now show a high speed of rotation, giving an equatorial diameter far greater than the polar. Such expectations are contrary to the facts. The sun revolves so slowly on its axis, once in twenty-five days, that it has no measurable equatorial bulge. In other words, centrifugal force is negligible in the sun. Furthermore, the equatorial plane of the sun, instead of lying precisely in the mean plane of the planets' orbits, is inclined seven degrees to such a mean plane.

A hypothesis to gain scientific credence must emerge successful from the test of observed facts and mathematical theory. The nebular hypothesis has not done so. It is on the defensive and has lost standing during the past generation. Nevertheless, it would be premature to abandon it entirely. It has the advantage of simplicity in that satellites, planets, and sun are explained as the products of a single process, convergence in a rotating nebula. But nature is often found to be complex in her operations, so that this advantage is of doubtful weight. 
Hypothesis of Planets Derived from a Small Secondary Nebula

Distinctive features of the planetesimal hypothesis. The planetesimal or spiral nebula hypothesis of Chamberlin and Moulton postulates the sun already in existence from the ingathering of a primal nebula. It was at some later stage disrupted through the tidal forces produced by the close approach and passage of another star. The result was a secondary nebula, but one essentially unlike the primary. The secondary nebula was developed in a plane and initially possessed a spiral form with the sun at its center. All of its parts moved with freedom and independence in elliptic orbits, a point of difference from the Laplacian hypothesis. The nebula contained only a minute fraction of the solar matter, but was endowed by the passing star with a great rotational energy, so that, although so insignificant in mass, the planetary matter dominates enormously over the sun in the moment of momentum of the whole system. Thus the planetesimal hypothesis is a bold and frank abandonment of the terms of the original or nebular theory. It is too early as yet to predict what will be the ultimate fate of this hypothesis of a secondary, and, in a measure, an accidental origin of the planets, but, as expounded by its originators, it must be regarded as dynamically more satisfactory than the present form of the hypothesis of primary origin. The essential features will, therefore, be presented as the more probable preliminary steps in the genesis of the earth.

Forces of tidal disruption. The power of stars to disrupt each other without coming into actual contact, merely through relatively close approach, must be understood, as it is the basis of the planetesimal hypothesis.

The sun and moon raise terrestrial tides by virtue of the pull of gravity and thus modify that spheroidal form of the earth which is given by its own gravity and the centrifugal 


\section{I4 EVOLUTION OF THE EARTH}

force of its revolution. Suppose, in other examples of heavenly bodies, the tidal pull to be many times stronger, the self-gravitative cohesion to be many times weaker. A limit will be reached at which the body may be pulled to pieces. This phenomenon, which has been actually observed in the case of comets passing close to the sun, has been called tidal disruption.
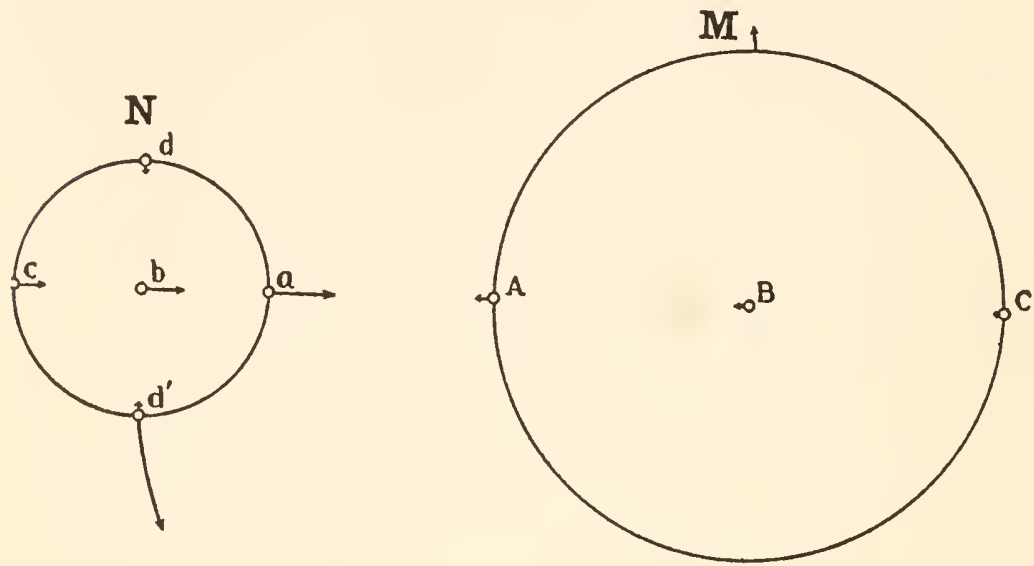

FIG. 1.-Diagram to illustrate tidal forces.

Let $\mathrm{M}$ and $\mathrm{N}$ in Figure $\mathrm{I}$ be two bodies passing each other in space, and consider the action of the larger on the smaller. According to Newton's law, the bodies attract each other directly as their masses and inversely as the square of their distances, causing them to swing toward each other while passing by, but soon losing influence as they separate in their journeys through space. Consider three particles, a, b, c, on the line of attraction, taking them as separate parts of the smaller body. But $a$ is nearer to $M$ than is $b$, and $b$ is nearer than c. Therefore if we represent the relative attractions by lines, these lines will correspond to the distances which the particles would move in a given time if free to obey the attrac- 
tion of the other body. The line at $a$ is longer than that $a t b$ and the latter is longer than that at c. If $\mathrm{N}$ was not bound together by its own gravity or rigidity, a, b, and c would therefore drift apart and fan out while passing $M$. Consider that rigidity is negligible, as in a fluid globe; then, if a minus $b$, or b minus $c$ are quantities which become greater than the self-gravitative force of $\mathrm{N}$ holding together a and c, the unity of the body becomes destroyed. The problem, however, is not quite so simple, since the influence of all other points in $\mathrm{N}$ must also be considered.

As the nearer part of the body is pulled from the center, and as the center is pulled from the farther side, there will, further, be two simultaneous tides of approximately equal height, but on opposite sides of the distorted body. They tend to be always on the line joining the two bodies. Thus, on the earth there are two tides on opposite sides, but the revolution of the earth on its axis, like a car wheel under two opposite brake-shoes, gives an apparent effect, to one on the surface of the earth, of a revolution of the tidal wave. As a result of the equal tides at opposite ends of a diameter there are, on any part of the ocean, two high tides in twenty-four hours.

Mode of tidal disruption in stars. A star is characterized by its enormous size and mass and by the possession of a gaseous constitution. The diameter and density are dependent upon the balance at every point between the tremendous expansive forces of internal heat and the equally great compressive forces due to its own gravity. If it contracts, then its surface and each component shell below comes nearer to the center, the effect of gravity upon any shell accordingly increases inversely as the square of the new radius, and a higher internal temperature becomes necessary to balance the higher gravitative force. From this there results the paradox known as Lane's law,-that so long as a body maintains a gaseous 
constitution its temperature must rise as it contracts, even though at the same time it is radiating heat. The temperature of the interior must furthermore be higher than the temperature of the surface, because of the greater compression with depth, as is illustrated in the different strata of the terrestrial atmosphere. In those convective or slow boiling movements which are necessary in the sun and other stars in order that they should be able to maintain their surface radiation, there is then a constant liberation of energy from the depths and a system of balanced motion which if disturbed could lead in any star to an explosive blowing out of material from it on an enormous scale.

The tide-generating force varies directly with the mass of the disturbing body and also with the radius of the body disturbed. It varies approximately inversely with the cube of the distance between the centers. The deforming force is, furthermore, greatest in the interior because the tidal forces acting on the zone at right angles to the line of attraction have a component which tends to squeeze in the points $d, d^{\prime}$ of Figure $\mathrm{I}$ toward the center. The gravitative control is accordingly weakened along the line $a, b, c$, and is strengthened in the directions at right angles. Now apply this principle to the gaseous balanced nature of a star, and it is seen that the expansion in the line $a, b, c$ is no longer exactly balanced by the gravitative compression, and the unbalancing is greatest in the center, where also is the region of highest compression and highest temperature. The effect is as if one squeezed a syringe bulb with orifices for exit at both ends, a bulb, however, like an air rifle, filled with gas compressed to an explosive degree.

Tidal disruption of the ancestral sun. The sun is occasionally observed to shoot out streams of gas, known as solar prominences, to heights of nearly 300,000 miles, and at velocities ranging up to 300 miles per second. Such phe- 
nomena indicate the enormous elastic and explosive energy resident in the sun's interior, an expansive potency held in restraint by the equally prodigious power of the sun's gravity.

Supposing then that the ancestral sun was subjected to tidal disruption by the approach of another and possibly much more massive star, it remains to be seen how the nebula resulting from tidal disruption can become the embryo of an orderly planetary system. If the matter were shot out from great depths in the sun by its normal expansive forces plus the tidal forces, the velocity of departure might rise high above the observed velocities of 300 miles per second. If 400 miles or more, it would be above the "critical velocity" of the sun. The gravitative attraction of the latter could then never reclaim that matter, because the decrease in the outward velocity due to the solar attraction would never bring the velocity down to zero, and could therefore never reverse the motion of the escaping matter and bring it back to the sun.

It is doubtful if the sun could have drawn back to itself material expelled with a velocity of even 300 miles per second, for the passing star, by lowering the gravitative power of the sun on the line passing through the two, would temporarily decrease on that line the critical velocity. In other words, it would help to drag matter away from the sun, even though that matter could not catch up to the passing star, but would be left wandering in interstellar space, forming possibly cometary and meteoric material for other systems. But some, or possibly all, of the matter of the exploded sun may have had lesser velocities of escape and would consequently remain within its gravitative control. In so far as it was not deflected sideways by some extraneous force, it would fall back on the surface of the sun as the water of a geyser falls back into its pool. But the gravitative pull of the passing star would serve as such an extraneous force, analogous to the wind which blows part of the geyser water, as it rises and falls, to one 
side of the basin. The matter shot out toward the passing star would be attracted sideways after it as the star receded into space. On falling back toward the sun it would consequently pass to one side and elliptical orbits of the separate particles would become established. The material shot out in the reverse direction, from the opposite side of the sun, would meet much the same conditions except that the sidewise pull of the passing star would be less on it than on the sun. It is seen that the lateral or deflecting force acting on both arms of the nebula would be due to the difference between the pull of the passing star on each arm and on the central body. The initial spiral arms do not then represent the path along which the material was shot out, but mark the rotation around the central body or sun, both of the axis of expulsion during the passing of the star and of the matter after it is expelled, as shown in Figure 2.

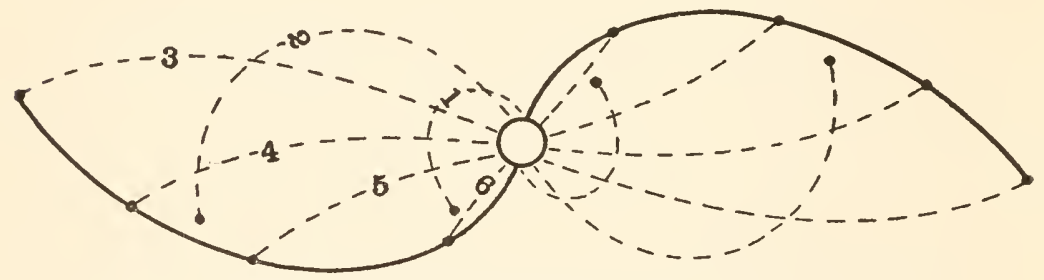

FIG. 2.-Origin of a spiral nebula according to Chamberlin and Moulton.

The spiral nebula would be developed in a plane. That plane is established by the hyperbolic orbit of the passing star with the sun at the focus of the orbit. The new system would thus show in its nature features imposed by both its parents.

From such a nebulous fiery birth Moulton especially has shown how, in accordance with the laws of celestial mechanics, a planetary system could result.

The matter which has converged into the planets would be that residue of the solar tidal disruption which did not pass beyond gravitative control and did not fall back into the body 
of the sun. This residue is only a very small fraction of the sun's mass. It would appear probable, however, that the solar disruption was very great in order to give an axial revolution to the reaggregated matter forming the present sun, so that its equator should be, as observed, only seven degrees from the mean plane of all of the planetary orbits. The present revolution of the sun is probably due then to the whirl produced during tidal disruption and not to an axial rotation belonging to the sun before the event took place.

This brings us to the final stage in the evolution of the planets according to the planetesimal hypothesis. In the arms of the spiral nebula were knots or nuclei of matter constituting the cores of the planets. Four small knots, the earth-moon knot being a double one, represented the beginnings of the four small inner planets (see table, page 5 ). In the zone of the planetoids there was, however, no dominating nucleus, and they have therefore remained to this day largely in the planetesimal state. Four greater nuclei beyond were the beginnings of the major planets. Smaller nuclei associated with the larger marked the presence of satellites.

The orbits of the planetary nuclei and of the scattered planetesimal swarm were highly eccentric, having the form of a tangle of ellipses of all forms and sizes but lying in nearly a common plane and with a common direction of revolution about the central body. Collisions would inevitably occur at the crossing of the paths in the course of numberless revolutions and the nuclei would have sufficient mass and consequent gravitative power to retain the matter colliding with them. In this way, each planet would in the course of time clear up an orbital zone, and these zones, because of the eccentricities of the orbits of the component particles, overlapped each other with the exception of a region between Mars. and Jupiter. But Moulton has shown that in such planetary growth by accretion, an axial revolution would arise in the 
same direction as the orbital revolution, and that the incorporation of all the planetesimals would cause the eccentricities to cancel out, giving to the whole mass a nearly circular instead of a highly elliptical orbit. This would lead us to believe that the original nucleus was but a small part of the completed planet, so that its original ellipticity of orbit was submerged beneath the average influence of the added masses.

Outstanding difficulties of the planetesimal hypothesis. The disruption or spiral nebula hypothesis explains the features of the solar system more successfully than the older nebular hypothesis has thus far been able to do, but there are difficulties still remaining, though these may perhaps be the result of special conditions.

The most striking departure of the real system from that expectation deduced from the hypothesis is found in the rotation of the sun. The passing of a star able to drag matter from the sun to the distance of the planet Neptune would be expected to lead to an enormous tidal distortion of the sun's mass. This great tidal wave would involve a lifting and revolution about the sun, tending to give it a certain energy of rotation. A very little stronger action and the sun would in fact have been literally pulled to pieces and its matter scattered beyond its gravitative control. It is possible that it may in this way have lost a part of its mass. Considerable quantities of the expelled matter should have fallen back obliquely in the sun and tended further to increase its velocity of rotation. The path of the approaching star could have had no relation to the previous equatorial plane of the sun. The probabilities would consequently be that the final rotation would be a resultant between the older and newer forces and lie in an intermediate plane at a considerable angle to the plane of the planets' orbits. Now, as a matter of fact, the sun, as has been previously noted, revolves but once in twentyfive days and its equator is inclined but seven degrees to the 
mean plane of the planets' orbits. To explain this, Chamberlin supposes that the sun had originally a rotation in a plane not greatly different from that in which the passing star approached, but rotated in the opposite direction. The whirl given to the solar mass by the tidal disruption is assumed to have been a little greater than its initial rotation, but, being in the opposite direction, the resultant was at a slow speed and yet nearly in the plane of the planetary orbits. ${ }^{3}$ Campbell points out that the chances are highly against such a special arrangement. If in a number of solar systems such an arrangement prevailed, it would constitute a conclusive proof against the hypothesis, but in the one example the exceptional combination may have occurred and it cannot be urged as a disproof. ${ }^{4}$

Turning to another aspect of the hypothesis, the innumerable spiral nebulæ of the heavens, although good illustrations of the initial hypothetical form of the solar planetary system, do not appear to be stages in a similar evolution in the way that Chamberlin and Moulton have conceived them to be. They are, as previously stated, of a much vaster order of magnitude, they avoid the region where the stars are clustered, are at remote stellar distances, and by their very number show a notable duration of their form. On the other hand, the postulated originally spiral form of the solar nebula would have been evanescent. Within a century from the time of origin all except the outer nuclei would have completed many revolutions about the sun. But the different periodic times of the nuclei would in a few revolutions have caused the initial spiral form to disappear. It would become wound up and further blended together owing to the high ellipticities of the constituent orbits.

${ }^{3}$ Chamberlin, T. C., "The Origin of the Earth," 1916, pp. 130-132.

4 Campbell, W. W., "The Evolution of the Stars and the Formation of the Earth." Scientific Monthly, vol. 1, 1915, p. 241. 
The temporary dispersal of the solar mass would lead to an enormous increase in its radiant energy. The planetesimal matter would as a consequence of its dispersion and increased radiating surface cool with great rapidity, except in the nuclei of masses, and cease to be self-luminous, the smaller particles almost immediately becoming cold except as they were heated by the larger and profoundly disturbed solar mass.

The new stars which have been observed are not regarded as of this nature since they are not expanded into a spiral. In fact, as previously mentioned, no examples are known which serve as illustrations, in the terms of this hypothesis, of the birth stage of planetary systems. This lack of examples may be connected with the small scale as well as the temporary character of such a nebula. The whole solar system, extending to the orbit of Neptune, would subtend slightly less than half a minute of arc as seen from the nearest star. The average star is hundreds of times farther away and at the greater distances a nebula of this order would not betray its existence by its form but only by the temporary great increase in radiance at the time of its birth.

Chances of close approach. Whether the chance is great or small of a planetary system being generated from any particular star by tidal disruption cannot be used as an argument for or against this hypothesis unless it were known what proportion of the stars possessed planetary systems. But that knowledge is hopelessly concealed from us in the depths of space, since such a system as ours after its temporary initial brilliance would, as shown, be invisible in the most powerful telescopes even if it existed about the nearest star.

It is not known how near an approach would be necessary to generate such a solar system; but the chances of close approach must be very small for any particular star. The motion at any instant of any individual star is the result of its motion inherited from the past plus the attractions of all the 
matter in the universe pulling upon it in the present. If two bodies without previous motion were to be attracted toward each other, and were able to ignore the gravitative pull of all other bodies, they would move in a straight line toward each other's centers with ever increasing velocity until collision would result. But the least inherited motion in any other direction, or the least deflecting pull upon one of them more than upon the other by other bodies would prevent to that degree a central collision, or in almost all cases any collision whatever. Now the velocities of the stars through space at great distances from each other are so great that individual stars can have almost no attractive influence upon each other. They must move in nearly straight lines past each other unless they happen to pass within a thousandth part of their average distance. It is seen then that the chances of close approach depend primarily upon the accidental crossing of their paths and only secondarily upon their mutually attracting each other. For this reason the chance of actual collisions may be regarded as negligible, even considering the vast number of stars. Approach sufficiently near to generate strong tidal forces would, however, have occurred during their long lifetimes as radiant bodies to a considerable number out of the hundred million or more of stars which are known to exist in the stellar system, but for any one individual star, where the spacing is of the magnitude existing in our part of the stellar system, the chance of such approach even in a billion years would be very small. In fact, it has been estimated as only one chance in 1,800 in that time. It is possible, however, that this happened once to our star, that is, to our sun of that time, in the distant past and from that disruptive tidal force was born our system of planets. If such an event was in fact a necessary antecedent condition, fortunate indeed has been our planetary fate, for not only did this happen so early in the sun's career 
that its radiant energy has been able to endure through all the ages needed for organic evolution, but the spacing of the stars is so wide and the chance of approach so rare that no other of them has since advanced sufficiently near to throw this system into disorder, or to disrupt and sweep away the earth and its sister planets as a wasted effort, and start the re-creation of a new heaven and a new earth.

\section{Hypothesis of Earth-Growth by Slow Accretion of Planetesimals}

Under the terms of either nebular or planetesimal hypothesis a scattered state of the planetary material is implied as a stage antecedent to the origin of the planets. Was this growth of the planets geologically slow or rapid? Did it take tens or hundreds of millions of years, or was it on the contrary largely accomplished in tens or hundreds of thousands of years? Was the material largely in dust-like or molecular form, or was it to a large extent in nuclei of considerable size? From these different postulates very divergent consequences may be traced in the formative stages of the earth; and finally the present nature of the earth itself may speak in favor of one or the other of these views.

Chamberlin, who has been the chief writer on this subject, adopts the hypothesis that the stages of earth-growth were very prolonged, even geologically speaking, and that the accretion was dominantly of dust-like or molecular particles. According to him the building up of the planets followed three stages: first, the direct condensation of the nuclear knots of the spirals into liquid or solid cores; second, the less direct collection of the outer, or orbital and satellitesimal matter; third, the still slower gathering up of the planetesimal material scattered over the zone between adjacent planets. This third factor, in Chamberlin's view, is 
regarded as very important and he believes this diffused matter contributed much of the earth substance, very slowly and in a dust-like form. This is one of the critical points in the details of the theory upon which turns much of the development of his following argument.

Chamberlin conceives the earth to have been built up as a solid body, not to have been fluid or viscous at any time later than the early nuclear stage and to have begun to hold an ocean by the time it contained 30 or 40 per cent of the present mass. Such liquid rock as was generated by compression or radioactivity during earth-growth is regarded as having been kneaded and squeezed to the surface, where it solidified approximately as fast as it was formed. In earth-growth, the denser planetesimal dust, he argues, tended to be somewhat segregated into the primitive ocean basins and served to maintain in them, as the earth was built outward, a greater density than in the elevated zones between, establishing thus a relation between density and elevation.

It seems a debatable question if such a large proportion of the added material was necessarily dust-like and capable of being weathered, sorted, and distributed by the primitive atmosphere and ocean. In fact, from this beginning of earth-growth the preponderance of the evidence appears to the writer to be against those sub-hypotheses which Chamberlin has followed. This evidence, its bearings and conclusions, will form the following parts of this article. It will be of ultimate value to both lines of argument that each may be weighed against the other.

\section{Hypothesis of Earth-Growth by Rapid Infall of Planetoids}

Preliminary statement. Alternative views quite different from those which have been presented under the previous 
heading will now be discussed. It appears to the writer that the chemical character of the igneous rocks, the limited depth of density variations in the crust, the limited amount of salt in the sea, the rotation periods of the moon and planets, - all point to a molten condition of the earth at the completion of its growth. In the limited space available the more technical aspects of the arguments must, however, be omitted. The questions raised by this conclusion are: What mode of growth would have favored a molten state and how far did this precede the beginning of the geologic record, as given by the oldest rocks exposed at the surface of the globe?

Up to this point the method of alternative hypothesis has been pursued, and from the standpoint of scientific procedure it should be continued to the end. The limitations of space in a single essay, however, forbid. This subject, which for complete analysis should be developed in a volume, must be compressed into a few pages. The judicial style must often be abandoned for the declarative. Descriptions of some things which no eye has ever seen will be given graphically as though viewed by a witness. This change in method necessitated by limitations of space is, however, least objectionable in the closing parts of the subject, since the foundation hypotheses have been already presented and the argument leads from them toward the established facts of the geologic record.

Significance of the planetoids. The belt of asteroids, better called planetoids, appears to have remained more nearly in its original state than have other parts of the solar system. The lack of aggregation into a planet may be due in part to the absence of any dominating center. More than eight hundred of these bodies have now been discovered and listed and countless others must be so small that they will largely remain unknown. The diameters range from a maximum of 485 
miles in increasing numbers down to I 5 to 20 miles, the limit of telescopic visibility.

At some diameter below the limit of visibility in the telescope, although the number may be increasingly great, the summation of their masses must begin to fall off, since otherwise the combined bulk would produce a perceptible glow in the sky. Furthermore, Leverrier demonstrated from the limited perturbations of Mars in its orbit that the whole amount of matter distributed between the orbits of Mars and Jupiter cannot exceed about one-fourth of the mass of the earth. It may be less. In fact, later calculations limit it to less than one-hundredth of the mass of the earth. The rate of increase in numbers in the smaller visible sizes suggests in connection with the limitation in aggregate mass that a considerable part, perhaps a larger part of the matter, is not in dust-like or molecular form but is in fragments of appreciable size ranging up to some miles in diameter. These masses, owing to their small diameters and weak gravitative force, would possess almost no power to grow by accretion. They must retain almost the original state of the nebula, or better, the meteoritic swarm, and are perhaps as likely to have suffered occasional shattering and scattering by impact as to have grown from a lower order of size. Their evidence favors the hypothesis that the scattered matter which was added to the nucleus to form the earth was largely of such size that the individual planetoids would have plowed through a primordial atmosphere and ocean, if such existed, and have penetrated beneath the surface of the liquid or solid body below. The energy of impact from dust-like material would be absorbed at the surface and, as heat, quickly radiated into space. The accretion of dust would favor the growth of an earth solid throughout. Larger masses would, on the other hand, carry the energy of impact into the earth. They would not strike with the high velocities of the meteors which collide with the 
earth, since the different planetoids were traveling in the same general direction, but nevertheless a state of incandescence and liquidity would be likely to result from the sizes of the masses involved. If in addition the infall of masses was sufficiently rapid to bury the heat of previous infalls before it could be dissipated by conduction to the surface, a general heating and liquefaction of the earth would tend to take place, both from the increased compression of the deeper nucleus and the effects of impact at higher levels.

The fact that the planets have cleared up the zones about them, whereas the planetoids have remained permanently in a scattered state, is an argument for holding that the existence of dominating nuclei determined the growth of the planets. It is likely that the nuclei were of various sizes, were clustered to various degrees, and many of them united by their impact. A somewhat limited number and considerable size of the units as well as their grouping would be in accord with the lack of relation of the amount of eccentricity and inclination of orbit to the masses of the several planets.

Indications of primordial tidal retardation. The moon keeps the same face turned always toward the earth. Consequently, from a point in outer space, it would be seen to rotate on its axis in exactly the same time that it completed its orbital revolution. Mercury is known also to keep the same face turned always toward the sun and the same relation is probably true of Venus. The other planets revolve many time on their axes during the period of revolution, the earth, for example, 366 times. The exact correspondence in the moon, Venus, and Mercury between their times of axial rotation and orbital revolution points to some causal relation between the two periods. That relation is one of tidal forces.

The moon distorts slightly the earth's figure, but as the tidal forces due to the moon are weak and the earth is very rigid, this distortion in figure is expressed mostly by the rise and 
fall of the earth's fluid envelope. In so far as the body of the earth yields, it is an elastic yielding which involves no measurable expenditure of energy. The oceanic tidal waves tend to continually face the moon and the earth revolves beneath them, like a wheel revolving between two opposite brake-shoes. This generates tidal friction which tends to slow down the axial rotation of the earth. There is no question as to the correctness of this theory, but there is a very serious question whether the forces are not so weak as to be without any geologic consequences, at least under the present rigid condition of the earth's interior.

Some of the latest work has been given to measuring directly the retardative influence of the tides, if such exists. MacMillan has made an estimate of the loss of energy by friction of the oceanic tides. He used the formulæ employed by engineers for the loss of head due to friction and viscosity, and applied them to the ocean. His conclusion is that the day would be lengthened by one second in about 500,000 years. Even if this figure be in error tenfold or a hundred-fold it is still in great contrast with the conclusion of Adams in the middle of the last century, that the earth was losing time at the rate of 22 seconds per century, a figure raised to 23.4 seconds by Darwin and lowered to 8.3 seconds by Newcomb. MacMillan's method brought to bear as a retardative agency practically all the friction of the tides, irrespective of their positions or directions of motions, and seems to show that the water tides do not have and have never had an appreciable effect on the earth's rotation. ${ }^{5}$

Tidal retardation if it has ever been an important factor in planetary history must then be chiefly due to a body tide. In so far as there is a mere elastic yielding of the body no energy

5 MacMillan, W. D., "On the Loss of Energy by Friction of the Tides." In "The Tidal and Other Problems." Carnegie Institution of Washington, Pub. No. 107, 1909, pp. 71-75. 
is consumed, but a viscous drag will produce retardation. Recent measurements of the rigidity of the earth under tidal stresses, both by the horizontal pendulum and by the water level in a horizontal pipe, show that the earth as a whole is more rigid than steel and that under the exceedingly small tidal stresses the yielding is essentially elastic. The estimates of viscosity are so small that they are within the limits of error of the measurements. The smallness of the tidal strains in the earth may be appreciated by citing Darwin's calculations. According to this investigator, the tides raised by the moon upon the earth generate a stress-difference of 16 grams per square centimeter at the poles, 48 grams at the equator, and I 28 grams at the center of the earth. Thus the earth is stressed by the lunar tidal forces even at the center to only about one part in fifteen thousand of the strength which granite has at the surface of the earth.

The tidal force exerted by the earth on the moon is about twenty-two times as great as the lunar tidal force on the earth, and reaches about one part in six hundred or seven hundred of the strength of granite. If the moon were once nearer the earth, the tidal stress-difference was much greater, varying inversely with the cube of the distance. Tidal retardation must have acted efficiently upon the moon, nevertheless, until the moon was at its present distance and the stresses reduced to their present magnitude, in order to have reduced its period of rotation to the same value as its final orbital period about the earth. The action must have been that of a viscous body tide since the moon has never been able to hold to itself an ocean envelope. The tidal force exerted by the earth upon the body of the moon consequently must have produced a notable viscous yielding and continued to do this in spite of increasing distance of the moon and increasing rigidity.

The far greater mass of the earth prevented such large effects of tidal retardation from being felt, but its period of 
revolution compared to those of Mars and the outer planets suggests that the tidal forces of the moon and sun have produced a notable slowing down of the earth also. The largest planet, Jupiter, 86,500 miles in diameter, revolves the most rapidly, completing one revolution in 9 hours 55 minutes; Saturn, the next largest, revolves in Io hours I4 minutes. Uranus also shows by the pronounced polar flattening of its disc that it revolves in some similar short period. Mars, with a diameter approximately half of that of the earth and a twentieth of that of Jupiter, revolves in 24 hours 37 minutes. These planets can never have suffered largely from tidal retardation and a rough rule appears to prevail that the larger the planet the more rapidly it rotates. Judging from its mass, the earth may consequently have originally rotated in a period of between I 5 and 20 hours. This argument is only of suggestive value, but it is in accord with other lines of argument. If the moon passed through a viscous state sufficiently prolonged for it to respond completely to tidal control in its rotation period, the presumption is clearly that the earth, a larger body and better able to retain its heat, also passed through a similar stage of viscosity. The present rigid and elastic condition of the earth appears then to be a secondary feature and the present ineffectiveness of the tides cannot be safely used as an argument against the strong indications of a primordial tidal retardation.

Significance of the oceanic salt. Sodium derived from the weathering of igneous rocks has been stored through all geological time in the ocean as sodium chloride. The ocean has grown more salty since it first gathered on the earth, yet it is so far undersaturated that sea water must be nine-tenths evaporated before sodium chloride begins to be precipitated. Furthermore, the indications are that it never was saturated, even though in primordial times the sea water may have been less in volume. Concentration to a degree which eliminates 
part of the sodium chloride raises the percentage content of bromine, magnesium chloride, and magnesium sulphate, so that sodium becomes subordinate to magnesium and the ratio of bromine to chlorine is increased Subsequent dilution would not change this ratio and the introduction of new salts could never bring it back to the original composition. The evidence from the sea itself is substantiated by the testimony of the sedimentary rocks. The amount stored as impregnations or as salt deposits in the sediments is quantitatively negligible, either as compared to the volume of the sediments or the mass of the oceanic salts. Salt deposits, furthermore, so far as known, began to be present only in the Paleozoic, in the later half of geologic time, the great masses of earlier sedimentary strata being barren of them.

It has been calculated that the total sodium in the ocean would be derived from the weathering and erosion over all the earth of a mantle of igneous rock of average composition only 2,300 feet thick, corresponding to 6,500 feet as the average thickness of erosion if restricted to the area of the continental platforms, including the lands and extending out to a depth of 600 feet below sea-level.

Daly has noted the significance of these facts upon the hypotheses of earth-growth. ${ }^{6}$ Chamberlin supposes an ocean to have existed for long geologic ages upon the surface of the earth during its growth from a body about half of its present diameter and one-eighth of its present volume. The planetesimal material, he holds, was weathered and sorted into lighter and heavier portions, leading to the development of lighter protuberant and heavy depressed areas. The limited quantity of salt in the sea, however, is distinctly against such a hypothesis of oceanic antiquity and continental building. The amount of erosion in evidence where the older rocks are exposed as crystalline masses and from the great ${ }^{6}$ Daly, R. A., "Igneous Rocks and Their Origin," 1914, pp. 159, 163, 164. 
uplifted tracts of later times is apparently about sufficient to account for all the salt in the sea. In fact, the estimates of erosion through known geologic time based on the nature of rock exposures and the thickness of sediments have fully equaled or exceeded the amount given by the quantity of salt in solution. Weathering, erosion, and the accumulation of salt had therefore played no considerable part previous to the time recorded by the oldest rocks. The earlier physical conditions must have been very different from those which later prevailed.

\section{Favored Hypothesis of an Earth Initially Molten}

Indications of a primordial molten state. The indications of primordial tidal retardation and the limited amount of salts in the sea both point to the conclusion that the earth was molten at the completion of its growth. A molten state suggests a rapid earth-growth due to an original clustering of the matter whose convergence built up the planet. Larger nuclei hundreds of miles in diameter and smaller ones comparable to the planetoids moved in elliptic and nearly intersecting orbits. Mutual perturbations kept modifying these orbits and providing new chances for collisions, union, and growth. Such collisions led to a development of energy of impact sufficient to produce in the growing earth a molten state, at least in the outer portions. The earth kept growing at the same time by sweeping up large quantities of finer material, but a molten state suggests that the greater growth was due to the infall of larger nuclei. Finally, but one outstanding nucleus, the moon, was left beside the earth, and the earth-moon system attained a condition of stability and completed growth.

If the composition of the earth as a whole is similar to that of the meteorites, those samples of matter which come to us from the heavens, the most abundant material in the deep body of the earth is metallic iron. Now the blast furnace 
makes familiar the fact that slag is insoluble in iron and, being lighter, gathers in the upper part of the crucible, like cream upon milk. The slag is similar in composition to basaltic igneous rocks. The density of the deep interior suggests that it is layered like the crucible of the blast furnace and that the silicate rocks form an envelope some hundreds of miles thick, grading down into a great metallic core. The silicate envelope ultimately differentiated further, resulting in a rise of the more siliceous and lighter fraction into an outer layer, perhaps 50 to 75 miles in thickness. This in turn crystallized into a primordial, universal, granitic crust above a thicker basaltic shell below.

The primordial atmosphere. Granting the conclusions in regard to the initial fluid state of the earth, let the primordial atmospheric conditions be pictured. A gaseous envelope existing in equilibrium with rock magma would be dominantly water-vapor, followed in order of importance by carbon dioxide and carbon monoxide, chlorine and hydrochloric acid, with some nitrogen, but no free oxygen.

The present atmosphere of nitrogen and oxygen penetrates by solution into the liquid envelope of water. The primitive atmosphere of water-gas penetrated in the same manner by solution into the ocean of molten rock. But such an admixture of molten rock and water-gas is known to have a remarkable effect upon the melting point of silicate magmas. Under dry fusion the exalted temperature of $1300^{\circ}$ to $1500^{\circ} \mathrm{C}$., a dazzling white heat, is necessary to make granite thinly molten. But if the fluid rock has dissolved an abundance of watervapor the mixture stays fluid until it has cooled below a temperature of $800^{\circ} \mathrm{C}$. The surface of the earth when molten was perhaps no hotter than this. At such a comparatively low temperature and even at somewhat higher temperatures there would be but little dissociation of water into its component gases, and the earth would be capable of holding to 
itself, even in its molten stage, an envelope of water in the form of a deep and heavy atmosphere of water-gas. Such an envelope, including also an abundance of carbon dioxide and carbon monoxide, formed an effective thermal blanket, preventing a precipitous chilling and freezing at the surface of the ocean of molten rock.

The effectiveness of the blanket depended upon the peculiarity of both water-gas and carbon dioxide in being opaque to the slow vibrations of dark heat, absorbing these near the bottom of the primitive atmosphere and reradiating them from higher levels as long, slow heat waves. Strong convection currents carried up these heated gases from the superheated base to the higher levels of the atmosphere. There the chilling condensed the water-vapor into a thick and universal canopy of cloud, boiling up like thunder-heads from below, shedding continuously a downpour of acid rain, rain dissipated again into vapor as fast as the drops fell into the deeper and hotter strata of the atmosphere. The intensity of the vertical convection maintained a high electric tension. Incessant flashes of lightning linked as with living, fiery tentacles the cloudy heavens to the lurid molten earth. Tremendous reverberations of thunder, unsensed by mortal ears, shook the atmosphere in the worldwide primeval storm.

The sunlight of the Primordial Era illumined and was reflected from the outer side of the mantle of cloud. The planet shone brilliantly by this reflected light, having an external appearance similar to that which Jupiter and Saturn still possess. Above the zone of cloud the carbon dioxide and other gases, with very minor amounts of water-vapor, extended with diminishing density as an upper transparent envelope.

During the more rapid growth-stages the molecular and dust-like matter swept up by the earth settled like a never ceasing cloud of volcanic ash. The planetesimals of sand and 
gravel size were swept up by the earth many millions of times more abundantly than are meteors at the present time. Those meeting the earth with the higher velocities were consumed by impact. Over the hemisphere of night the otherwise invisible atmosphere above the cloud canopy scintillated with incessant flashes of light and trails of luminous dust. Bodies of larger size gave in their dissolution a still more brilliant display and penetrated to greater depths. At longer intervals, with titanic rush and roar, a greater projectile, tens or even hundreds of miles in diameter, cleaved through the canopy of cloud, leaving a tumultuous maelstrom behind, drove almost unchecked through the deep and dense atmosphere below, and, with worldwide commotion, was engulfed, with development of fervid heat, within the molten sea.

\section{The Passage of the Molten into the Rigid Earth}

Density stratification by fractional crystallization. The central parts of the earth were compressed during the growth stages by the increasing load above. This compression developed heat, but also raised the fusion point and made for a greater rigidity. It is not known, consequently, whether during earth-growth the center tended toward a liquid or solid state. The outer part, however, with a thickness of perhaps the outer quarter of the radius, comprising about onehalf of the volume of the sphere, seems to have passed into a truly molten condition.

The heavy atmosphere and canopy of cloud prevented a rapid radiation from the molten surface, probably sufficient during the highly liquid stage to prevent a crusting over of frozen rock. The method of solidification approached nearer to that which occurs in a large reservoir of magma intruded into the crust than to the freezing of a modern lava stream in contact with the air. 
At last the rapid generation of heat by impact lessened, and the fluid sphere, seething with slow convection currents, began to cool. Certain compounds in the mutual solution of rock elements became insoluble and fractional crystallization was initiated. The heavy basic crystals were the first to form: crystals of metallic sulphides, magnetite, hornblende or pyroxene, and olivine. These crystals, because of their high specific gravity, tended to work downward in the convective movement. At first they were dissolved again in the abyss, but as time went on they remained undissolved and accumulated in the deeper parts of the fluid zone. The remaining magma was more siliceous, of lighter gravity, and in crystallization gave to the upper shell a higher proportion of feldspar and quartz. The original crust of the earth was consequently a granite. The process of fractional crystallization may, however, not be a sufficient explanation. An immiscibility of the complex mineral solutions may have developed upon the lowering of the temperature. In one way or the other or by a combination of several causes a density stratification is suggested by a number of lines of evidence as existing in the earth. The conclusion, then, is more than a mere inference from theories of crystallization.

The gathering of the ocean waters. At last the ocean of molten rock had shallowed, crystallization went forward in separate basins, convection became hindered, the surface froze as in a lava caldron. Then rain, ever descending from the shield of perpetual cloud, but never heretofore reaching the bottom of the atmosphere, at last began to splash on the hot surface of the earth. The raindrops at first were dissipated by contact and sent flying back as scattered molecules of gas. But, owing to the low conductivity of rocks, the transition stage was very brief, and perhaps even in a few thousand years from the time when the crustal congelation of the earth had taken place a permanent ocean of acid water began to 
rest upon the surface. For a while the balance swung, as one section or another of the crust was broken through and lavas would pour out abundantly. Rapidly, however, from the geologic standpoint, as the surface cooled, the atmosphere of water-vapor condensed in a never ceasing deluge until an ocean, probably universal in its extent, had gathered to a mean depth of several thousand feet. The remaining atmosphere was comparatively rare and cold. Carbon dioxide became the dominant gas, and water-vapor subordinate. Solar heat began to play the principal part in warming the equatorial zone. A system of planetary winds developed in accordance with the new order of nature. The cloud canopy became thin and broken, resolving itself into climatic belts. Sunlight for the first time began to pierce the lower atmosphere and illumine from without the surface of the earth.

During the earlier time, when the water could exist only as gas in the atmosphere, the great pressure of this envelope had kept much, perhaps most, of the gases in the molten rocks. With the great fall in atmospheric pressure which accompanied the gathering of the ocean, magmas which broke through the higher levels of the crust into the regions of this decreased pressure were able to give off great volumes of gases which in the earlier stage had been repressed. These gases, freed for the first time, are termed juvenile and from this time forward juvenile waters were added to the ocean. In the first ages following the solidification of the earth the additions were large in volume, but igneous. action continues to bring new magmas to the surface recurrently from age to age. These give off the gases which have been repressed in them since the origin of the earth. Thus, in intermittent and lessened rate, the surface waters have increased through geologic time. As Suess has said, the body of the earth has given forth its oceans. 
The Origin of Ocean Basins

The relations of crustal density to ocean basins. The fluid earth had a surface as level as the ocean, and the process of solidification which has been outlined does not account for those marked variations in density and in surface form which are expressed by the outer crust of the solid earth being divided into continents standing high above the ocean floors. A sketch of the formative period is therefore not complete unless the processes are briefly discussed which are thought to have shaped the earth's surface, giving rise to the existence of lands even before the period of the oldest known rocks.

Reasons will be given below for holding that the ocean basins have been formed by subsidence of broad areas of the crust, owing to the weight of magmas of high specific gravity rising widely and in enormous volume from a deep core of greater density into these portions of an originally lighter crust. This regional subsidence was especially characteristic of primordial times, but the process did not wholly cease then; since certain lines of evidence suggest that some ocean basins have been extended in later geologic ages, breaking into once wider continental platforms. The resultant increase in the volume of the ocean basins has led to a drawing off of the ocean waters from the continental areas, and a marked diminution of the shallow seas of earlier ages.

The cause of the continued generation of new bodies of molten rock in the sub-crustal shell, adequate to account for the observed results of later geologic time, is thought to lie in the slow accumulation of heat from radioactivity in these depths below the crust. This is discussed in the subsequent topic on the rise of basic magmas.

Some very thick bodies of intrusive rock are observed to be more dense and basic below, lighter and more siliceous above. The lower part is a gabbro, whereas the upper may 
be a granite. The separation has taken place after the intrusion of the magma, the denser material sinking, the lighter rising. There are indications that the process goes forward on a larger scale also, a scale so large that the dark and heavy base is never seen, erosion of later ages being restricted entirely to the granite zone. Such a splitting in composition is indicated in that the earlier intrusions in a period of igneous activity are intermediate or basic and the later products are vast bodies of granite. The greater density in the earth's interior suggests a primal density stratification on even a larger scale, which has been discussed under a previous topic.

But in the outer shell, 50 to 75 miles thick, the density is far from being uniform. In recent years it has been proved by means of precise geodetic measurements on the local intensity of gravity and deflections of the vertical that the crust beneath the continents is notably less dense than that beneath the oceans. The most of this difference in density exists probably within the outer 50 miles. The continents stand high, consequently, for the same reason that an iceberg rises above the surface of the sea: it is the position of equilibrium. At a certain depth the downward pressures given by the thicker continental and the thinner oceanic crust are the same and a condition of hydrostatic equilibrium prevails in the sub-crustal shell.

This condition of equal pressures at a certain depth is called isostasy. It is not inconsistent with a solid and rigid condition of the earth, but does mean that at a greater depth, apparently from 50 to 300 miles or more, hot but solid rock can slowly yield and flow by recrystallization. The process is physically the same as that by which a glacier flows under the slight stimulus of an almost level surface slope. The condition for such ready recrystallization is found in-temperatures which are close to those of fusion. At such temperatures molecules under strain pass readily from the solid to the liquid 


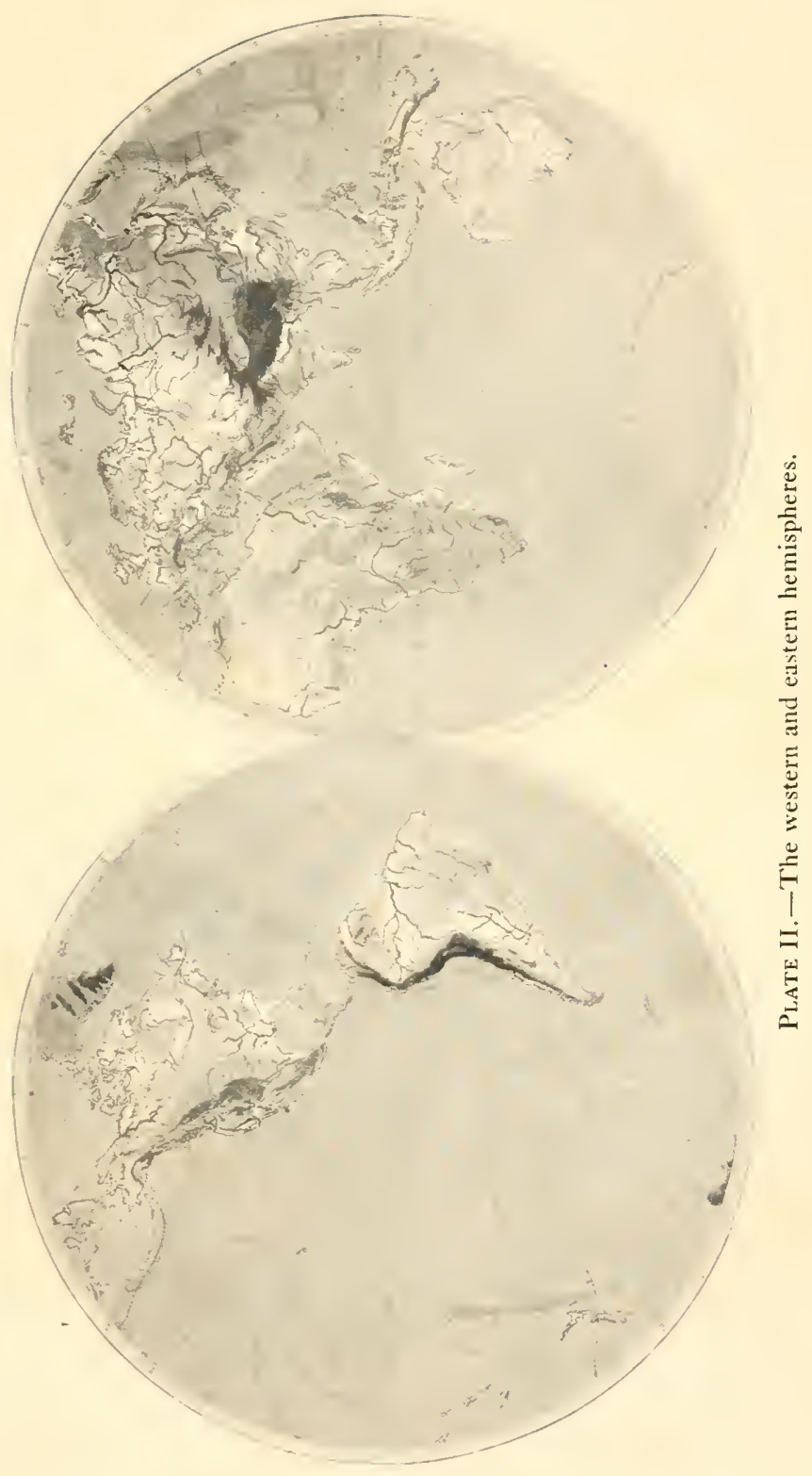





\section{AND ITS INHABITANTS}

state, shift into positions which ease the strain, and again enter into a crystalline solid condition. The proof that such a process exists in the earth is based on several lines of evidence.

First, evidence of a broad isostatic equilibrium notwithstanding the agencies of mountain folding, of erosion, and of sedimentation, all of which work through geologic time tending to destroy those relations of elevation which are needed to maintain isostasy, giving equal pressures by broad crustal areas of unlike density upon the yielding zone below.

Second, the evidence of increasing temperature with depth, giving temperatures close to those of fusion at depths below 40 to 50 miles.

Third, the evidence from tides and earthquakes that the earth as a whole is more rigid than steel and cannot possess a fluid shell beneath the crust.

Fourth, the physical principle that at temperatures close to fusion a crystalline substance is incapable of supporting permanent shearing stresses, but yields slowly by recrystallization, notwithstanding the fact that under short stresses the same substance may be as rigid as steel.

The conclusion to which this argument leads is that an outer crust or lithosphere, the rock sphere, 50 to 75 miles thick and very strong, is marked by broad variations in density amounting to as much as 5 per cent, and more local variations up to Io per cent, which correspond to the broader relief of the earth's surface. Below this lies a thick, hot, basic, rigid yet weak shell which the writer has named the asthenosphere, ${ }^{7}$ the sphere of weakness. The problem of the origin of the ocean basins and of continental platforms resolves itself consequently into the origin of the density differences in the lithosphere and the maintenance of the heated and weak condition in the asthenosphere.

7 Barrell, Joseph, "The Strength of the Earth's Crust." Jour. Geology, vols. 22, 23, 1914, 1915. 
Rise of basic magmas from the asthenosphere. The series of radioactive elements slowly break down into elements of lower atomic weight and give off in the process enormous quantities of energy. Uranium, in degenerating through radium to the stable element lead, develops more than a million times the heat given by the combustion of an equal weight of coal, but the disintegration of the element and the liberation of its heat are so slow that the whole duration of geologic time has not sufficed to eliminate uranium from the crust of the earth. Therefore it has acted as a permanent generator of heat in the rocks which contain it.

Uranium and thorium, the parents of the radioactive series, are widely though sparsely diffused through the lithosphere. It has been calculated that, if they extend in their surface amount to a depth of 40 miles, they must supply heat to the surface as fast as it is lost by radiation into space. The earth therefore appears not to be growing colder, though losing heat.

The small content of radioactive elements in the basaltic shell below the granitic crust of the continents would then supply that slow increment of heat which is necessary to generate new molten rocks. The granitic shell above, though somewhat richer in radioactive elements, is sufficiently near the surface to lose its excess heat by conduction. The excess heat generated in the asthenosphere is, on the contrary, so deeply buried that it cannot escape in that manner but must slowly transform some of the solid rock into liquid form. Reservoirs gather, until their mass, combined with their decreased density in the fluid form, enables them to work their way through the crust above and demonstrate their existence in igneous activity at the surface of the earth. The magma which thus comes from the greatest depth and in greatest volume would, because of the initial density stratification, produce a notable increase in the density of the outer crust. 
In order to reëstablish isostatic equilibrium such a region must subside.

Most of the igneous rock of later geologic ages which has been intruded into the outer continental crust clearly has not increased the density sufficiently to produce a foundering and would appear therefore either to have come from somewhat higher levels or to have risen in lesser quantity. In some regions, however, as in that of the Lake Superior basin, large masses of basic magma do seem to have overweighted the crust in an early geologic period and produced a tendency to settle as a basin. The same effect may have taken place to even a larger degree in some regions of notable subsidence, as in the Mediterranean basins. In the earliest times, following the solidification of the earth, the forms and relations of the ocean basins suggest that dense molten matter from the depths of the earth broke into or through the outer crust, on a gigantic scale, eruption following eruption until the widespread floods had weighted down broad areas and caused their subsidence into ocean basins.

As seen in the lava plains of the moon, such an action, once started at a certain point, is conceived to have gone forward with widening radius, leading to the origin of the many rudely circular outlines characteristic of the ocean basins. The process left great angular segments of the original lighter crust as continental platforms standing in relief between the coalescent basins. The waters gathered into the basins and the continents emerged.

The Reign of Surface Processes and Beginning of the ARCHEAN

It is possible that shallow ocean basins began to form nearly as fast as the waters gathered, tending to maintain some land areas above the level of the primordial sea. Or the lands may have emerged later, as the ocean basins spread and deep- 
ened. With the separation of the lands from the seas, erosion began, carbon dioxide was abstracted from the atmosphere to make carbonates, and a further cause of atmospheric depletion was initiated. Thinner, rarer, and colder grew the gaseous envelope, until an oscillating balance was established between the supplies of new gases from the uprising molten rocks and the losses involved in the weathering of their solid forms. Nitrogen was at first relatively small in quantity and oxygen not present in more than a trace. An evolution in atmospheric composition had still to go forward through following ages to transform it into a gaseous medium for the support of the higher life. But even in the early periods following the gathering of the oceans and the emergence of the lands, the sun warmed the atmosphere and earth. An environment suitable for the lowest organisms had arisen and the earliest forms of life may not have been long in coming into existence. The reign of the surface processes had begun, but, at age-long intervals, the still youthful energies of the interior broke forth. Magmas in great volume ascended, now seen as the most ancient granite-gneisses. In the great crustal overturning of these earliest revolutions the foundation rocks appear to have been everywhere destroyed. The oldest rocks preserved are mashed and crystallized sediments and lava sheets resting as fragments of a cover on the reservoirs of younger magma. Such sediments, altered and intruded, are the oldest Archean rocks: It is not known how close they stand in point of time to the formative processes whose description has been attempted. With these oldest rocks, the dimly known, heroic and mythical eon of the earth is closed and the first historic eon opens as the remote and long enduring Archean division of geologic time. 


\section{CHAPTER II}

\section{THE EARTH'S CHANGING SURFACE AND CLI- MATE DURING GEOLOGIC TIME}

CHARLES SCHUCHERT

PROFESSOR OF PALEONTOLOGY IN YALE UNIVERSITY

UNIFORMITY OF NATURE. The previous lecturer in this course had to seek for the probable origin of the earth in far-off space among the stars, examining them through the great telescopes of our time, through the light-sensing chemical plate of the photographic camera, and through the even more wonderful spectroscope. With this knowledge in hand, postulate upon postulate has been tried out through that talismanic study, mathematics, and so through astronomy and the science of numbers there is revealed an earth evolution still hazy, to be further established through geodesy, mechanics, and chemistry before the geologist comes to be its interpreter. Then, hand in hand with the geologist, the paleontologist, or student of ancient life, reveals the organic hordes that have gone on and through whose fossil remains is unraveled the history of the earth. In all of this we see the brotherhood of the sciences and the fundamental postulate of the uniformity of nature.

The geological time-table. As some geologic terms must be used in this lecture, it is desirable to define them here. The geologic history of the earth is now divided as follows:

Present time.

Psychozoic era. Age of man or Age of reason. Includes the present or "Recent time," and the time during which man attained his highest civilization, estimated to be probably less than 30,000 years. 
Geologic time.

Cenozoic era. Age of mammal dominance.

Glacial or Pleistocene time. Last great ice age.

Late Cenozoic or Pliocene and Miocene time. Transformation of apes into man.

Early Cenozoic or Oligocene and Eocene time. Rise of higher mammals.

Mesozoic era. Age of reptile dominance.

Cretaceous period. Rise of archaic or primitive mammals.

Comanchian period. Rise of flowering plants and higher insects.

Jurassic period. Rise of birds and flying reptiles.

Triassic period. Rise of dinosaurs.

Paleozoic era. Age of fish dominance.

Permian period. Rise of reptiles. Another great ice age.

Pennsylvanian period. Rise of insects and first time of marked coal accumulation.

Mississippian period. Rise of marine fishes.

Devonian period. First known amphibians.

Silurian period. First known land floras.

Ordovician period. First known fresh-water fishes.

Cambrian period. First abundance of marine animals, and dominance of trilobites.

Proterozoic era. Age of invertebrate dominance. An early and a late ice age.

Archeozoic era. Origin of protoplasm and of simplest life.

Cosmic time.

Formative era. Birth and growth of the earth out of the spiral nebula of the sun. Beginnings of the atmosphere and hydrosphere, and of continental platforms and oceanic basins. No known geological record.

Origin of the sun and earth. Professor Barrell, in the previous lecture, pointed out that the sun is a star, and one of the smaller among the countless millions seen through the telescope. It may have had its origin in a diffuse nebula like Orion, and, according to the disruption hypothesis of Cham- 
berlin and Moulton, had a long antecedent history before it gave birth to its planetary system. Therefore before there was an earth, the sun had been condensing and moving undisturbed in space for countless ages, until it came within the influence of another and a greater star. The gravitative influence of this mighty passing intruder acted catastrophically upon the sun and caused its partial disruption. As a consequence, from opposite sides of the sun there streamed rapidly outward materials of its own mass that soon arranged themselves into a two-armed luminous spiral nebula. The mass which was so extruded, and which did not fall back again into the sun, was less than I per cent of the sun's mass, and yet it gave rise to the planetary system which encircles the parent body. From this we also the more readily appreciate the great size of the parent sun, whose volume is $1,300,000$ times greater than that of the earth.

Growing earth during the Formative era. In the solar nebula there existed eight knots of more or less loosely aggregated denser and hotter matter, the nuclei of the future minor and major planets and their satellites, and these in the course of time attracted to themselves most of the surrounding nebulous material, usually spoken of as the planetesimals. The earth-knot, it is estimated, may have had an original diameter of about 5,500 miles, and the moon-knot perhaps half its present diameter of 2,162 miles. In the course of cosmic time, the earth and moon, revolving as companions about the sun, gathered into themselves the planetesimals that lay within their spheres of influence.

The speaker holds to the postulate of Barrell that the planetesimals conceived by Chamberlin to have been of the size of sand and dust were probably for the most part much larger and more like the planetoids in dimensions. From time to time, as one or more of the planetoid-like bodies, singly or in combination, plunged in upon the earth with velocities up to 
tens of miles per second, their impact with and engulfment by the earth engendered much additional heat. In fact, they liquefied themselves and their earth surroundings as a result of their great impacts. Furthermore, the high internal heat of the earth was accentuated by the condensation accompanying the increase of mass from an original earth diameter of 5,500 miles to one initially larger than 8, ioo miles. At no time, however, does it appear that the earth was necessarily in an astral condition, shining like a star.

The present diameter of the earth is 7,9 I 8 miles, but at the close of the growing period it must have been 200 and possibly even 400 miles greater, for it is well known to geologists that throughout geologic time it has been losing volume, due in part to the loss of heat into space, but probably in greater degree to internal molecular rearrangements. It is now known that the earth does not shrink all the time because of these changes, but does so only periodically, and at these times the surface of the planet becomes wrinkled, giving rise to more or less high ranges of mountains. Even though the earth has been dissipating its inherited and derived energy for at least some hundreds of millions of years, and in so doing repeatedly giving birth to new series of mountains, our mundane sphere is still far from having attained the internal stability that will, when achieved, result in a featureless earth, an atmosphere devoid of the carbon dioxide that is the basis of life, and a universal lifeless ocean-the facial expression which the earth will have in its old age.

Volcanism during the Formative era. While the earth was internally very hot and viscous, the body-mass was in slow movement, with the heat ever rising toward the surface. These movements simulated a slow boiling process, and the upwellings of the molten matter repeatedly broke through the outer cold shell and engulfed it. As the cold crustal masses descended, they liquefied, and in expanding brought about 
increased pressures that again found relief in the rising tongues of heated matter. This condition is believed to have continued for a very long time, and to have been particularly active during the last half of the Formative era and the first era of geologic time, an age that may have endured for one-eighth to possibly one-fourth of the earth's entire history. The boiling process not only disseminated the internal heat, but also brought about an irregular sorting out of the heavier and lighter substances, so that the more basic and metalliferous materials as a rule sank to ever lower levels, while the less heavy acidic ones rose as granitic rocks toward the surface of the earth. Finally, at the close of this first era, the Archeozoic, the lithosphere or outer rocky and more or less rigid shell may have had a thickness of 50 miles. Through such a rocky mass little of the internal heat rises to the surface, and life would be impossible on the earth if it were not for the constant flow of the sun's radiant warmth, made equable and usable by the atmosphere. These conditions were already present in the Archeozoic era.

Origin of continents and oceanic basins. It is well known to geodesists and geologists that the continents are built of lighter materials, essentially of granites, while the greater oceanic areas have the heavier basaltic rocks beneath them, and that the difference in specific gravity amounts to about 3 per cent. We have seen that these differences came about seemingly as a result of the internal boiling process that prevailed during the Formative era and the Archeozoic, and so it appears that the higher continental masses and the depressed oceanic basins came into being very early in the history of the earth. The same interrelation of masses is also to be seen in the moon.

This is the igneous theory of the origin of oceanic basins and continental platforms of Barrell, and it holds that the differentiation took place after the earth had attained its com- 
plete growth, in other words during the closing time of the Formative era and during the Archeozoic era. The differences between the densities of the lands and oceans are held by Barrell to be only skin deep-in the outer one-fiftieth of the earth's present diameter, or in the outer shell of about I 50 miles in thickness.

On the other hand, it is true that the lands throughout geologic time have repeatedly gone down as well as up, but the sum of their movements has been upward, and for this reason geologists speak of them as the positive areas of the earth's surface. In the same way, the lower-lying fields have also risen locally at times, but their movement has in the aggregate been downward, bringing about the increasingly greater oceanic basins, the negative areas, by far the largest of the earth's surface. We shall see later on that the oceanic fields have become larger at the expense of the lands to accommodate the ever increasing volume of water, and it therefore naturally follows that the continents in former geologic times were considerably larger than they are now, possibly even 25 per cent larger. But the newer geology no longer holds to the theory that the oceans and lands have repeatedly changed places; quite the contrary, we agree with Dana that the present positions of the land and water areas have been more or less permanent throughout geologic time.

Origin of the atmosphere. It was not so long ago that most geologists held with the French astronomer Laplace and with Dana that the earth was originally very hot, and that all of the water of the hydrosphere, the salts of the oceans, and the carbon dioxide of the air and oceans had been parts of the primal gaseous envelope. Not only this, but that the latter also included all the carbon locked up in the rocks, estimated to be 30,000 times greater than the amount now in the atmosphere. Accordingly, as the earth was held to have been cooling throughout its history, it was thought that only 


\section{AND ITS INHABITANTS}

recently, geologically speaking, was the present thin condition of the atmosphere brought about.

Even though more than sixty years ago a few English geologists who were familiar with the geology of India and Africa began to point out that the earth had passed through a cold period toward the close of the Paleozoic era (see Figs. 4 and 5 ), this discovery did not at once break down the teachings of Laplace and Dana. When, however, still older glacial periods began to be discerned in the stratified rocks and especially in the oldest ones near the beginning of the Proterozoic era (see Figs. 7 and 8) -a record that is remarkably well preserved in Canada-the final straw was at hand to break down the theory that the climates of the earth had passed progressively from an astral through a torrid to a temperate condition, along with a slow clarifying of the atmosphere (see Figs. 3-8).

The newer geology holds, with Chamberlin, that the growing earth was originally too small in mass to hold an atmosphere and accordingly there was a time when our planet had none. As it grew in diameter, the earth was more and more able to hold an atmosphere and a hydrosphere, and during the long growing period there was finally originated an atmosphere probably not much unlike the present one, which in a roughly approximate way may be said to be composed of four-fifths nitrogen and one-fifth oxygen. It should, however, be noted here that at first the atmosphere had but little oxygen. Since life came to be, using the carbon and freeing most of the oxygen of the carbon dioxide of the atmosphere, the quantity of oxygen has more or less steadily increased, though at all times much of it has been consumed in the oxidation processes of the rocks and minerals.

The most constant accessory constituent of air is carbon dioxide, one of the three fundamental materials at the basis of life. In the present atmosphere there are about three vol- 
umes of this gas to IO,000 of air, and there is as much more in living things as there is in the atmosphere. On the other hand, there is in the oceans of today, according to F. W. Clarke, the geochemist, from I 8 to 27 times more carbon dioxide than in the air (Johnston and Williamson say that at $15^{\circ} \mathrm{C}$. there is about 70 times more), while the still vaster volumes locked up in the sedimentary rocks and in the fuels and carbonaceous deposits of the earth are computed to be 30,000 times greater than the volume in the present atmosphere. These facts are brought forward at this time to show that the constituents of the atmosphere have always varied because of the constant loss of carbon dioxide and oxygen to the sedimentary rocks, but that at the same time there has always been a resupply of carbon dioxide through the ever active volcanoes and the mineral springs, and of oxygen through the life activities of plants. Holmes says:" "Even now, the outer 70 miles of the earth's crust would be competent to supply all the nitrogen of the atmosphere, the water of the oceans and the vast quantity of carbon dioxide represented by limestones and carbonaceous deposits."

It has been well said that if volcanism should cease it would not be long before the existence of life would be impossible because of the absence of carbon. We should add here that if there were again as much life as there is at present, all the carbon of the atmosphere would be in the living plants and animals, and, if such a condition were possible, death would come to them all. Therefore life and its abundance at any time are conditioned by the amount of this gas present in the atmosphere.

Climates of the past. The quantity of carbon dioxide in the atmosphere is to a certain extent also a climatic regulator, though the greater factor in this matter is water-vapor, which is also the most variable constituent of the atmosphere. With

${ }^{1}$ Holmes, A., "The Age of the Earth," 1913, p. 30. 


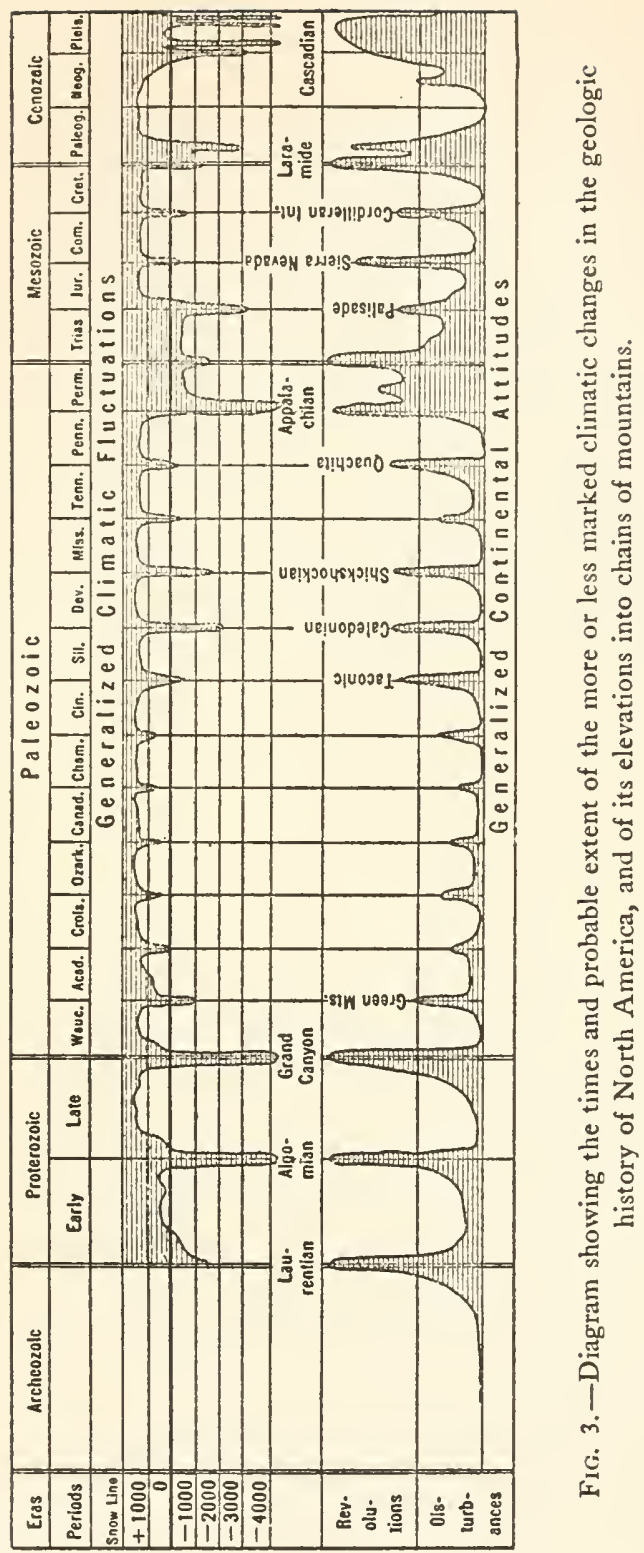


a greater abundance of both, and especially of aqueous vapor, there results a thickened atmospheric blanket that not only holds in more of the earth's warmth but takes up greater amounts of the sun's radiations, and when there is less of this gas and of water-vapor the climates are thinner and cooler. The amount of carbon dioxide and water-vapor in the atmosphere has varied much throughout the geologic ages.

Huxley in his interesting book Physiography has well said that without the sun "There could neither be rain nor rivers. ... Rain is dependent for its distribution upon currents in the atmosphere, but these currents are due to disturbances of equilibrium which are brought about by means of solar heat. Without the sun, then, there could be no winds." The currents of the sea in their final analysis are also due to the heat of the sun. Therefore through the radiant action of the sun, water-vapor is added to the atmosphere, and the amount of it is at present and always has been the latter's most variable constituent, and, as rain, is of the greatest importance geologically. Clarke states ${ }^{2}$ that water "is not merely a solvent and disintegrator of rocks, but it is also a carrier, distributing other substances and making them more active. To the circulation of atmospheric moisture we owe our rivers, and through them erosion is effected. The process of erosion is partly chemical and partly mechanical, and the two modes of action reënforce each other. By flowing streams the rocks are ground to sand, and so new surfaces are exposed to chemical attack. On the other hand, chemical solution weakens the rocks and renders them easier to remove mechanically. . . . It is through the agency of rain or snow that the atmosphere produces its greatest geological effects. . . . Aqueous vapor dissolves and concentrates the other ingredients of air, and brings them to the ground in rain."

${ }^{2}$ Clarke, F. W., "The Data of Geochemistry." U. S. Geol. Survey, Bull. 491, 1911, p. 48. 


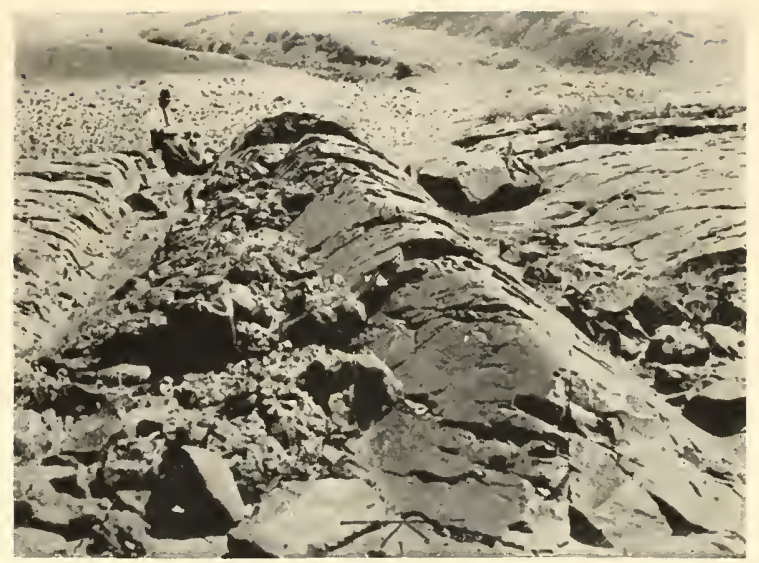

FIG. 4.-Glacially striated diabase, made in early Permian time. Vaal River north of Kimberley, South Africa. Photograph by W. M. Davis.

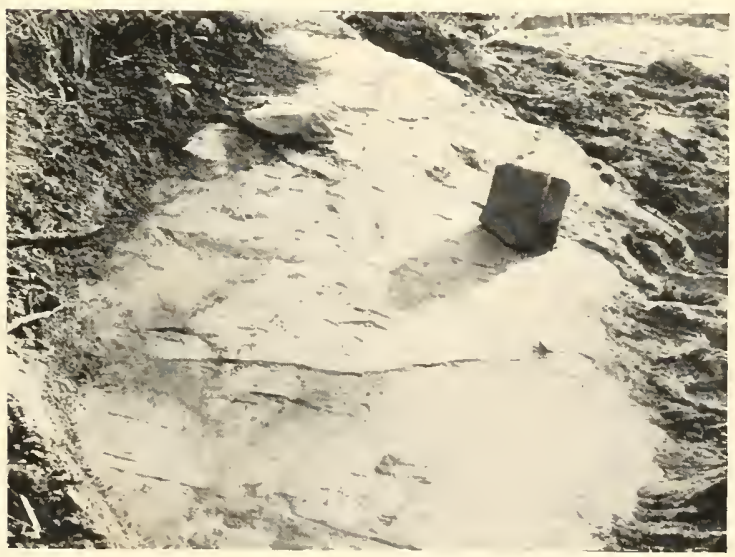

FIG. 5.-Lower Cambrian quartzite, striated in early Permian time. Inman Valley, South Australia. Photograph by T. WV. E. David. 

We are living at a time when the earth has marked climatic differences, varying between icy polar climates and hot moist or dry tropical conditions. This has, however, not always been the case, for not long ago geologically the temperature of the entire earth was even colder than it is now, although most of the climates of the past have been warm and fairly equable the world over (see Fig. 3). The ancient plants and animals are "self-registering thermometers" with regard to the climates of the past, and they indicate that warm climates persisted during long geological ages, and that even though there were at all times zonal belts and fluctuations in the temperature, the polar areas were usually inhabited, as is now well known, by plants and animals of kinds that were adjusted to winterless environments. These temperature fluctuations were greatest during the closing and opening stages of the periods and eras.

The very long warm times were separated by short periods of cool to cold climates. Geologists now know of seven periods of decided temperature changes (earliest and latest Proterozoic, Silurian, Permian, Triassic-Lias, CretaceousEocene, and Pleistocene), and of these at least four (those in italics) were glacial climates). Cooled climates occur when the lands are largest and most emergent, during the closing stages of periods and eras, and cold climates nearly always exist during or immediately following the times when the earth is undergoing most marked mountain making (see Fig. 3).

Origin of the earth's waters. There was a time when the earth was too small in mass to hold a hydrosphere, the envelope of water that lies beneath the atmosphere and above the rocky surface of the planet. As the earth grew in mass, it became more and more possible for it to have standing bodies of water and clouds of water-vapor floating with the winds of the atmosphere. All of this water, the newer geology 
thinks, came forth out of the earth itself, through volcanic activity and thermal springs. Even though some of the surficial waters vanish through soaking into the cold earth-shell, their volume has increased throughout geologic time; the greatest amount was added during the later part of the long growing period of the earth and during the Archeozoic era, when from 25 to 50 per cent of the present volume is believed to have come into existence. The rest has been added during subsequent geologic time.

Source of the salts of the oceans. It is well known that the seas and oceans are salty, and that on the average there are 3.5 pounds of saline matter to every $\mathrm{I}$ oo pounds of marine water, and in each 100 pounds of sea salts there are nearly 78 pounds of sodium chloride or our table salt. Clarke has estimated that if all of the saline matter of the oceans were concentrated, and the volume placed on the United States, its surface would be completely covered to a depth of I.6 miles. As all of this saline matter has been leached out of the rocks of the dry lands since the earth has had rains, and as very little of it, comparatively, has been taken out of the ocean by the accumulating rocks, it has been further estimated that it represents the breaking down of a mass of average igneous rock equal to at least 6,900 feet in thickness over all the continental platforms. Probably it is more correct to state that the continents have suffered erosion of igneous rocks amounting to between $I$ and 2 miles of average depth. Of course all erosion throughout geologic time was far greater, perhaps, as Barrell states, from $5^{\circ}$ to even 100 per cent higher. It included the reworking of older materials, igneous and sedimentary. Furthermore, "more than a half, perhaps fourfifths, of the erosion of igneous rocks was accomplished before the beginning of the Paleozoic" (Barrell).

Various computations have been made as to how long it has taken the salts in the oceans to accumulate and the best 


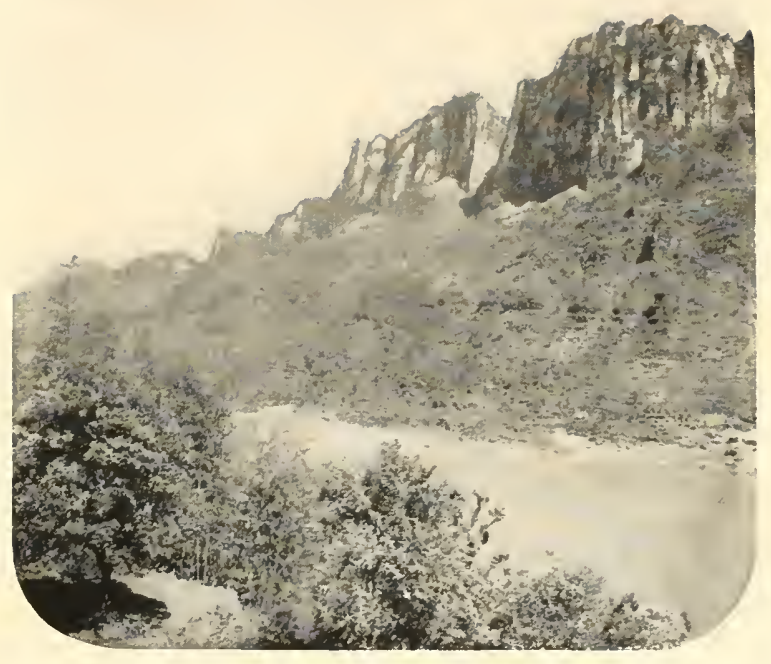

FIG. 6.-Glacial bowlder beds beneath thick formations of dolomite on the upper Yangtse River, China, in latitude $31^{\circ} \mathrm{N}$. Age of till, late Proterozoic. Photograph by Bailey Willis. Published in "Researches in China," Publication No. 54, Vol. I, 1907, of the Carnegie Institution. 



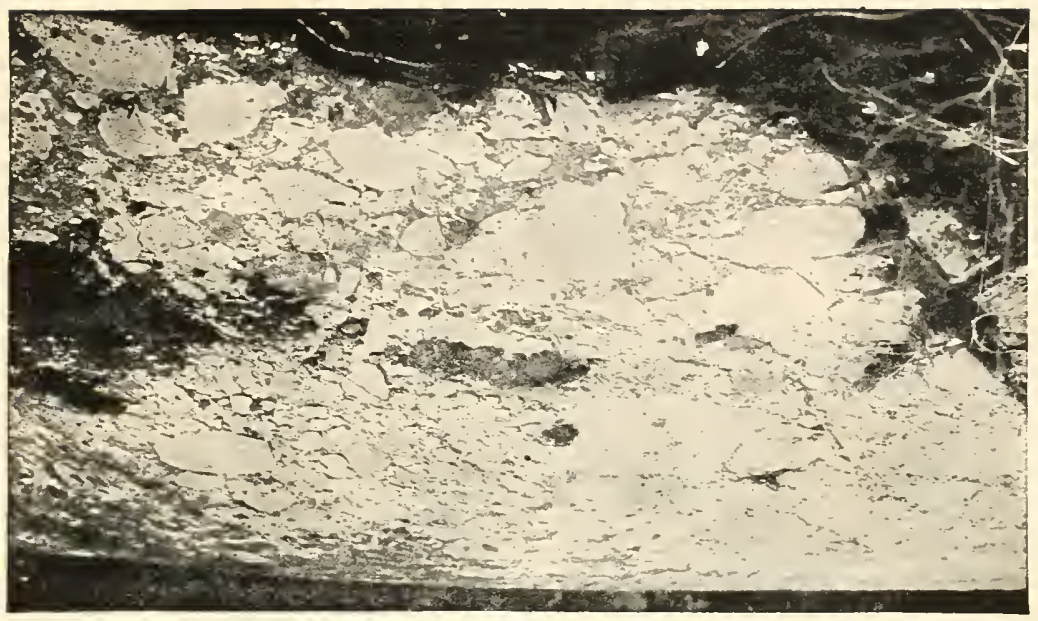

FIG. 7.- Eroded exposure of the oldest known glacial deposits (Lower Huronian), near Cobalt, Ontario. Photograph by A. P. Coleman.

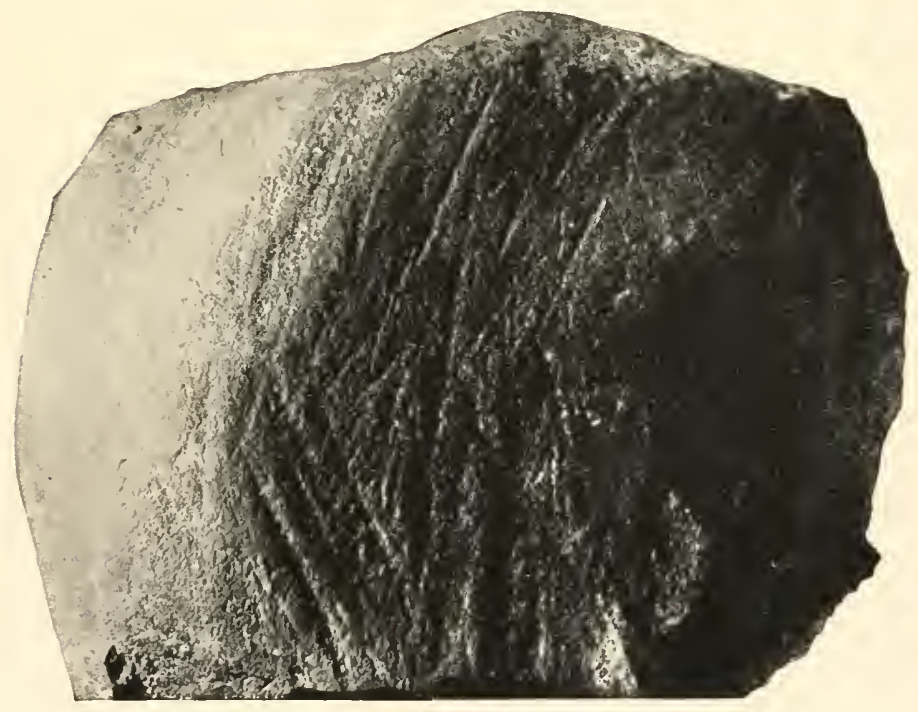

FIG. 8.- Striated bowlder taken from the oldest known glacial deposits. Photograph by A. P. Coleman. 

of the calculations arrive at about $\mathrm{I} 00$ million years. This figure is based on the postulate that the present rate has been continuous throughout geologic time; this rate, however, appears to be excessive, and renders the postulate erroneous. The rate was highly variable during geologic time, as will be seen from the evidence throughout this chapter, so that the latest calculation of Holmes ${ }^{3}$ gives the time as between 2 Io and 340 million years, with the warning that these high figures "must not be supposed to possess any serious value. For the present we can only conclude that our knowledge of the part played by sodium and chlorine in the constant redistribution of the materials of the earth's crust is still lamentably imperfect, and that quantitative deductions drawn from it must be regarded as being purely provisional."

Origin of the sedimentary strata. The great variability of geologic climates also leads to variations in the power of the atmosphere to weather and break down the high places of the lands. The earliest atmosphere, far richer in carbon monoxide and carbon dioxide than subsequent climates, was a most active weathering agent in dissolving and breaking up the oldest rocks of the lithosphere, the igneous basaltic and granitic rocks. Then, too, there had not yet developed a vegetation on the most ancient lands to hold the fast-forming soils, and these conditions made it inevitable that all of this loose and solvent material should be rapidly washed by the rains and rivers into the oceanic basins. Therefore the stratified or water-laid rocks accumulated during the earlier geologic eras more quickly than in the later ones. On the other hand, the erosive power of both air and water has varied much throughout geologic time because of the periodically varying height of the land and the ever changing humidity and temperature of the air. Accordingly, the rivers carry their loads of sediments for long times very slowly and at others much

${ }^{3}$ Holmes, A., op. cit., pp. 74-75. 
more quickly. If the erosion on the land is rapid and the rivers are not long, the land débris is apt to be coarser in grain and less well assorted, but of whatever nature the waste of the lands is, the rivers finally deliver it to the seas and oceans; and here the materials are subjected to a long process of reworking and assorting into muds and sandstones. As all of this work is done in waters, as the character of the sediments varies, and as the wave-power is variable with the winds from day to day, it follows that the materials must be laid down in horizontal sheets of different kinds of rock that make up the strata of the stratified rocks. From this it is apparent why the sedimentary rocks of the earth's outer shell not only are of different kinds, but why they so often occur in more or less long cycles of deposits that begin with coarse sandstones or even conglomerates and pass upward into the much finergrained mudstones and finally into limestones. The limestones are in the main the deposits due to the chemical activities of organisms or the accumulating débris of plants and animals. Geologists therefore speak of limestones and chalks as organic deposits. So throughout the geologic ages, cycle upon cycle of sedimentation succeeded one another, the débris of successive ranges of once majestic mountains, and in this orderly sequence of deposits lies buried much of the life of the past.

The United States Geological Survey stated in I9 I 2 that the surface of the United States is being removed by solvent denudation at the average rate of .00I3 of an inch a year, or $I$ inch in 760 years. This means a removal by the streams of over 270 million tons of dissolved matter and 5 I 3 million tons of suspended matter annually. In other words, there is delivered into the seas and oceans each year from the area of the United States alone 783 million tons of rock materials. The amounts removed from different drainage basins show interesting comparisons. In respect to dissolved matter, the southern Pacific basin heads the list with 177 tons per square 
mile per year, the northern Atlantic basin being next with I 30 tons. The rate for the Hudson Bay basin, where the topography is nearly flat and the rocks are mainly granites, is lowest, with 28 tons.

Holmes states ${ }^{4}$ that the known denudation rates vary between I foot in 400 years (Irawadi basin) to I foot in 47,000 years (Hudson Bay region). For North America the rate for solvent denudation is I foot in 30,000 years, and for mechanical removal I foot in I 2,000 years. "Taking both together, the average rate of denudation is found to be I foot in 8,600 years."

The ancient life is known to us in the countless fossils of the rocks, for they are the remains of plants and animals living on the lands and in the seas at the time when the sediments were accumulating. Most of them, like the shellfish, lived on or in the bottom of the seas, other active forms swam about in the water, while the remains of the plants and animals of the lands were drifted by the streams into the marine areas, where they eventually sank to the bottom and came to be covered over-buried-by the accumulating sands, muds, or limestones. It should, however, be added that but little of the life of any time is preserved as fossils, for much of it is too soft to be preservable, or it is eaten or destroyed by other organisms or reduced by the solvent powers of bacteria and the acids of the waters.

The record of the physical forces which automatically entomb the successive upwellings of life is found upon all the continents, but is woefully incomplete in any one. For many cycles the marine record is best in North America, at other times in Europe or the Mediterranean countries or in Asia. The land or fresh-water record is even more scattered and imperfect, with the longest deposition in Africa, a continent that, south of the Sahara desert, has been invaded but little

${ }^{4}$ Holmes, A., op. cit., p. 57. 
by the ancient oceans. Out of all these widely scattered records the geologist pieces together the geological column, embodying the history of the earth, and yet at best we seem to have recovered far less than half of it. The record may be complete in the oceanic basins, but here it is forever hidden from hammer and mind. However, if we piece together all of the thicker known geological formations of sandstones, mudstones, and limestones into a superposed sequence, we get a pile of about 53 miles in thickness as a mean estimate, with the maximum thicknesses attaining to over 67 miles (Sollas gives a maximum of 63.5 miles). This means the more or less rapid wearing away almost to sea-level, one after another, of more than twenty ranges of mountains like the present European Alps or the American Rockies. During the incredibly long intermediate times, when the lands were planed to a low relief, there was very little erosion.

Ratios of muds, sandstones, and limestones. We have seen that the continents have lost through atmospheric erosion a layer of igneous rock between I and 2 miles thick in the course of geologic time. This amount of eroded average igneous rock should theoretically resolve itself into 30 per cent of solution materials and 70 per cent of detritals, or 80 per cent of mudstones, I I per cent of sandstones, and 9 per cent of limestones. Holmes gives 70 per cent of shales ( 20 per cent quartz), I 6 per cent of sandstones ( 75 per cent quartz), and 14 per cent limestones ( 75 per cent calcium carbonate). However, actual observations of the stratified rocks of America and Europe show quite different percentages for these three categories of water-laid sediments, and the difference is due to a great increase of pore-space in the fragmented materials and to the addition of material extracted out of the atmosphere and hydrosphere during the weathering processes. Accordingly, Leith and Mead $^{5}$ have shown that the cubical

${ }^{3}$ Leith, C. K., and Mead, W. J., "Metamorphic Geology," 1915, pp. 59-97. 
content of average igneous rocks thus increases in volume by at least 28 per cent, and that on the continents we appear to have 48 per cent of mudstones, 32 per cent of sandstones, and 20 per cent of limestones. This marked difference between chemical theory and actual presence is further explained by the unknown quantitative loss from the continents of the finest muds, sands, and solvent materials that the lands have permanently contributed to the oceanic basins. On the basis of the circulation of radium, Holmes estimates that the loss from the lands to the deep-sea deposits is about one-thirtieth of all the material eroded, i.e., about 300 million tons of the 9,000 million tons annually.

Distribution of the sedimentary rocks. We have seen that, according to theory, all of the continents have lost a layer of original igneous rock that is on the average between I and 2 miles in thickness, and it is this material, removed and reworked time and again by the weathering processes and the further chemical and assorting agencies of the rivers and oceans, that has gone into building the known geological column, with its maximum summation thickness of 67 miles. In no one place, however, can be seen more than a small part of this record, for usually the local thickness is under I mile, though there are limited regions where as much as 20 miles of it is present. This is because the deposition of the geologic formations in the periodically rising and flooding oceans, as described later in this lecture, takes place at any given time in very limited areas, most commonly, as at present, along the margins of the continents, or in long and narrow troughs-the geosynclines (see Fig. 9) -within the continental borders, and only periodically over the wider inner portions of the lands. We may add that over the surface of one-third of North America the rocks are all of igneous or crystalline character, that over more than one-half of it the thicknesses of the sedimentary rocks are under I mile, and 


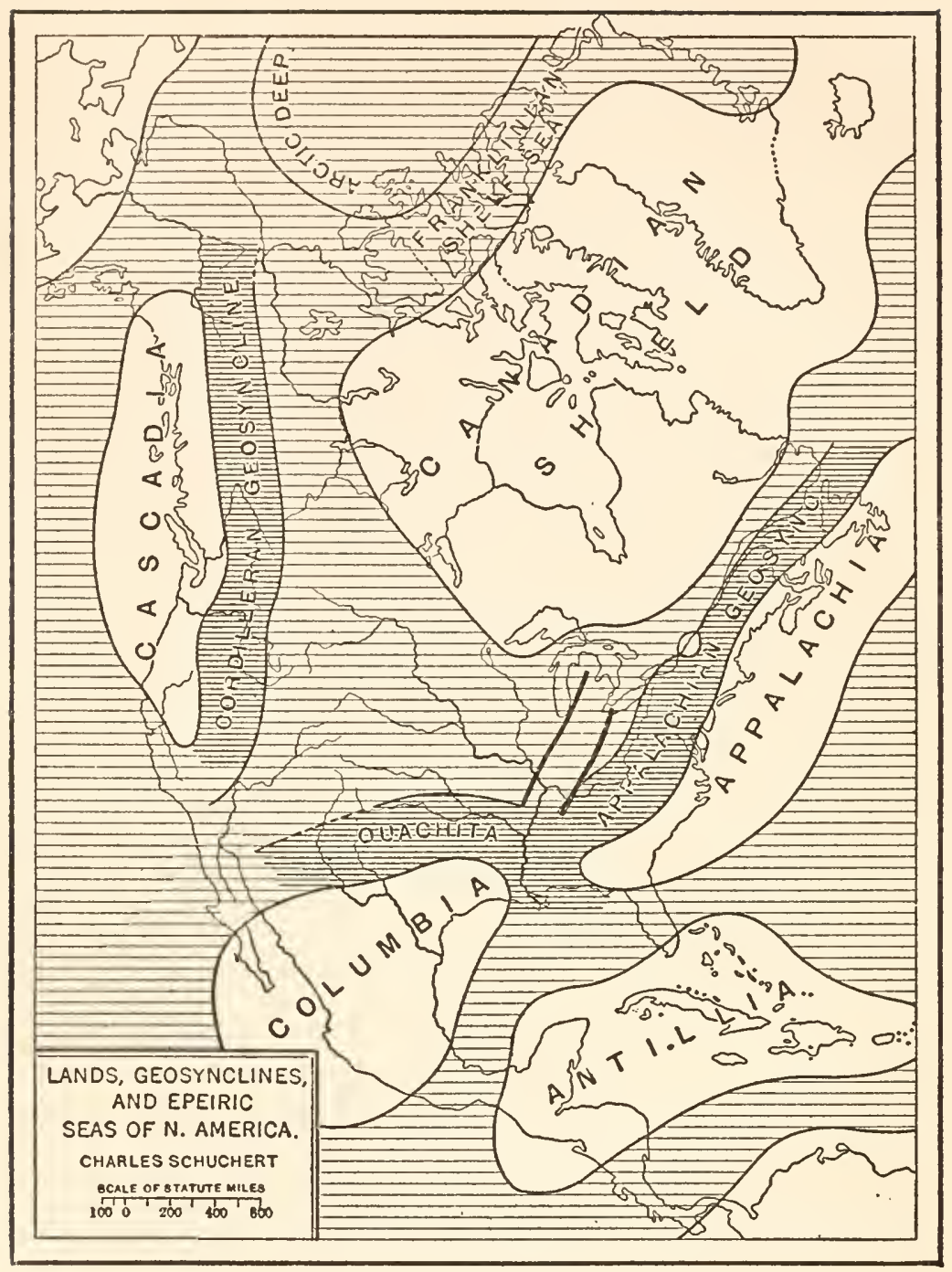

FIG. 9.-Generalized map of North America in Paleozoic time, showing in white the lands or positive elements, in darkest shading the three geosynclines or subpositive elements, and in lightest shading the extensive neutral medial area of the continent. The two heavy black lines indicate the Cincinnati and Ozark (Kankakee) uplifts. From the Pirsson-Schuchert "Text-book of Geology," published by John Wiley \& Sons, Inc. 


\section{AND ITS INHABITANTS}

that over the remaining small portion they vary from I to 20 miles; yet the greater depths do not cover more than oneeighth of the continent, and they occur in the long and narrow troughs of sedimentation, of which the two best known lie in the Appalachian and Rocky Mountain regions (see Fig. 9).

Eras of geological time. Now let us see how geologists divide this great pile of at least 53 miles of sediments and their included fossils. (A synopsis of geologic time is presented on page 46, and in Fig. 3.) The first era, or Archeozoic time, with the oldest known strata, has no proved fossils, though a very low form of water-living alga appears to have been present. Even if we exclude the probable fossil evidence, the presence in Ontario of 18 miles of sediments, of which about one-half is impure limestone along with much graphite, indicates unmistakably that life was already in existence. As we are treating of the oldest known time in the history of the earth, this is the place to emphasize what results were then attained and what natural processes were at work.

At the very beginning of the Archeozoic era, the earth had a rocky and fairly stable exterior known as the lithosphere, an atmosphere and a hydrosphere; protruding continents, and oceanic basins that were filled with slightly saline water; twicedaily tides, wear and tear of the ocean waves against the lands, reduction of the high lands by the atmosphere, and, through the rains, washing of the soil and solution materials into the seas and oceans. The sun shone then as now and made life possible, and the man in the moon was as clearly developed as he is today, remaining so ever since because this satellite has had neither atmosphere nor water to wash away his face. We therefore see that the earth was then very much as it is now, with these great differences, that at first the atmosphere was almost devoid of free oxygen and probably richer in carbon dioxide, that the lands were not covered with verdure, and that what there was of life was of a very low 
order and possibly more prevalent on the lands than in the oceans.

Then follows the second era of geologic time, the Proterozoic, with a thickness in south-central Canada of nearly I4 miles of coarse sediments almost devoid of fossils, and 4 miles of lavas. Probably more than three-fourths of this mass is of fresh-water and volcanic origin, and less than one-fourth may be of marine origin. In the Rocky Mountains there are upwards of 7 miles of less coarse sediments that include about I.5 miles of possibly marine limestones. In this connection it should also be noted that one of the remarkable recent discoveries in geology is that we know very little of marine Proterozoic sediments (in the sense of marine and fossiliferous Paleozoic formations) and that there is as yet even no hint as to where geologists are to look for them.

The Archeozoic and Proterozoic eras have the most ancient strata of the earth and their combined thickness is 32 miles as against about 2 I miles for all subsequent, fossiliferous strata. In this we discern the astounding fact that at least one-half of geological time and the greater part of the earth's history had passed before organisms became sufficiently endowed with hard parts to be abundantly preserved as fossils in the sedimentary rocks. It also means that the evolution of life for an incredibly long time was exceedingly slow in rising from the simple unicellular forms into the multicellular forms of plants and animals. It may be that the Archeozoic was entirely occupied in originating only the unicellular plants and animals. In the Proterozoic, organic differentiation appears to have gone on faster, because at the very beginning of the Paleozoic era are found all of the main kinds of marine animals other than fishes. The subject of the origin and progress of life from the unicellular forms to the most complex modern vertebrates will be developed by Professors Woodruff and Lull in subsequent lectures. 
The third era of geologic time, the Paleozoic, is based upon a thickness of about 4.75 miles of muds and sands and 3.4 miles of limestones. These thicknesses are in the Appalachian region, and form one of the most complete of all known Paleozoic records. In the Cordilleran area, where the record is far less complete, there are about 2 miles of coarse deposits and 3 miles of limestones. Toward the medial regions of the continent the thick lateral sections thin down to about I mile, essentially of limestones.

Shortly after the opening of the Paleozoic appear the fishes, the first of the vertebrates, and now, surprising as it may seem, in the fresh waters of the land and not in the seas. Before half of the Paleozoic is gone, double-breathing is perfected, and the amphibia begin to people the dry lands, and long before the close of the era give rise to the reptiles. It is also in the middle Paleozoic that the most primitive land floras arise, and not long afterward, in the Coal Measures, their remains, falling into great swamps, create the world's greatest supply of fuel in the soft and hard coals (see Fig. Io).

The fourth era, known as the Mesozoic, has, in western North America, about 7.5 miles of sediments, of which not more than I.25 miles are limestones. On the other hand, in the lands bordering the Gulf of Mexico and chiefly in Mexico there are less than 3 miles of Mesozoic sediments, but here the limestones make up more than one-half of the total thickness.

The Mesozoic is the Age of Reptiles, and yet the little mammals and the toothed birds are storing up intelligence and strength to replace the reptiles when the cycads and conifers shall give way to the higher flowering plants. Then follows the Cenozoic era, the Age of Mammals, with a thickness in California of about 5 miles of coarse sediments, contrasting with about 4 miles of fresh-water detritals in the Rocky Mountain area, and in these rocks occurs a most wonderful 
array of modernized animals. The era closes with a very decided glacial climate and another marked change in the animal world, out of which man rises to his present primacy among organisms. Geologists therefore call the present time the Psychozoic era or the Age of Reason.

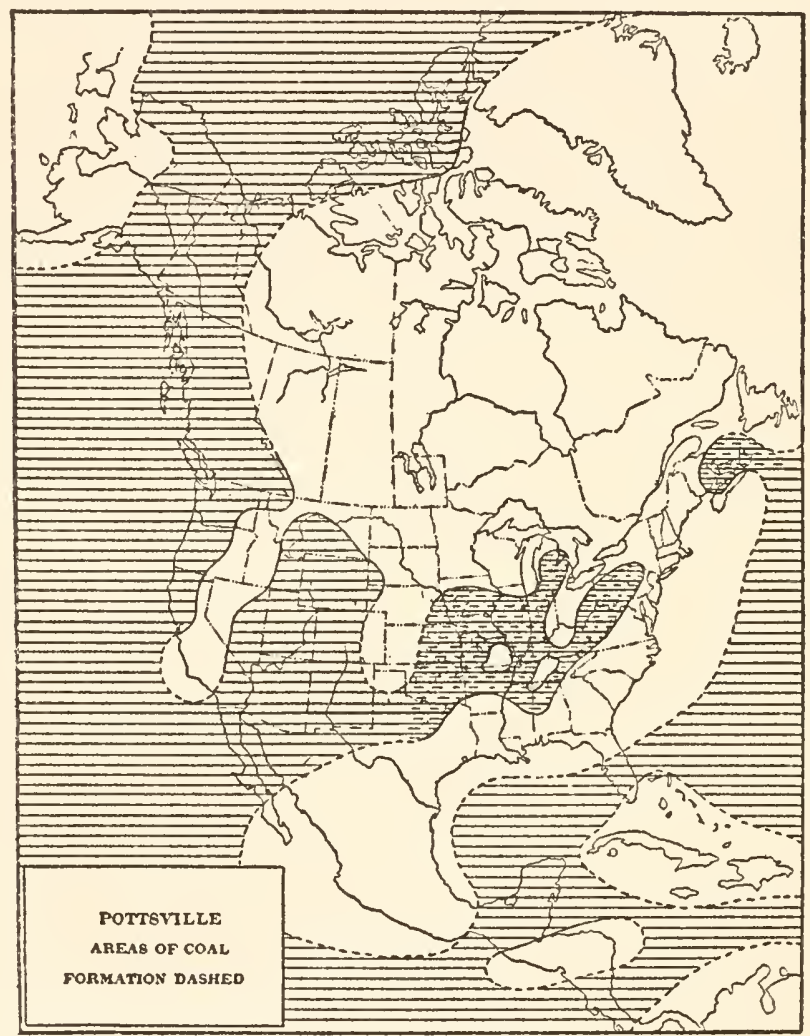

FIG. 10.-The marine inundation in Pennsylvanian time. Coal swamps in partially marine areas indicated by broken lines. From the Pirsson-Schuchert "Text-book of Geology," published by John Wiley \& Sons, Inc. 


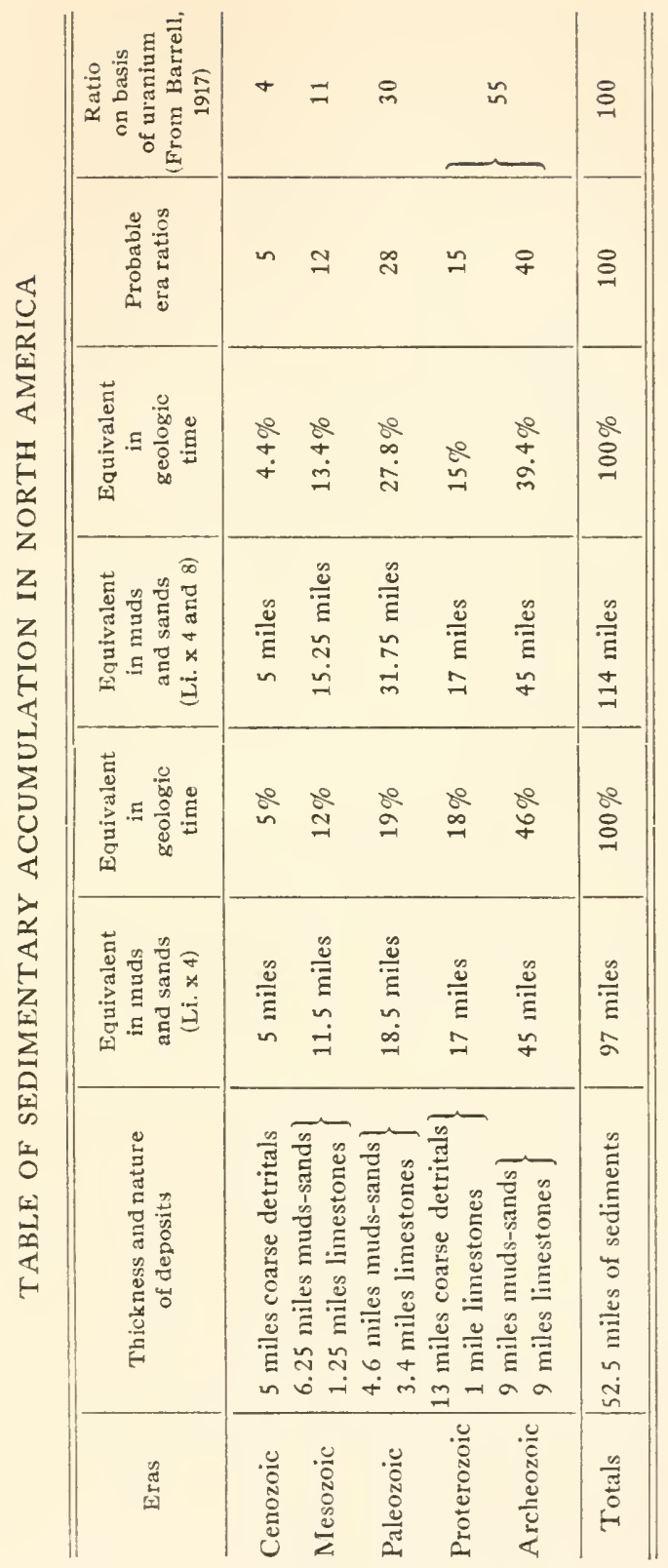


Relative duration of the eras. The preceding table gives the generalized thicknesses of the sedimentary rocks of North America in terms of the detritals (muds and sands) and the solution materials (limestones and dolomites). To attain more clearly to the relative duration of each of the eras it is desirable to restate the probable time taken by the far more slowly accumulating solution materials in terms of those of the detritals. Geologists differ greatly as to the time required to deposit any kind of sediment, but most of them will agree that limestones take from four to ten times longer than the coarser materials. On the other hand, the rate of deposition is exceedingly variable from place to place and from time to time. Further, the limestones of pre-Cambrian time are on the average far less pure than those of the later eras. Accordingly, on the basis of per annum rate of sedimentary accumulation there are as yet no reliable estimates, and as we are just beginning to appreciate that the geologic record is very incomplete, any percentages given at present must be taken as only suggestive of geologic time. A far more reliable standard is that of the rate of disintegration of radioactive minerals, though here the estimates of geologic time, of not less than $\mathrm{r}, 600$ million years, appear to the writer to be excessive by 50 per cent.

Now let us compare the above results with the ratios obtained by other geologists, but before doing so it should be said that their statements relate almost always to postProterozoic time. If, however, we follow Dana's ratios, it is clear that he held in his famous text-book that about onehalf of geologic time lies back of the Cambrian. It is on this basis that the following table has been prepared, and the figures in parentheses restate the ratios in percentages of all geologic time. 


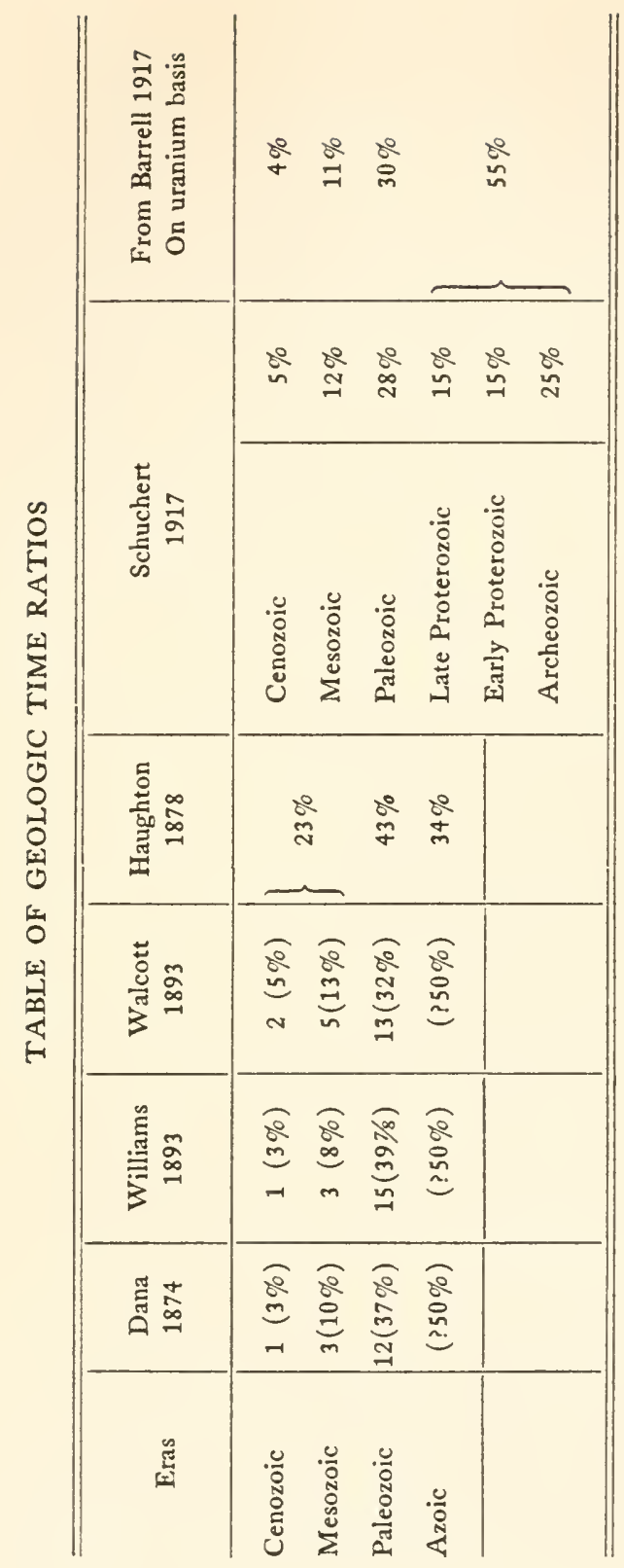


Periodic reclevation of the lands. We have thus far presented the sedimentary evidence in the main as if it had continuously and regularly formed, without stoppages or "breaks." 'The geologic record, however, was not laid down in this way, because the surface of the earth does not remain stationary. Even though to humanity the "everlasting hills" appear to be permanent features of the earth's surface, they are all doomed to be carried away by the rain and transported by the rivers into the seas and oceans. Erosion of the land goes on until all is worn to near sea-level, and then there is but a very sluggish run-off of the rain that falls upon the planed continents. The earth has repeatedly had such a low relief; in fact, this has been the condition during the greater part of its history.

The continents are repeatedly reellevated in relation to the strand, and this goes on many times in a small way and less often on a large scale ( see Fig. 3). We have said that in the course of the geologic ages the earth has shrunk at least 200 and possibly 400 miles in diameter. The earth is still shrinking all the time, and this gives rise on the surface to small warpings whose difference of elevation is usually not more than a few hundred feet. These are but surficial symptoms, due to internal readjustment, remarkable as it may seem, in an earth as rigid as steel-local accommodations of the earth's mass to loss of heat and molecular rearrangements. These alterations finally set up strains in the lithosphere which are too great for its strength to bear, and then there is a time of breaking and greater readjustment between the relatively settling and rising masses. At these times ranges of mountains are slowly raised up near the margins of the continents, due to the shortening, folding, and breaking of the earth's crust, and the ranges have lengths of between $\mathrm{I}, 000$ and $\mathrm{I}, 500$ miles. These are the minor shrinkage movements, the "disturbances," which are coming more and more to be regarded 
as the basis for dividing the eras into periods of time, and how often they occurred is one of the things that geologists are trying to ascertain. In North America we know of at least eight of these minor crustal readjustments, but in all the world there are many more than this.

Finally, there comes a time of major shrinking that adjusts all of the strains and stresses set up in the earth's mass by the minor, incompletely adjusted shrinkages. The earth has just passed through one of these major readjustments, and accordingly we see all of the continents standing far higher above sea-level than has been the rule throughout geologic time, and in many of them rise majestic ranges of mountains (see Fig. 3). A grander, more diversified, and more beautiful geography than the present one the earth has never had; this statement is made advisedly and with the knowledge that our planet has undergone at least six of these major readjustments of its mass. These greater movements are the "revolutions" that close the eras. Because the lands are then high they are suvject to more active erosion and in the last analysis all of the broken-up detrital and dissolved material is carried away by the streams to the oceans. At these times the continents are also largest and the materials received by the oceans are laid down on the outermost edges of the lands, where subsequent transgressions by the sea cover and hide them from our observation. After a long time the sea again comes to press further and further upon the land and spreads more formations of stratified rocks over those left by the previous floodings, the older geologic formations (see Fig. Ir). Therefore there is upon the present continents between each two such successive formations a "break" in deposition, a hiatus in the geologic record, a "time interval" when no record other than erosion is at hand. These "breaks" in sedimentation are representative of loss of record and are called "intervals"; they are regarded as the closing times of the eras. 

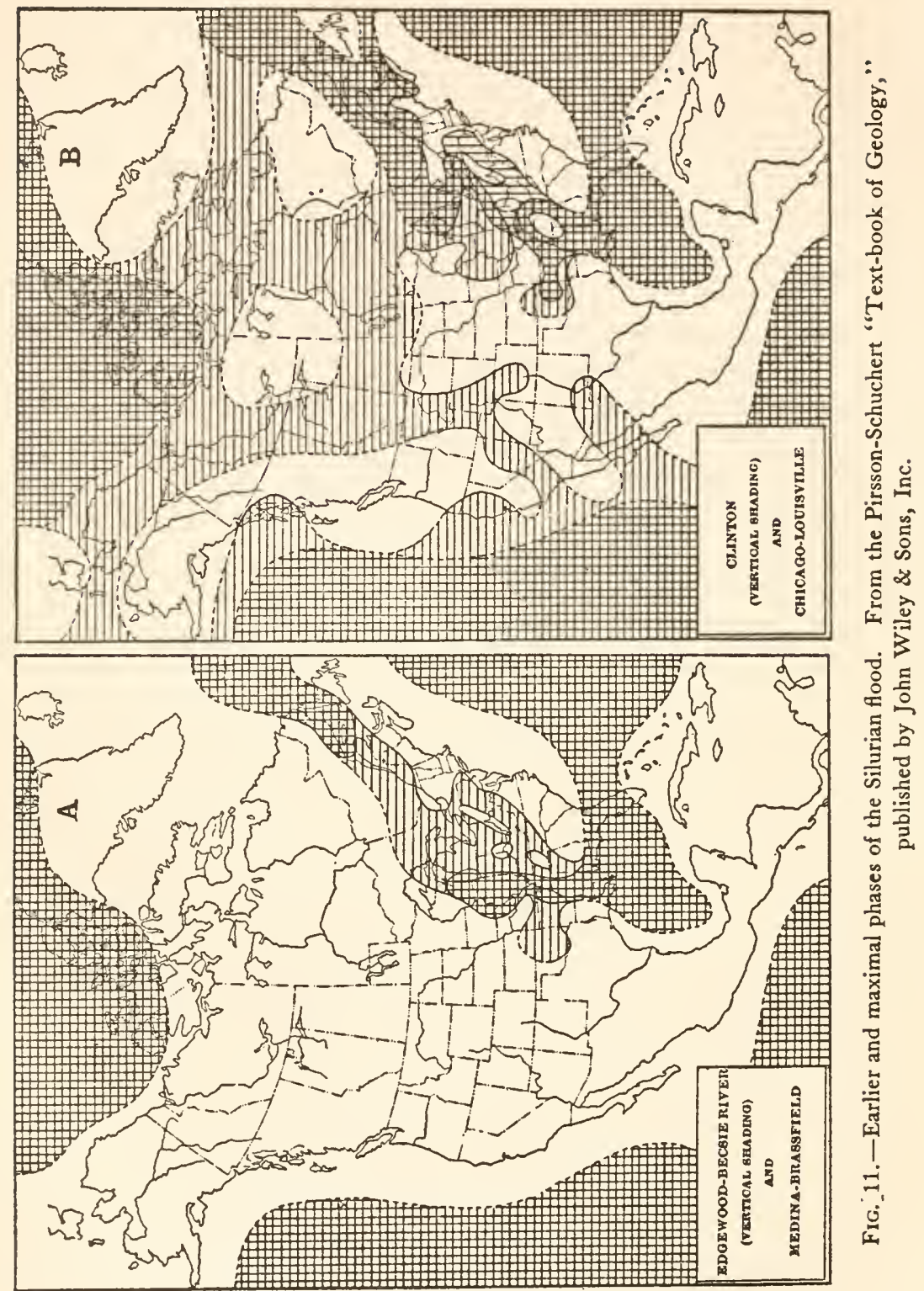
During these intervals when the continents are highest and largest, the oceans are smallest in areal extent, the separate continents are often united by land-bridges as Panama unites the Americas, such bridges alter the direction of the great ocean streams like the Gulf Stream, the high mountain ranges alter the directions of the air currents and take out of them their moisture so that great desert areas arise like our interRocky Mountain country, and because of these vast changes nearly all of the major movements are accompanied by glacial climates. Such mighty changes in the geography, topography, and climate of the earth react strikingly upon the life of the polar and temperate belts and so disarrange it that the major "intervals" following the "revolutions" are spoken of as the critical times in the earth's history-critical not only for the geography, separating or uniting continental masses, but also for life, since as a result of the lands then becoming high and cool to cold in places and elsewhere moist or dry, vast domains of organisms are forced to adapt themselves to the altered cunditions, or to migrate into more favorable areas, or to die out and make room for the rising hordes of fitter types.

In this way cycle after cycle of organisms appear and vanish, and their coming and going is brought about by the changing environment. Thus in the Mesozoic era, we see the lands mastered by the cycads and conifers among the plants and the dinosaurs among the animals, the air by the flying dragons, and the seas and oceans by other reptiles and hordes of ammonites and squid-like molluscs. The Great Reaper then steps in and through struggle and the elimination of countless organisms, resulting in regressive and progressive evolution, the lands in the Cenozoic begin to bloom with more and more flowering plants and grand hardwood forests, the atmosphere is scented with sweet odors, a vast crowd of new kinds of insects appear, and the places of the once dominant reptiles of the lands and seas are taken by the mammals. Out of these 
struggles there rises a greater intelligence, seen in nearly all of the mammal stocks, but particularly in one, the monkeyape-man line. Brute-man appears on the scene with the introduction of the last glacial climate, a most trying time for all things endowed with life, and finally there results the dominance of reasoning man over all of his brute associates.

The Cenozoic era was a time of especially marked geographic alteration, as is especially well seen in the evolution and spread of the elephant stock or Proboscidea. These animals arose in Africa early in the era, but there was no means by which they could spread into other continents, because Africa remained isolated. At about the middle of the Cenozoic, the Alps were rising and these crustal alterations also gave birth to a land-bridge across the Mediterranean connecting Europe and Africa. Across this bridge the long-faced elephants, now all gone, spread first into Europe and thence into Asia. A little later much of Asia began to rise, and the culmination is seen in the grandest of all mountains, the present Himalayas. These alterations permitted the elephant stock to spread across Asia and the Nome bridge into Alaska and wider North America, and they had no sooner arrived there than they were on their way across the newly arisen Panama bridge, thence to spread all the way south into distant Argentina. North America was then peopled with many kinds of camels and horses, and they, along with many other animals, migrated into South America. Wanderlust was upon the world, and from South America there migrated into our country great sloths, a claw of one of which was found by Thomas Jefferson in Virginia, and described as that of a huge lion. The great Democrat may be excused for his error, since in those days fossil sloths were unknown in North America; rather should he be praised, for he is the only president who has described a fossil, other than live ones!

Times of volcanic activity. In all that has been said we 
see the periodic rejuvenation of the lands and the renewal of active erosion. During these times of crustal unrest and subsequent internal readjustment the molten portions deep down in the lithosphere are forced to rise as great hot tongues into the cores of the mountain ranges, and in many places they break through and give rise to active volcanoes. Beneath lie great and highly heated masses that subsequently cool into granitic rocks, and when long afterward the mountains are worn away we discern among their roots these cores of granite. However, during all the time of crustal rising and readjustments the volcanoes are more or less active, spewing violently or quietly into the atmosphere tremendous volumes of rocks blown into volcanic ashes and of lavas, and great quantities of gases that increase the volume of the atmosphere, and much juvenile water is added by them and the thermal springs to the vadose water of the hydrosphere. Even though the lithosphere absorbs much vadose water through soaking and mineralization, the oceans are yet constantly growing in volume thiough this accession of juvenile water. In the same way, even though vast quantities of carbon are taken out of the atmosphere by organic agency and buried in the rocks, there to be transformed into natural gases, petroleum, asphalt, peat, and coal, the air is periodically resupplied by the volcanoes and by the hot-water springs.

Periodic spreading of the oceans. So far we have been describing the alterations that take place in the dry land; let us now turn to the realms of Neptune and note briefly the areal fluctuations of the oceanic waters during the latter half of geologic time. The geography of the earlier times we have not as yet deciphered and therefore cannot relate the movements of the oceans. It has been stated that when the earth shrinks, the lands rise in relation to the strand-line, and that this is especially true at the times of major crustal alterations. It is now definitely known that at the close of all the eras the 
continents were largest and at some of these times were even larger than they are now. On the other hand, the present oceans are more than full and for some time have been spilling over the outer edges of the continental platforms, apparently to the extent of nearly ten million square miles or about 5 per cent of the earth's surface. In other words, the present continental platforms occupy 35.5 per cent of the lithosphere, while the total water areas are equal to 69.6 per cent of the earth's surface.

The mean height of the present continents above the sea is given by Sir Archibald Geikie as about 2,400 feet, and if these protuberant masses were deposited in the sea, as they surely will be by the future rivers, the ocean waters would be displaced to the extent of raising the strand-line about 650 feet. We see therefore that the ocean level is also inconstant, and accordingly, even though the North American continent should remain stationary, about half of it would be covered by the displaced seas to depths of several hundred feet.

Between the comparatively short intervals of mountain making and crustal unrest occur the long quiet times of erosion when the lands are planed down to near the sea-level. This transference of rock leads, as has already been stated, to more or less flooding of the continents by the oceans (see Fig. I2). During the Paleozoic, Mesozoic, and Cenozoic eras, North America, and especially the United States, was widely flooded by warm and shallow marine waters at least sixteen times -Waucobian, Croixian, Canadian, Chazyian, Mohawkian, Cincinnatian, Silurian, Devonian, Mississippian, Pennsylvanian, Permian, Triassic, Jurassic, Comanchian, Cretaceous, and in an oscillatory and marginal way during the Cenozoic (see Fig. 13). These shallow-water spreadings begin in a small way, grow to greater dimensions throughout a very long time, and then, declining, recede more rapidly than they came (see Fig. II). They vary in areal extent up to $4,000,000$ 


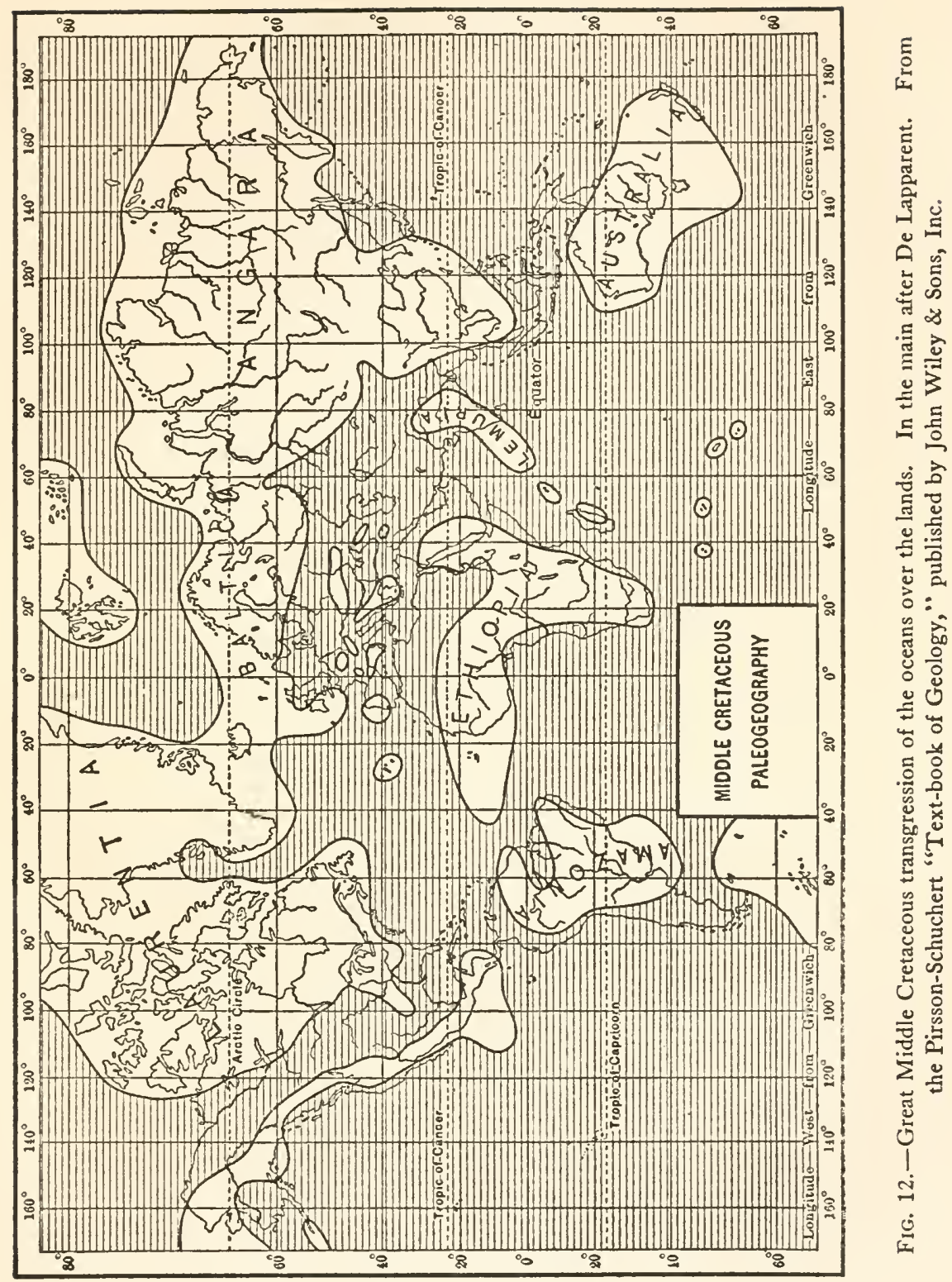


square miles. The greatest floods have spread from the Arctic Ocean, others from the Pacific, and those of least amount from the Atlantic. On the other hand, the number of floods was greater from the south than from the north, and the waters were most persistent in the Appalachian, lower Mississippi, and Rocky Mountain areas. Where the greatest thicknesses of sediments accumulate, out of this continental débris there will arise, phœnix-like, a future mountain range. After about 40,000 feet of strata had been deposited in the Appalachian trough, there arose near the close of the Paleozoic era the majestic Appalachian Mountains, some of which may have towered to at least 20,000 feet above the sea. In fact, the original mountains were destroyed by erosion during the Mesozoic era and the reëlevated Appalachians of today are due to later uplifts of more than 2,00o feet; subsequent erosion has developed them into their present interesting forms. Today one may travel comfortably over the roots of these once grand mountains by way of the Pennsylvania, the Baltimore and Ohio, and the Chesapeake and Ohio railways.

Areal variability of organic habitats. We have seen that the dry lands become alternately larger and smaller, and in the same way the shallow-water areas of the oceans are vastly increased when they spread over the lands, and are again greatly decreased when the land areas increase in size. Thus when the lands are widely flooded there is a great increase in the quantity of marine life, but little is originated that is new, while on the lands the climate becomes insular, warm and moist, and productive of the greatest amount of life in the then restricted areas. On the other hand, when crustal readjustments occur, the lands are largest, driest, and coolest, and these changing environments react on the life and bring about great alterations in the composition of the floras and faunas. At these times the shallow-water marine areas are smallest and most variable in turbidity and salinity-conditions that 


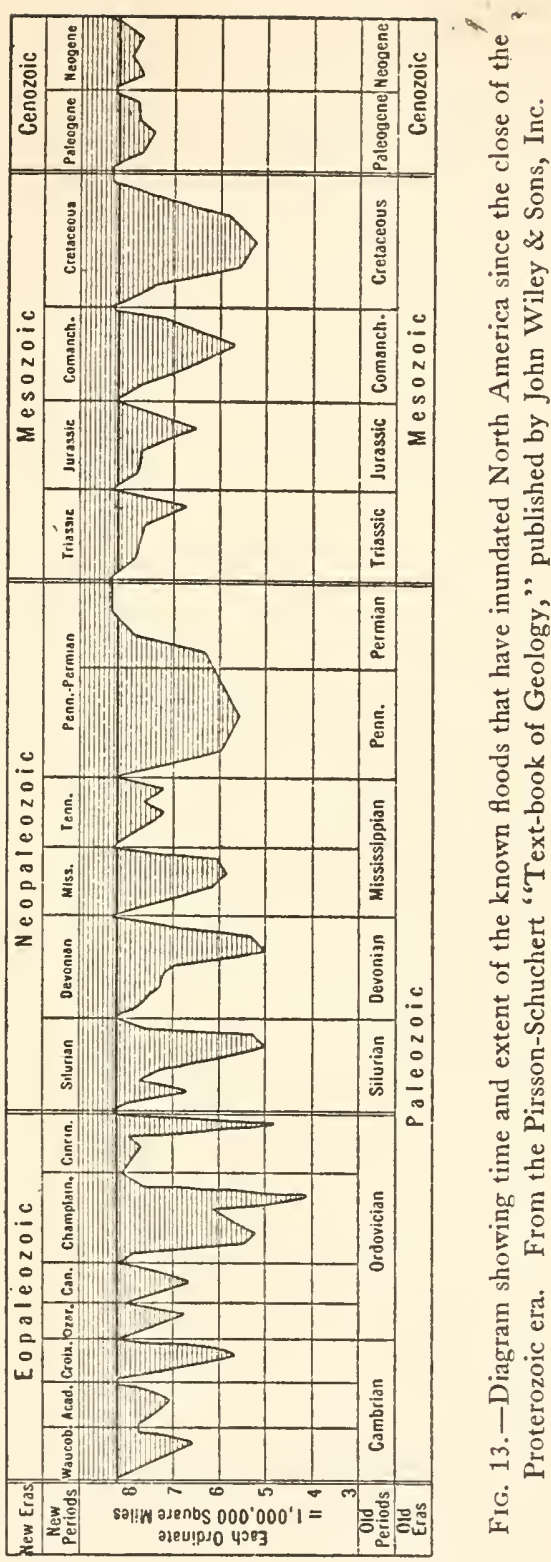


set up renewed evolution, resulting in the rise of new stocks. In these various periodic physical changes we see the stimulus that quickens organic evolution. Each cycle begins and closes with a comparatively short time of accelerated evolution, while the far longer intermediate tranquil periods lead to but little that is striking in the way of new organisms.

\section{Conclusion}

From this summary of the earth's changing surface and climate during geologic time the following facts may be selected for emphasis:

First, geologic time is very, very long, indeed so vast as to be beyond human comprehension. No geologist today thinks that the evolution of the earth and its life could have taken place in less than 100 million years. My own view as a student of Historical Geology is that geologic time endured about 800 million years. In all of this we perceive how slowly the physical and organic processes bring about the results of nature. Second, the constant shrinking of the earth leads to an instability of surface that brings about periodic changes, not only in the areal space relations of the water and land, but in the shapes and heights of the lands as well. Third, no sooner are the lands elevated above the sea-level than the weathering processes become more active and through the agency of the rain and wind all high places are, according to human standards, slowly but surely moved into the seas and oceans. Fourth, as a result of the transference of the high lands into the water areas the latter are to a certain extent displaced and periodically flood more or less of the lands. Fifth, due to these surficial changes the atmosphere and the climate are constantly changing in a small way, but every now and then when the lands a re largest, highest, and driest, a cold period appears and disarranges the entire organic world, both on the lands and in the waters. Sixth, when these "critical 
periods" are upon the world, the face of the earth is scenically grand and beautiful and at the same time the struggle for existence among the living is most intense. The rulers of the various domains find themselves overtrained and overspecialized, and succumb one after another to the changing environment. Their places are taken by the small, less specialized, and heretofore little known stocks, which quickly adapt themselves to their environments and become the dominators of the organisms about them. In all of this unceasing organic struggle most of the unadaptive families fail to continue; others are pushed by the pulse of life into the less desirable places, where they continue to exist as the static forms-the living fossils that tell us so much that is most interesting of once prominent stocks of plants and animals; but at all times much of life quickly responds to the changing environment and is remolded into the more fit, active, and alert types. The experiences thus gained are passed on to successive generations, and so the organic world as a whole advances to ever better living mechanisms endowed with higher and higher mentality.

The greatest mentality in the sea has been repeatedly derived from the continents, first in the fishes, then in the reptiles, and lastly in the mammals, and they have adapted themselves to the sea because of the ease with which they can there prey upon the less alert and intelligent. Such adapted stocks in the course of geologic time grow larger and larger, as, for instance, the whales of today. Out of them, however, comes no higher mentality. They represent an adaptation in the wrong direction, that is, to an easier life, for the highest organisms with the greatest mentality have been developed only on the land where the struggle for existence is fiercest because of the constant necessity of adaptation to an environment subject to intense changes. Organic supremacy is attained only through constant vigilance. 


\section{CHAPTER III \\ THE ORIGIN OF LIFE

\author{
LORANDE LOSS WOODRUFF
} \\ PROFESSOR OF BIOLOGY IN YALE COLLEGE}

Protoplasm. The phenomena to which we apply the term life have as their physical basis an inconceivably complex physicochemical organization called protoplasm. The conception of a common basis of all vital activities-that all living nature is one-was the culmination of a long series of researches during the first half of the nineteenth century, and forms the corner-stone of modern biology. At the present time biology is the study of the properties of protoplasm, because to it, in the last analysis, the multifarious activities of animals and plants must be referred.

Since we are only familiar with life as a manifestation of protoplasmic activity, the problem of the origin of life naturally resolves itself into the problem of the origin of protoplasm, and it is obviously impossible to discuss the origin of living matter without an insight into its composition and organization. The crude attempts of the alchemists of the Middle Ages to produce artificially in crucible or retort an homunculus complete, though they had not the slightest conception of its composition, affords, in contrast with the present trend of intensive analysis of protoplasm, a vivid illustration of the progress of scientific method in the interim. Obviously, analysis must precede synthesis even though the latter may never be achieved.

1 This lecture is published essentially as it was presented to a general university audience except that some of the more important references to the literature of the subject have been inserted as footnotes. 
From one point of view it is impossible to analyze protoplasm because the least disturbance of its fundamental organization results in a cessation of those phenomena characteristic of life, leaving matter in the non-living state before us. However, since in the transformation of matter from the living to the lifeless condition there is certainly no loss of weight, it follows that the complete material basis of protoplasmic organization remains for examination, and we may assume, as a working hypothesis, that the properties of protoplasm are a resultant of the properties of its constituent elements. But it may be noted in passing that an analysis of the débris from a destroyed factory probably would give one very little insight into the modus operandi of the intact organization.

Physical characteristics of protoplasm. Since the fundamental activities of all forms of protoplasm are of the same nature, biologists have naturally tried to discover a corresponding fundamental physicochemical basis in all living matter, and thus far research, broadly speaking, indicates that such exists. Living protoplasm ordinarily appears under a moderately high power of the microscope as a viscid, granular fluid. When studied with the highest magnifications, usually after being killed and stained, it often exhibits an extremely complex structure which, however, cannot be briefly described, as it is subject to considerable variation not only in the protoplasm of different organisms and tissues, but in the same microscopic unit mass under varying physiological conditions. Most frequently, though, it seems to present a foam-like appearance, due perhaps to closely crowded minute drops of a liquid alveolar substance suspended in a continuous interalveolar substance, also liquid but of a different physical nature. But it seems clear, since studies of protoplasmic structure have revealed by no means a complete correlation between its morphological organization and its activities, that the key to the latter must lie in an ultra-microscopic architecture whose varying phases 
are as it were reflected in the changing picture which the microscope is capable of resolving.

Chemical characteristics of protoplasm. Chemical analysis shows that protoplasm is a colloidal complex comprising chiefly the elements carbon, hydrogen, oxygen, nitrogen, sulphur, phosphorus, potassium, calcium, sodium, chlorine, iron, and magnesium-all of which are commonly found in the inorganic world. Indeed, there is no chemical element present which is peculiar to living matter.

But there are combinations of elements which are distinctly characteristic of protoplasm, not being found in nature except as the result of protoplasmic activity. These chemical combinations are the proteins, carbohydrates and fats, and of them the proteins are the most significant because they are universally present as a part of all living matter and form quantitatively its chief organic constituent. Proteins invariably consist of the elements carbon, oxygen, hydrogen, nitrogen, sulphur, with sometimes phosphorus or iron; the nitrogen, however, particularly distinguishing them from the other organic compounds of the living complex. Although the stereochemical composition of a protein molecule has not been determined, analyses show that it may be split up into a large number of simpler, though still very complex molecules, and it is evident that its few elements may be represented by hundreds and even thousands of atoms. As Underhill has said: "Viewed from the chemical standpoint protein is seen as a huge molecule, complex in structure, labile in character and therefore prone to chemical change. So large and intricate is the make-up of the molecule that chemists for generations have been baffled in their attempts to gain any adequate conception of its nature. At the present stage of our knowledge it is impossible to form any satisfactory definition of a protein based either on its chemical or physiological properties.".

2 Underhill, F. P., "The Physiology of the Amino Acids," 1915, published by Yale University Press. 
It must suffice then to emphasize that it is the presence of proteins and the power of forming them which is the diagnostic chemical characteristic of matter which is alive. It will be recognized, of course, that proteins are not "alive," and even if the biochemist should succeed in artificially synthesizing a protein, which has not thus far been accomplished, by grouping together amino acids, which already have been made synthetically, this would not be in any sense the artificial production of life. But since proteins are the one molecular system of which we are aware which is diagnostic of protoplasm, we have the right to assume, for the present at least, that they represent in a way the quintessence of that arrangement of matter which exhibits life, while clearly recognizing that they are but an integral part of the more complex, physicochemical structure of protoplasm. Protein is, as it were, "the chemical nucleus or pivot around which revolve a multitude of reactions characteristic of biological phenomena."

The vehicle of life manifestations is thus clearly a physicochemical complex and one of its most conspicuous and fundamental phenomena is what has been described as "energy traffic" or the function of trading in energy. This consists in appropriating energy from the environment, storing it in a state of higher potential and later expending it in the kinetic form. The lability of many of the molecular aggregates of protoplasm, that is, their tendency to change in composition toward greater or less complexity, coinciding with deoxidative and oxidative processes, is an important characteristic and one which endows the protoplasmic system as a whole with its perennial plasticity- "its peculiar proneness to change its composition under the stimulus of slight changes in the energyequilibrium between itself and its surroundings.",

Definitions of life. This continual flux, which is now em-

3 Allen, F. J., "What is Life?" Proc. Birmingham Nat. Hist, and Philos. Soc, vol. 11, pp. 44-67, 1899. 
phasized as characteristic of protoplasm, was recognized as a characteristic of organic individuals long before it was recognized in their physical basis, and is expressed in nearly all definitions of life. Aristotle described life as "the assemblage of the operations of nutrition, growth and destruction"; Bichat as "the sum total of the functions which resist death"; De Blainville as "the twofold internal movement of composition and decomposition, at once general and continuous"; Lewes as "a series of definite and successive changes, both of structure and composition, which take place within an individual without destroying its identity"; while Spencer defines it as "the definite combination of heterogeneous changes, both simultaneous and successive, in correspondence with external coexistences and sequences" and as "the continuous adjustment of internal relations to external relations."

Obviously these statements are far from satisfactory, but no adequate, concise and yet comprehensive definition of life ever has been formulated, though it has been essayed by the best minds for generations. The fact is that life is too complex to be described concisely, and so unique that it is impossible to resort to the lexicographer's trick of comparing it with something else. Although many physicochemical phenomena contribute to life, not one of them will serve as a criterion and all of them collectively do not offer, as yet, a satisfactory explanation. Whether behind the physical phenomena there are intangible metaphysical factors is a question outside the realm of biology. Since the limitations of our senses confine our perception to that part of our environment, perhaps a very small part, denoted by the fundamental concepts of science, matter, and energy acting in space and time, we are forced to interpret, in so far as we are able, the life processes in these terms. Thus far, however, the study of protoplasm has given no reason for abandoning the productive working hypothesis that life phenomena are an expression of 


\section{AND ITS INHABITANTS}

a complex interaction of physicochemical laws which do not differ fundamentally from the so-called laws operating in the inorganic world.

Individuality of organisms. We have seen that, although all protoplasm has a similar fundamental physicochemical basis, nevertheless there is a considerable, indeed a great, diversity in the minor details of its composition, not only in different species of animals and plants, but also in the various parts of the same animal or plant. In fact, organisms are organisms because of specific local differentiations in the immediate substratum of their vital activities.

This specification of protoplasm is rendered possible by the fact that the structural units of all organisms are microscopic masses of protoplasm, termed cells. The bodies of all higher animals and plants are congeries of millions of these protoplasmic units, while many of the simpler forms of life consist of but a single one. Therefore it is apparent that a fundamental characteristic of organisms as we know them today is not only that the material basis of their activities which we call life is the somewhat protean, though no less real, protoplasm, but also that this physical basis is individualized into structural moieties, the cells. It is not an overestimation to say that the recognition of this dual similarity of physicochemical and morphological organization of all living things must be considered the greatest single generalization which biological science has attained, and must be ranked with the theory of organic evolution, of which it is the corner-stone, in its far-reaching bearings. ${ }^{*}$

${ }^{4}$ See Allen, F. J., op. cit.

Minchin, E. A., "The Evolution of the Cell." Amer. Nat., vol. 50, 1916, pp. 5-38, 106-118, 271-283.

Conklin, E. G., "The Basis of Individuality in Organisms from the Standpoint of Cytology and Embryology." Science, new ser., vol. 43, 1916, pp. 523-527.

Driesch, H., "The Problem of Individuality," 1914. 
Obviously, then, the biologist in dealing with living substance has it only in the form of cells, and these, singly or collectively, constitute individual organisms. Thus in the final analysis protoplasm is known to us only in the form of living individuals, and the expressions "protoplasm" and "life" are merely abstractions, one indicating that all individuals have to a certain extent a common organizational foundation and the other that they exhibit certain characteristic actions and reactions. The living organism is a microcosm which exhibits a permanence and continuity of individuality correlated with specific behavior, and this it transmits to other matter which it makes a part of itself and to its offspring in reproduction.

It is apparent that the phenomena which we call life are dependent upon the interplay and interchange between the highly organized protoplasmic complex and its environment. Although the organism, whether animal or plant, is an individual, still it retains its individuality-lives-solely by its powers of developing and maintaining exquisite adjustments to its surroundings, and therefore the concept protoplasm has little or no content unless environmental relations are included. This fitness of the organism, as Henderson has recently emphasized, is but one part of a reciprocal relationship of which the fitness of the environment is the other. "The fitness of the environment results from characteristics which constitute a series of maxima-unique or nearly unique properties of water, carbonic acid, the compounds of carbon, hydrogen, and oxygen and [for primordial life] the ocean." "No other environment consisting of primary constituents made up of other known elements, or lacking water and carbonic acid, could possess a like number of fit characteristics" for protoplasmic phenomena. The properties of matter and the course of cosmic evolution are intimately related to the structure of the living being and to its activities. Indeed, "the whole evolutionary process, both cosmic and organic, is one, and the biolo- 
gist may now rightly regard the universe in its very essence as biocentric." 5

History of the establishment of biogenesis. The previous lectures in this course have described the theorjes in regard to the origin of this environment on the earth, so we turn now to the question of the origin of life-that primeval question which has been asked by all ages and the answers to which, if they do no more, at least epitomize the philosophic and scientific perspective of the times.

One of the greatest intellectual characteristics of the Greeks was their scientific curiosity, and therefore it is not strange that the first biological question which they propounded was in regard to the origin of life. Even to the best minds of the ancients there was little incongruity in the idea of animals and plants arising de novo from earth or water. Although Aristotle, whose scientific studies formed the foundations of natural history, devoted a great deal of thought and ingenuity to the subject of the origin of animals, he apparently accepted with little reservation the statements that even such highly developed organisms as worms, insects, and some fishes could come into being from mud. Such ideas are voiced over and over again through more than twenty centuries by philosopher and poet, theologian and layman.

Lucretius, in his De rerum natura, says that "with good reason the earth has gotten the name of mother, since all things are produced out of the earth, forming in rain water and in the warm vapors raised by the sun." Virgil in the fourth Georgic, which is devoted to a discussion of bees, graphically describes a simple method used in Egypt for obtaining bees from the dead bodies of bullocks.

Coming to the mediæval period and later we find Cardan stating that water engenders fishes and that various types of animals arise from fermentation. Swan in his Speculum mundi

5 Henderson, L. J., "The Fitness of the Environment," 1913. 
says that a dead horse breeds wasps, a mule produces hornets, while from an ass arise bumble bees. Van Helmont, one of the founders of chemical physiology, gives particularly specific directions for the experimental production of scorpions and mice, while Kircher actually figures animals which he avers arose under his own eyes through the influence of water on the stems of plants; an instance, perhaps, not of spontaneous generation but of the transformation of plant into animal, which was also a notion prevalent at the time. The ironical reflections of one Ross, aroused by the scepticism of Sir Thomas Browne in regard to mice arising by putrefaction, are quite typical of seventeenth-century opinion. He says: "So we may doubt whether in cheese and timber worms are generated, or if beetles and wasps in cow-dung, or if butterflies, locusts, shellfish, snails, eels, and such life be procreated of putrefied matter, which is to receive the form of that creature to which it is by formative power disposed. To question this is to question reason, sense, and experience. If he doubts this, let him go to Egypt, and there he will find the fields swarming with mice begot of the mud of Nylus, to the great calamity of the inhabitants."

That such ideas of the origin of life were prevalent and their truth untested by experiments is an eloquent commentary on the general state of the scientific method before the Renaissance. It was Francesco Redi, an eminent Italian scholar, physician, and naturalist, who, not content with tradition, but with great faith in observation, made a study of the origin of maggots in decaying animal matter. By the simplest of experiments he found that maggots never developed in meat to which flies were not allowed access and that the seeming transformation of meat into maggots was the result of flies laying their eggs on the meat. When this was prevented, no matter how he varied the materials of his experiments, he obtained the same result, and naturally concluded that the sup- 
posed appearance of life where life had not been previously was due to the introduction of foreign living material. ${ }^{8}$

One may imagine that the practical man of affairs, who scoffed at Redi toiling under the Italian sun with meat and maggots to satisfy a scientific curiosity, little dreamed that the practical results which germinated from this folly would be among the most important factors in twentieth-century civilization. Indeed, it is difficult to overestimate the importance of Redi's conclusion from either the theoretical or practical viewpoint, for with it was definitely formulated the theory, which has gained content and impetus as the years have rolled on, that matter does not assume the living state, at the present time at least, except under the direct influence of preëxisting living matter.

The influence of this work gradually became apparent in scholarly literature; Derham, for instance, stating that "Spontaneous generation is a doctrine so generally exploded that I shall not undertake to disprove it. It is so evident that all animals, yea and vegetables, too, owe their production to parent animals and vegetables, that I have often admired at the sloth and prejudices of the ancient philosophers in so easily taking upon trust the Aristotelian, or rather Egyptian doctrine of æquivocal generation." as soon say that rocks and woods engender stags and elephants as affirm that a piece of cheese generates mites. Stags are born and live in woods, and mites in cheese, but they both owe their being to that of other animals." And again, Henry Baker, the versatile miscroscopist of the Royal Society, says: "Nothing seems now more contrary to reason, than that chance and nastiness should give a being to uniformity, regularity and beauty . . . and create living animals. . . This, however,

- Redi, F., "Esperienze Intorno Alla Generazione Degl' Insetti," 1668. English translation by M. Bigelow, 1909.

'Derham, W., "Physico-Theology," 1713. 
was the opinion not only of the ignorant and illiterate, but of the most learned grave philosophers of preceding ages; and would probably still have been taught and believed had not microscopes discovered the manner how all these things are generated, and restored to God the glory of his own amazing work.",

Although it is relatively easy to follow when one's eyes are opened, it is not to be imagined, of course, that one experiment, or even the long series of studies made by Redi, could annihilate a time-honored belief. Indeed, the history of the establishment of the theory extends down even to the present time, for no sooner had experiment apparently disposed of it completely than it arose again, phœnix-like, with fresh vigor in a slightly different phase demanding further study.

Among others, a Scotch priest, Turbervill Needham, studied the problem and believed that various minute organisms, which improvements in the microscope were bringing to the fore, appeared spontaneously in infusions which he boiled and corked up in flasks. ${ }^{9}$ His results attained considerable notoriety, since Buffon, the famous French naturalist, found in them a substantiation of his theory that all organisms are aggregates of indestructible units, which upon the death of the individual are disseminated in nature and later are employed as moieties in the organization of arising generations.

Needham's results, however, were soon shown by Lazzaro Spallanzani ${ }^{10}$ to have been obtained by inadequate sterilization and sealing of the infusions which he studied; but at this point objections came from another source-the chemists who had recently discovered oxygen and the importance of this element

8 Baker, H., "The Microscope Made Easy," 1742.

${ }^{9}$ Needham, T., "A Summary of Some Late Observations upon the Generation, Composition, and Decomposition of Animal and Vegetable Substances." Philos. Trans. Roy. Soc. London, 1748.

10 Spallanzani, L., "Expériences pour Servir à l'Histoire de la Génération des Animaux et des Plantes," 1786. 
in the free state for the processes of life and for putrefaction and fermentation of organic matter. The treatment to which Spallanzani subjected his infusions might well have so changed the organic matter, they argued, that it was incapable of producing life. This objection was met by a series of experiments by various investigators during the first half of the last century, which showed conclusively that thoroughly sterilized infusions never developed living organisms when air was admitted which had been rendered sterile by heat or by having all suspended matter removed, while the studies of Schwann and Cagniard de la Tour intimated that fermentation and also putrefactive changes in organic infusions are themselves the result of micro-organisms.

So far it was clear that organic infusions in which no life is present do not develop living organisms except when contaminated with material from an extraneous source, which is ordinarily the atmosphere, but it remained then to be shown that living organisms are practically ubiquitous in the atmosphere and thus are available for the initiation of the microflora and fauna of infusions. This was put upon a broad empirical basis chiefly by the labors of Pasteur. Tyndall, who himself made a notable contribution to the solution of the problem by researches in experimental physics, confidently asserted that there seems to be no flaw in the reasoning, and it is so simple as to render it unlikely that the notion of life developing from dust can ever again gain currency among the members of a great scientific profession.

We thus reach the general conclusion that, so far as human observation and experimentation go, no form of life arises today except from preëxisting life. But since life is present on the earth now and the paleontological record indicates that it has been present without interruption for some hundreds of millions of years, we have to consider the following alternative: Either life was transported to this planet from some 
other part of the universe; or life arose spontaneously from non-living matter at one period at least in the past as a natural result of the evolution of the earth and its elements.

\section{Theories of The Origin OF Life}

It will be useless to offer any extended discussion or specific criticisms of the individual theories of the origin of life, for each one rests on many uncertain postulates, which have a greater or less degree of probability dependent, to a considerable extent, on the personal equation of the critic. It should be said, however, in justice to the authors of the theories which we shall outline, that the theories are not advanced as final solutions of the problem of the origin of life, but rather as gropings toward a formulation of the conditions which conceivably might have attended and contributed to its genesis. The magnitude of the problem may be inferred from a recent statement by the dean of American biologists that "the study of the cell has on the whole seemed to widen rather than to narrow the enormous gap that separates even the lowest forms of life from the inorganic world." 11

Vitalism. The vitalistic conception that life phenomena are in part at least the resultant of manifestations of matter and energy which transcend and differ intrinsically in kind from those displayed in the inorganic world - a denial, as it were, in the organism of the full sufficiency of known fundamental laws of matter and energy-has arisen many times in the development of biological thought, either as a reaction against premature conclusions of the nascent sciences or from an overwhelming appreciation of the complexity of life phenomena. Vitalism goes back as far as the history of science is recorded, but it attained its most concrete formulation as a doctrine during the early part of the eighteenth century, in opposition to the obviously inadequate explanations which 11 Wilson, E. B., "The Cell in Development and Inheritance," 2d ed., 1900; "The Problem of Development," Science, new ser., vol. 21, 1905, pp. 281-294. 
chemistry and physics could offer for the phenomena of irritability of living matter then prominently before the professional biologist. The vitalists at that period abandoned almost completely all attempts to explain life processes on a physicochemical basis and assumed that an all-controlling, unknown, and unknowable, mystical, hyper-mechanical force was responsible for all living processes. It is apparent, of course, that such an assumption in such a form is a negation of the scientific method and at once removes the problem from the realm of scientific investigation. No biologist at the present day subscribes to vitalism in this form; some uphold vitalism (if it must still be called vitalism) in its modern aspect, while all will undoubtedly admit that we are at the present time utterly unable to give an adequate explanation of the fundamental life processes in terms of physics and chemistry. Whether we shall ever be able so to do is unprofitable to speculate about, though certainly the twentieth century finds relatively few representative scientists who really expect a scientific explanation of life ever to be attained or who expect that protoplasm will ever be artificially synthesized. But, "In ultimate analysis everything is incomprehensible, and the whole object of science is simply to reduce the fundamental incomprehensibilities to the smallest possible number." ${ }^{12}$

Cosmozoa theory. The establishment of the fact that, so far as we can determine, life does not arise except from preexisting life at the present time, and the dawning realization of the intrinsic and unique complexity of the architecture of matter in the living state, which has thwarted the attempts of alchemist and biochemist to synthesize even one of its chief molecular aggregations, have led several scientists to suggest and elaborate the hypothesis that life has never arisen de novo on the earth but has been transported hither from elsewhere in the universe.

12 Huxley, T. H., "Darwiniana." “Collected Essays,” vol. 2, 1893, p. 165. 
Such an idea was advanced by Richter, and later independently suggested and discussed by Helmholtz and Kelvin. ${ }^{13}$ On the assumption that some of the heavenly bodies have always been the abode of life, and from the fact that small solid particles, which presumably have formerly been an integral part of such bodies, are moving everywhere in space, Richter pictures these particles as the vehicles which disseminate the simplest forms of life through interstellar space to find lodgment and development upon such planets as afford a suitable environment. Clearly, from this point of view, life is as old as the universe itself-living matter has never originated but has been transported from world to world. Hence the acceptance of this permanent dualism of living and lifeless matter does not answer the broad question as to the origin of life, but transfers its origin to a "conveniently inaccessible corner of the universe where its solution is impossible." However, the question before us is the origin of life upon the earth, and the plausibility of this cosmozoa theory depends on two assumptions-that life exists elsewhere in the universe and that life can be maintained during the interstellar voyage. Neither assumption has, of course, any empirical foundation whatsoever, though the second offers at least something tangible for discussion.

Many of the lower forms of life, such as the bacteria and protozoa, have the power of developing, particularly under the influence of unfavorable environmental conditions, protective coverings of various sorts about themselves and of assuming a resting condition in which all the metabolic activities characteristic of active life are reduced to the lowest ebb. In this spore or encysted state they are immune to extremes of temperature and desiccation to which they readily succumb during vegetable life. It has recently been found, for example,

13 Verworn, M., “Allgemeine Physiologie," 5th ed., 1909. English translation of $2 \mathrm{~d}$ edition by F. S. Lee, 1899. 
that certain types of bacteria can successfully endure a temperature of nearly $-200^{\circ} \mathrm{C}$. for six months, and about $-250^{\circ} \mathrm{C}$. for shorter periods, that is, a temperature considerably lower than that at which any chemical reactions are known to occur; and again the spores of other bacteria can withstand a temperature as high as $120^{\circ} \mathrm{C}$. for a short time. The cysts of some relatively highly specialized protozoa can retain their vitality for at least fifty years, and the seeds of the higher plants, particularly those with a thick and impermeable integument, have been found to retain the power of germination for nearly a century, though the statement that grain from Egyptian tombs still maintains its power of growth has been disproved. The ability to continue dormant life clearly seems to depend to a large extent on the presence of a dry enclosing membrane, since under these conditions the entrance of gases is impossible and the chemical processes within are at a minimum. Thus it is apparent that certain organisms may survive unfavorable conditions for a long period, and we have no reason for believing that the limits of endurance of other forms do not greatly exceed that of the few which have thus far been studied.

On the other hand, the exigencies to which living matter would be exposed when started on its interstellar journey are not inconsequential. Meteors in their fall through the earth's atmosphere become incandescent and, if they are the vehicle of transfer, it would only be conceivable for life to survive far below the surface where the temperature is lower. To avoid this and other difficulties it has been suggested by Arrhenius that the radiation pressure of light is sufficient to overcome the attraction of gravitation for particles of the extraordinary minuteness of some of the lowest forms of life, and that isolated germs might make the journey to the earth. But on the assumption that such an individual organism were forced out into space by the mechanical pressure of the light 
waves from the sun of the nearest solar system, it would require many thousand years to reach the earth. Only on the view that cells are potentially immortal and can remain in a dormant condition nearly indefinitely can we believe that life has reached the earth from other planets. Arrhenius maintains that this is possible owing to the exceedingly low temperature and absence of water-vapor which must prevail in cosmic space; and Loeb states that there is no reason why spores should lose appreciably more of their germinating power in ten thousand years than in six months. ${ }^{14}$

Without further discussion it is apparent that the theory is one which cannot be proved or disproved. At first thought, and as first outlined by Richter, it commanded little serious attention; but with its strictly scientific formulation by later physicists and biologists, and especially in view of our increasing appreciation of the potentialities of life in the latent state, we are justified perhaps in seriously questioning, with Helmholtz, "whether after all life has ever arisen, whether it may not be even as old as matter, and whether its germs, passing from one world to another, may not have developed where they found favorable soil." But the majority of biologists undoubtedly would agree with Schäfer that, "knowing what we know, and believing what we believe, as to the part played by evolution in the development of terrestrial matter, we are, without denying the possibility of the existence of life in other parts of the universe, justified in regarding these cosmic theories as inherently improbable-at least in comparison with the solution of the problem which the evolutionary hypothesis offers." 15

14 Arrhenius, S., "Worlds in the Making." English translation by H. Borns, 1908.

Loeb, J., "The Organism as a Whole from a Physicochemical Viewpoint," 1916.

Woodruff, L. L., "A Pedigreed Race of Paramecium." Proc. Soc. Exp. Biol. and Med., vol. 9, 1912.

15 Schäfer, E. A., "Life: Its Nature, Origin and Maintenance." Presidential address, Brit. Assoc. Adv. Sci. Science, new ser., vol. 36, 1912, pp. 289-312. 
With this in mind we may briefly survey some of the modern scientific conjectures which attempt to formulate the phenomena attendant upon the evolutionary origin of matter in the living state from the inorganic upon the earth.

Pfluger's theory. Assuming that the surface of the earth was once incandescent, Pflüger has offered a suggestive theory the crucial points of which turn on the chemical characteristics of the proteins. He emphasizes that there is a fundamental difference in the nitrogenous radicals of what he terms "dead" proteins, as egg albumin, and "living" proteins taking an active part in the economy of protoplasm, since the nitrogenous decomposition products of the latter either contain the cyanogen radical or can be artificially produced from compounds of cyanogen by atomic rearrangement. This suggests to Pflüger the probability that the cyanogen radical is an integral part of the molecular complex of living proteins and since in the formation of cyanogen a large amount of heat is absorbed, it follows that this radical possesses a large amount of internal energy and thus with it there is "introduced into the living matter energetic internal motion."

Pflüger's idea that the protein molecules of living protoplasm owe their diagnostic characteristics, in particular their lability, to cyanogen is supported, he believes, by certain analogies, which we need not consider, between cyanogen compounds and "living" proteins. Indeed, he says, the "similarity is so great that I might term cyanic acid a half living molecule." "When we think of the beginning of organic life, we must not think primarily of carbonic acid and ammonia; for they are the end of life, not the beginning." "The beginning lies rather in cyanogen." Pointing out that cyanogen and its compounds arise only in an incandescent heat, he holds that "life is derived from fire, and its fundamental conditions were laid down at a time when the earth was still an incandescent ball." Thus living material owes its genesis to cyanogen com- 
pounds which, on account of their tendency to decomposition, entered into relations with carbon compounds arising at similar temperatures. When the temperature conditions of the earth's surface permitted the precipitation of water, this with the salts and gases in solution joined the growing cyanogencarbon complex and gave rise to the highly labile protein molecules so characteristic of protoplasm. Thus, according to Pflüger's hypothesis, arose a relatively simple, homogeneous material from which has been evolved the highly differentiated protoplasmic masses or cells of organic life today. ${ }^{16}$

Moore's theory. Moore essays to picture with rather bold strokes the origin of life from the inorganic elements of the cooling earth, by a continuation of the slow process of complexification which he sees inherent in matter. "This note," he says, "cannot be too strongly sounded that as matter is allowed capacity for assuming complex forms those complex forms appear. As soon as oxides can be there, oxides appear; when temperature admits of carbonates, then carbonates are forthwith formed. . . . Next in order of development prior to life inorganic colloids begin to appear in solution, or suspension, in the waters of the cooling globe, alumina and silica deposited in colloidal form are seen in many sedimentary rocks. Single molecules existing in solution, and capable of forming colloids, with alterations in temperature, and in chemical reaction of the environment, begin to form complexes, or solution aggregates, in which the unit of chemical structure passes from the atom to the molecule."

Accompanying these structural changes, the energy types and phases inhabiting the unit of structure also vary. The rates of vibration or of phasic activity in the colloidal aggregates become slower than in the simpler molecules of the

${ }^{18} \mathrm{Cf}$. Verworn, op. cit.

Pfüger, E., "Ueber die physiologische Verbrennung in den lebendigen Organismen." Arch. f. d. ges. Physiol., vol. 10, 1875. 
crystalloids. The characteristics of colloids, slowness of reaction, metastable equilibrium, delicacy of union, and increased reactivity of specific type, become present in the forms of matter now capable of existing in equilibrium with the environment. As the complexity of structure increases, the nature of the equilibrium in the colloidal aggregates approaches more and more towards that labile, easily destroyed, but also more readily constructive condition which is characteristic of life.

Moore then states in a general way as a "law universal in its application to all matter, although varying in intensity in different types of matter, and holding throughout all space as generally as the law of gravitation-a law which might be called the Law of Complexity-that matter so far as its energy environment will permit tends to assume more and more complex forms in labile equilibrium. Atoms, molecules, colloids and living organisms arise as a result of the operations of this law, and in the higher regions of complexity it induces organic evolution and all the many thousands of living forms." In this manner he conceives that the hiatus between non-living and living things can be bridged over, and that life arose as an orderly development, which comes to every earth in the universe in the maturity of creation when the conditions arrive within the suitable limits. ${ }^{17}$

Allen's theory. We may now consider certain theories which conform with the primal earth conditions as postulated by the planetesimal theory of its origin. Allen, for example, maintains that it is simplest to believe that the circumstances which support life would also favor its origin and that if life formerly existed actively outside the range of the freezing and boiling points of water, it must have been quite different from that which now exists. Life then arose at the period when the physical conditions of the earth came to be nearly 17 Moore, B., "The Origin and Nature of Life," 1912. 
what they are at present. At such a time, as now, discharges of lightning passing through the damp air produced ammonia and oxides of nitrogen, which were carried down by rain into the streams and pools. If this process went on unmodified, the result would be a large accumulation of nitrogen compounds in the terrestrial waters, which would also contain carbon dioxide probably in larger amounts than the waters of the present day, because since that time much carbon dioxide has been withdrawn from the air and water and locked up in organic matter. In the same waters the usual metallic elements, in the form of chlorides, sulphates, phosphates, etc., would also be present.

Thus there must have been brought together an abundance of such raw materials as are required for the production of living matter, and, provisionally, Allen imagines some such reactions as the following to have occurred: solar energy, acting on the water or damp earth containing the raw materials just mentioned, caused dissociation and rearrangement of the atoms, the nitrogen abstracting oxygen from its compounds with carbon, hydrogen, sulphur, and other elements and delivering it to the atmosphere. Not much energy would be absorbed by a transparent liquid; but such actions as the above would occur particularly in water containing compounds of iron in solution or suspension since these compounds would absorb the solar energy. In this way compounds of nitrogen, carbon, etc., accumulated in the water or damp earth; and further reactions, anabolic and catabolic, occurred among them by virtue of the lability of the nitrogen compounds. Life at this stage was of the humblest kind since there were no definite organisms, only diffuse substances trading in energy, and between this stage and the evolution of cellular organisms an immense period probably elapsed.

Allen questions whether the earliest organisms were able to utilize the energy of sunshine or whether their whole energy 
was derived from the nitrogen compounds produced in the atmosphere by lightning, but in any case he thinks the faculty of appropriating the energy of sunshine must have developed at an early period, if not at the very beginning. In the functions of life, constructive process precedes destructive, and it therefore seems reasonable to suppose that the earliest forms of life were concerned more in accumulating than in dispersing energy, and that the energy-dispersing organisms, like bacteria and fungi, have had a comparatively late origin.

Allen's view of the origin of life "implies that the first attempts at life are still continuing, and that if by chance all life were wiped out, another cycle would begin." Such he believes to be the case, and to the question, "Why do we not find evidence of these processes in the form of primitive vital substances in water or elsewhere?" he answers that as soon as any such substances begin to be formed, they are seized and assimilated by the already developed organisms. ${ }^{18}$

Troland's enzyme theory. With the increasing realization of the importance of enzymes in the economy of organisms it is not strange that in these chemical bodies has been sought the key to life's origin, and accordingly we find Troland stating that life is something which has been built up about the enzyme. This author assumes that, at some moment in earth history, a small amount of a certain autocatalytic enzyme suddenly appeared at a definite point within the yet warm ocean waters which contained in solution various substances reacting very slowly to produce an oily liquid immiscible with water. If, when this occurred, the enzyme became related to the reaction in such a way as to greatly increase its rate by reducing the chemical friction involved, Troland believes it is obvious that the enzyme would become enveloped in the oily material resulting from the reaction and the little oil drop would increase until it was split into smaller globules by water

${ }^{18}$ Allen, F. J., op. cit. 
currents, provided the original substances which combined were soluble in oil as well as in water. Thus arose, according to his theory, the first and simplest life-substance, possessing the power of indefinitely continued growth, by virtue of the postulated autocatalytic character of the initial enzyme. Troland is convinced that this theory of the origin of life satisfies most of the objections which have been advanced against ordinary chemical hypotheses, since the characteristic catalytic power of the enzyme accounts for the elevation of the rate of synthetic action from practically zero to one making possible rapid growth of the protoplasmic mass. The same catalytic property explains the localization of the reaction in a definite region, for catalysis can occur only where the catalyzer itself is present. "The theory also provides a basis for the permanent growth of the primitive organism-if such we dare to call it - as well as for its reproduction, without, in general, the loss of its specific individuality." Troland suggests that the most fundamental objection which can be raised against his ideas is the fortuitous formation of the original enzyme; but he insists that since only a single molecule of the enzyme was required, and since multitudinous chemical reactions undoubtedly took place in the primordial ocean, this objection of improbability is almost absurd. ${ }^{19}$

Osborn's theories. The most recent consideration of the origin of life is that by Osborn, published during the past year. Starting with the postulate that "the primal earth, air, and water contained all the chemical elements and three of the most simple but important chemical compounds, namely, water, nitrates, and carbon dioxide, which are known to be essential to the prechlorophyllic and chlorophyllic stages of the life process," Osborn suggests that an initial step in the origin of life was the coördinating or bringing together of

${ }^{19}$ Troland, L. T., "The Chemical Origin and Regulation of Life." The Monist, vol. 24, 1914, pp. 92-133. 
these elements, which, so far as we know, had never been in combined action before. He states that the thermal conditions of present-day living matter point to the probability that this coördinating of the "life elements" was initiated when portions at least of the earth's surface and waters had temperatures of between $6^{\circ}$ and $89^{\circ} \mathrm{C}$. and before the atmospheric vapors admitted a regular supply of sunlight. The earliest function of living matter appears to have been to capture and transform the electric energy of the chemical elements characteristic of protoplasm, and this power probably developed only in the presence of heat energy derived from the earth or from the sun. Frankly admitting, however, that both the time and place of the origin of life is a matter of pure speculation, in which we have as yet no observations or uniformitarian reasoning to guide us, Osborn advances five hypotheses in regard to it as follows:

An early step in the organization of living matter was the assemblage of several of the chemical elements essential to life. Of these the four most important elements were obtained from their previous combination in water, from the nitrogen compounds of volcanic emanations or from the atmosphere, consisting largely of nitrogen, and from atmospheric carbon dioxide. The remaining elements came from the earth.

Whether or no there was a sudden or a more or less serial grouping of these elements, one by one, Osborn is led to a second hypothesis that "they were gradually bound by a new form of mutual attraction, whereby the actions and reactions of a group of life elements established a new form of unity in the cosmos, an organic unity or organism quite distinct from the larger and smaller aggregations of inorganic matter previously held or brought together by the forces of gravity."

This leads to the hypothesis that since all living cells are colloidal the grouping of the "life elements" took place in a 
state of colloidal suspension, for it is in this state that the life elements best display their incessant action, reaction and interaction.

With this assemblage, mutual attraction, and colloidal condition, a fourth hypothesis is that there arose the rudiments of competition and selection. "Was there any stage in this grouping, assemblage, and organization of life forms, however remote or rudimentary, when the law of natural selection did not operate between different unit aggregations of matter? Probably not, because each of the chemical life elements possesses its peculiar properties which in living compounds best serve certain functions. This coöperation was also an application of energy new to the cosmos." In other words, every "life element" has its single and multiple services to render to the organism.

And as a fifth hypothesis relating to the origin of organisms, Osborn advances the idea that the evolution and specialization of various enzymes has proceeded step by step with the evolution of plant and animal functions, "since in the evolution from the single-celled to the many-celled forms of life and the multiplication of these cells into hundreds of millions, into billions, and into trillions, as in the larger plants and animals, biochemical coördination and correlation become increasingly essential." 20

Conclusion. Such are the principal attempts of modern biologists to formulate in some concrete way the evolution of matter in the living state from the elements of the earth. Their consideration is valuable in that it indicates the uniformitarian trend which, at the present day, biological thought follows in this field, and also the diversity of results arrived at by the scientific imagination when it is largely untrammeled

20 Osborn, H. F., "The Origin and Evolution of Life upon the Earth." Scientific Monthly, vol. 3, 1916, pp. 5-22, 170-190, 289-307, 313-334, 502-513, 601-614. 
by facts. One, however, cannot but admire the scientific caution of Huxley when he said:

"Looking back through the prodigious vista of the past, I find no record of the commencement of life, and therefore I am devoid of any means of forming a definite conclusion as to the conditions of its appearance. Belief, in the scientific sense of the word, is a serious matter, and needs strong foundations. To say, therefore, in the admitted absence of evidence, that I have any belief as to the mode in which existing forms of life have originated, would be using words in a wrong sense. But expectation is permissible where belief is not; and if it were given to me to look beyond the abyss of geologically recorded time to the still more remote period when the earth was passing through physical and chemical conditions, which it can no more see again than a man can recall his infancy, I should expect to be a witness of the evolution of living protoplasm from not living matter. I should expect to see it appear under forms of great simplicity, endowed, like existing fungi, with the power of determining the formation of new protoplasm from such matters as ammonium carbonates, oxalates and tartrates, alkaline and earthy phosphates, and water, without the aid of light. That is the expectation to which analogical reasoning leads me; but I beg you once more to recollect that $\mathrm{I}$ have no right to call my opinion anything but an act of philosophical faith." ${ }^{21}$

Thus since biologists are at the present time absolutely unable, and probably will be for all time unable, to obtain empirical evidence on any of the crucial questions relating to the origin of life on the earth, their endeavors are and must be directed chiefly toward an intensive analysis of life manifestations as exhibited in the physical basis of individual

${ }^{21}$ Huxley, T. H., "Biogenesis and Abiogenesis." Presidential address, Brit. Assoc. Adv. Sci., 1870. "Collected Essays," vol. 8. 
organisms, in their bionomic relations, and in the kaleidoscopic panorama which geological history presents of their evolution.

In the closing words of Darwin's Origin of Species:

"It is interesting to contemplate a tangled bank, clothed with many plants of many kinds, with birds singing on the bushes, with various insects flitting about, and with worms crawling through the damp earth, and to reflect that these elaborately constructed forms, so different from each other, and dependent upon each other in so complex a manner, have all been produced by laws acting around us. . . There is grandeur in this view of life with its several powers, having been originally breathed by the Creator into a few forms or into one; and that, whilst this planet has gone cycling on according to the fixed law of gravity, from so simple a beginning endless forms most beautiful and most wonderful have been, and are being evolved." 


\section{CHAPTER IV}

\section{THE PULSE OF LIFE}

\section{RICHARD SWANN LULL}

PROFESSOR OF VERTEBRATE PALEONTOLOGY IN YALE UNIVERSITY

THE stream of life flows so slowly that the imagination fails to grasp the immensity of time required for its passage, but like many another stream, it pulses as it flows. There are times of quickening, the expression points of evolution, and these are found to be coincident with geologic change. These coincidences are so frequent and so exact that the laws of chance may not be invoked to account for them. They stand to each other in the relation of cause and effect.

This does not imply the acceptance of any one philosophical factor of evolution, for whether the creature is directly modified by environmental change, or indirectly through induced habit, or whether nature merely sets a standard to which the organism must attain if it would survive, matters not; the fact remains that changing environmental conditions stimulate the sluggish evolutionary stream to quickened movement. Whenever it has been possible to connect cause and effect, the immediate influence is found to be generally one of climate, back of which lies, as the main cause, earth shrinkage and a consequent warping of the crust, with the elevation and spread of the lands and the formation of mountain ranges. In addition to this mundane cause, there are the complex rhythms in solar energy and the consequent variation in the amount of solar-derived heat. For example, the most generally accepted 
single cause of the last or Pleistocene glacial period is the great continental elevation which formed the Cascadian revolution, but, so far as our knowledge goes, that would not account for the successive advances and retreats of the ice mantle, with the attendant climatic variation, and some other factor such as the rhythms of solar energy must be invoked as of supplemental influence. Nevertheless, the ultimate source of profound and far-reaching crises in the evolution of the organic world may have been, geologically speaking, of a very simple character.

Through the collaboration of my colleagues, Professors Schuchert and Barrell, the appended chart, Figure 14, has been prepared to show the relation between the changing continental elevation and climate. To this I have added a curve representing the consequent acceleration and retardation of the evolutionary stream. The climatic records of pre-Paleozoic time are so vague and unreliable that it was not thought wise to include the vast Archeozoic and Proterozoic eras within the scheme. The time values of the several included eras are not proportionally indicated, too much space by far being given to the Cenozoic because of its biologic interest. As a matter of fact, its duration is more nearly comparable to that of Permian time.

The curves are necessarily generalized, for there was neither space nor necessity for greater detail. In the altitudinal curve, the upslope of the diastrophic peaks signifies rising diastrophism; the downslope, the period of erosion before the continents are low enough to have mantles of sediment spread upon them. A greater or lesser part of the peak and downslope represents, therefore, the unrecorded interval between eras or periods, as the case may be. The tangential lines drawn to the diastrophic peaks show the relation of a series of movements: a gradual rise culminating in the great revolutions. Were the Cenozoic compressed into its normal 


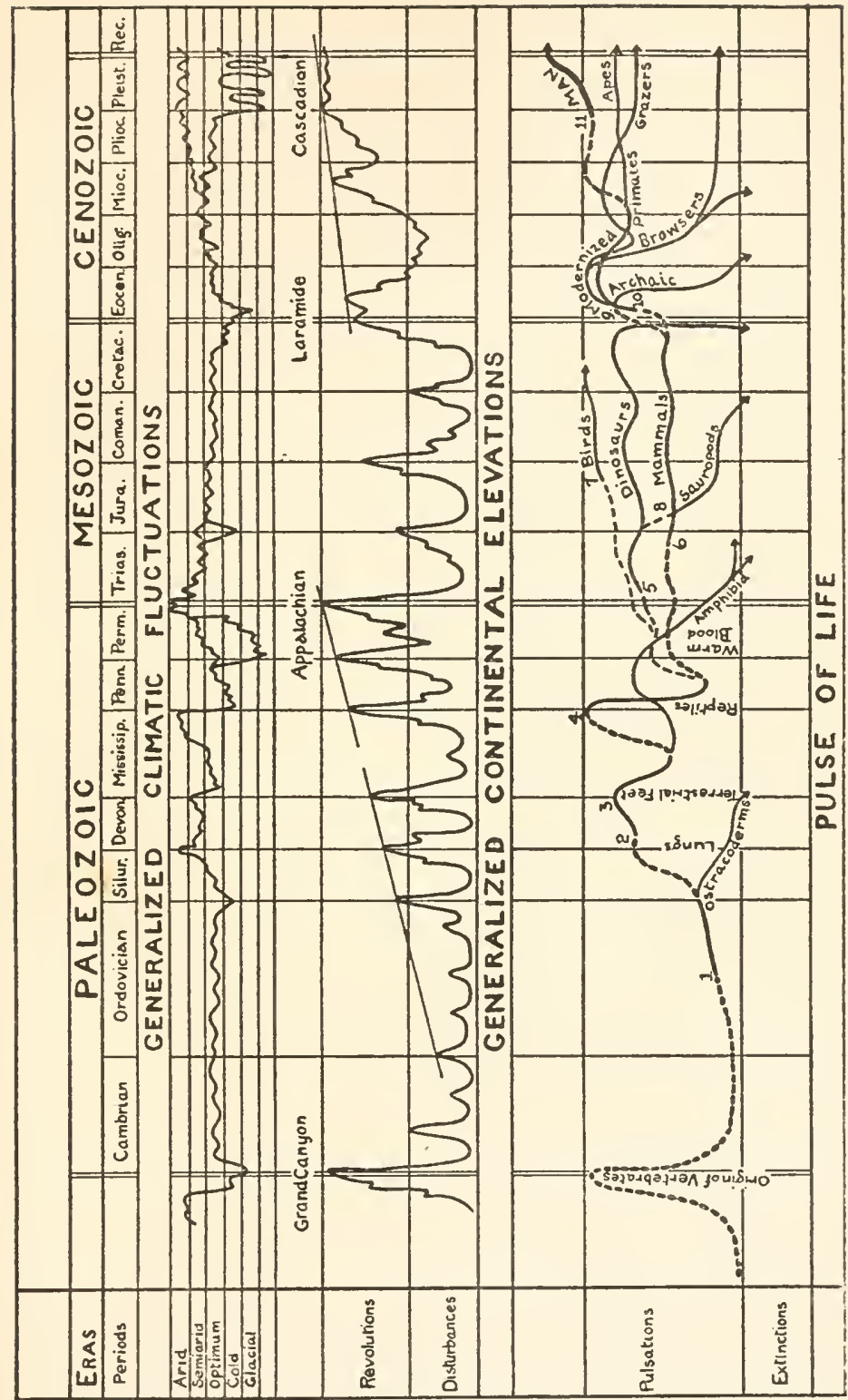

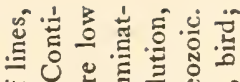

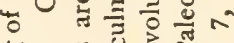

bै

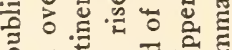

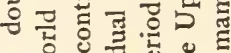

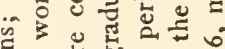

โ อ

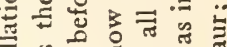

ป气

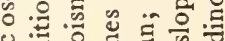

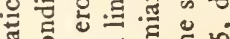

ฮํ.

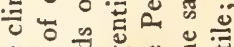

$\% 2.0$

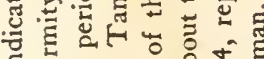

. 0 क 0 क

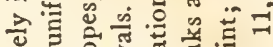

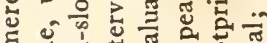

ह.

क

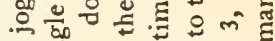

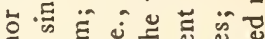

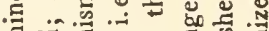

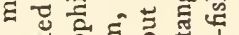

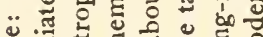

.

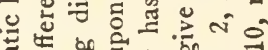

讨

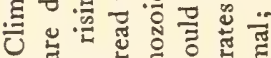

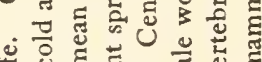

\& छ

पे

$\& \geqslant 0$

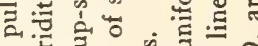

ब

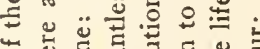

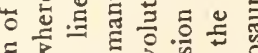

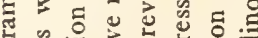

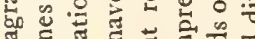

.

1 กั

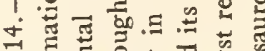

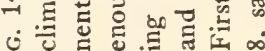

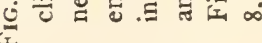


relative length, the slope of the tangent drawn to its peaks would correspond more nearly to those of the Paleozoic.

In the climatic line, the minor undulations indicate in a very general way the climatic oscillations which must have existed but of which we have as yet no very exact data; the larger movements, on the other hand, are based upon observed fact. The optimum embraces a normal range of temperature and degree of moisture; a rising curve, increased aridity; its depression, a lowering of temperature. Where the line is single there is a supposed uniformity of conditions the world over; where it splits, aridity and cold are differentiated. It is highly probable that with more detailed knowledge the divergence of the moisture and temperature curves will be more extensive.

The life line is dotted where theory precedes the recorded fact, solid when actual fossils attest the truth of the assumed evolution. The numbers indicate the times of these first records as follows: I, first vertebrates; 2 , lung-fishes; 3 , vertebrate footprints; 4 , reptiles; 5 , dinosaurs; 6 , mammals; 7 , birds; 8 , amphibious dinosaurs; 9 , archaic mammals ; Io, modernized mammals; I I, man. (Vide infra, page I44.)

\section{Crises of Evolution}

Origin of life. The first great crisis in the evolution of organic beings was the origin of life: the marvelously subtle combinations attained by certain very familiar inorganic elements, increasing their molecular complexity until a substance was produced endowed with the attributes of life. Of this momentous event we have no record, nor does the geologic cause come either within the scope of our knowledge or conjecture, for the time was too remote and the first living substance too delicate to leave any decipherable record upon the rocks. All we can say of it is that in the fullness of time, when the earth had, in the course of its physical evolution, become adapted as the abode of life, living substance came into being. 
Establishment of the lime-secreting habit. The first recorded crisis, that of the assumption of the lime-secreting habit-perfected by animals in the Upper Cambrian, by plants, marine algx, much earlier-has again no accepted geologic cause. The importance of this crisis is doubtless not as great as that of many unrecorded ones which had gone before, its significance lying mainly in the fact that the development of hard parts enabled the organisms which bore them to write imperishable records of their existence upon the rocks. Previous to this, the indications of life are indirect, such as the accumulation of graphite, which is never produced in nature except as the result of organic activity; or the records are in the nature of the rare fossils of algx, of Protozoa (Radiolaria), and of the burrows of annelid worms. It may be assumed that the presence of Protozoa, on the one hand, and of Annelida, on the other, in late Proterozoic sediments implies the existence of all the intermediate phyla of invertebrates-sponges, cœlenterates, flat and round worms-and the probabilities are that all the other invertebrate groups except the Arthropoda were also present.

The culmination of this crisis, like several which are yet to be discussed, did not come until long after its inception, for while certain creatures like the Archæocyathinæ (probable corals) and brachiopods show limy skeletons in the early Cambrian, others were as yet chitinous, and it is not until the Middle Ordovician that the process is entirely complete.

The definite fossil record thus established shows us that the evolution of great invertebrate groups occurred largely before the close of the Proterozoic, hence we may not speak confidently of cause and effect. Vertebrate evolution, on the other hand, lies within the period of recorded evolutionary history, and while there is little direct evidence regarding the origin of this important phylum, the evolutionary crises through which it passed are entirely within the scope of our 
observation. That the invertebrates also have advanced since the Proterozoic is certainly true, but their evolution is largely one of detail and does not represent the establishment of any new principle or type, that is, if we except the insects. With the vertebrates, however, this is not true, for some of the most momentous advances in the evolution of higher forms lie within the range of their fossil record.

Origin of vertebrates. The distinction between the vertebrates and invertebrates is largely dynamic, for the former are principally motor types, the latter largely quiescent, sluggish forms, often actually sedentary, that is, fixed in their mode of life. A review of invertebrates, especially the aquatic forms, will serve to emphasize this point. The sponges are entirely sedentary, while the cœlenterates are either fixed forms like the corals or capable of very slight creeping locomotion like the sea-anemones; or are feeble swimmers like the jelly-fishes, subject to the whim of tidal and other marine currents, or to the turmoil of a wind-swept sea. Of the worms, using the term in its old collective sense, some again are fixed, some crawling, some feeble swimmers, and the same is true of echinoderms and many molluscs. The arthropods are perhaps the most venturesome of marine invertebrates except the cephalopod molluscs, but even to them do the same three conditions of fixedness, crawling, or none too effective swimming apply. Such as are pelagic are, like the jelly-fish, so non-resistant as to be largely the victims of circumstance.

Of all aquatic invertebrates, the cephalopods alone have developed locomotive powers of marked significance, but their locomotion is strikingly different from that of a vertebrate in that it is the perfection of a method of jet propulsion which other invertebrates have also developed, although none have carried it so far. Briefly, the perfected cephalopod, such as the squid (see Fig. 15), has an elongated, spindle-shaped body, at the hinder pointed end of which are two horizontal 
stabilizing fins that may be used for slow forward swimming by means of wave-like undulations. The body is enclosed in a muscular fold of the body-wall known as the mantle, but does not fill it, leaving a space beneath known as the mantle cavity. There is on the under side of the well-developed head, with its huge eyes and long tentacles, a tubular funnel (Fig. I $5, f$ ) whose larger end connects with the mantle

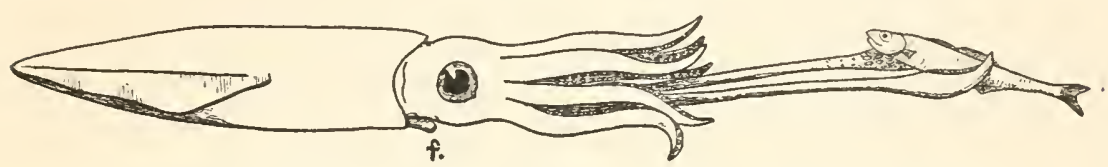

Fig. 15.-Squid, Loligo sp., capturing a fish: $f$, funnel. After Doflein, from Lull's "Organic Evolution," published by the Macmillan Company.

cavity, the smaller one pointing forward beneath the head. Relaxation of the mantle permits the ingress of water into the cavity; closure of the muscular margin around the animal's neck, on the other hand, prohibits its egress except through the funnel. A forcible contraction of the entire mantle forces the water out in a sharp jet which impinges against the surrounding water and thus drives the creature backward at a very rapid rate. As compared with the easy undulatory movements of an aquatic vertebrate, however, this jet propulsion mode is highly costly of effort, and its adoption by mankind for steam-propelled craft was to meet peculiar conditions of short choppy seas and a disastrously "racing" screw propeller rather than because of any inherent virtue in the basic idea. Its rejection from ordinary usage is due largely to its extreme lack of economy.

The cephalopods, being predaceous forms, must overtake their prey, and in turn must flee from devouring Cetacea for which they form a principal dietary staple, hence their urgent need of locomotion; but for the great host of invertebrate forms their static habitat places no premium upon locomotive 
powers, and the evolution of so marked an attribute as high speed must have some powerful incentive. The thesis has been advanced therefore that the main distinction between vertebrate-or more properly chordate-and invertebrate is largely a response to habitat, the invertebrate being the product of static waters, marine or sluggish terrestrial, where an effortless existence, carried hither and yon by wave and tide, would not remove it from the environment. The chordate, on the other hand, is the outcome of dynamic or flowing terrestrial waters which enforced swimming powers as the only means of resisting eviction from the realm. The distinction is not one of contour, for the fusiform shape of the speedy animal is the result of swift movement through a more or less resistant medium, whatever the motive power; but the segmental body muscles, the internal resistant axis, and the fin-like expansions to resist the thrust of the muscles, all are the direct outcome of the mode of locomotion, that by lateral undulation of a primitively elongated body. (See Fig. I6.) That this locomotive device might have been developed in static waters is not denied, for some marine worm-like organisms swim by a wriggling movement, though invariably in the dorso-ventral plane, but there is in the sea little incentive to enforce its rapid perfection, such as dynamic waters would produce. Hence the assumption that the vertebrates are the outcome of terrestrial waters. To illustrate the means whereby the evolution was initiated, Chamberlin ${ }^{1}$ has discussed the peculiar habit of a stream-borne lamprey, Petromyzon (Fig. I 6, E, left-hand eel), which adheres to the bottom by its suctorial mouth and allows its body to undulate in the pulsating current as a flag is whipped in the breeze or a rope of grass in the stream. Unless the stream be very shallow so as to cause distinct vertical displacements of the water, this undulation is always lateral or

${ }^{1}$ Chamberlin, T. C., "On the Habitat of the Early Vertebrates." Jour. Geology, vol. 8, 1900, pp. 400-412. 

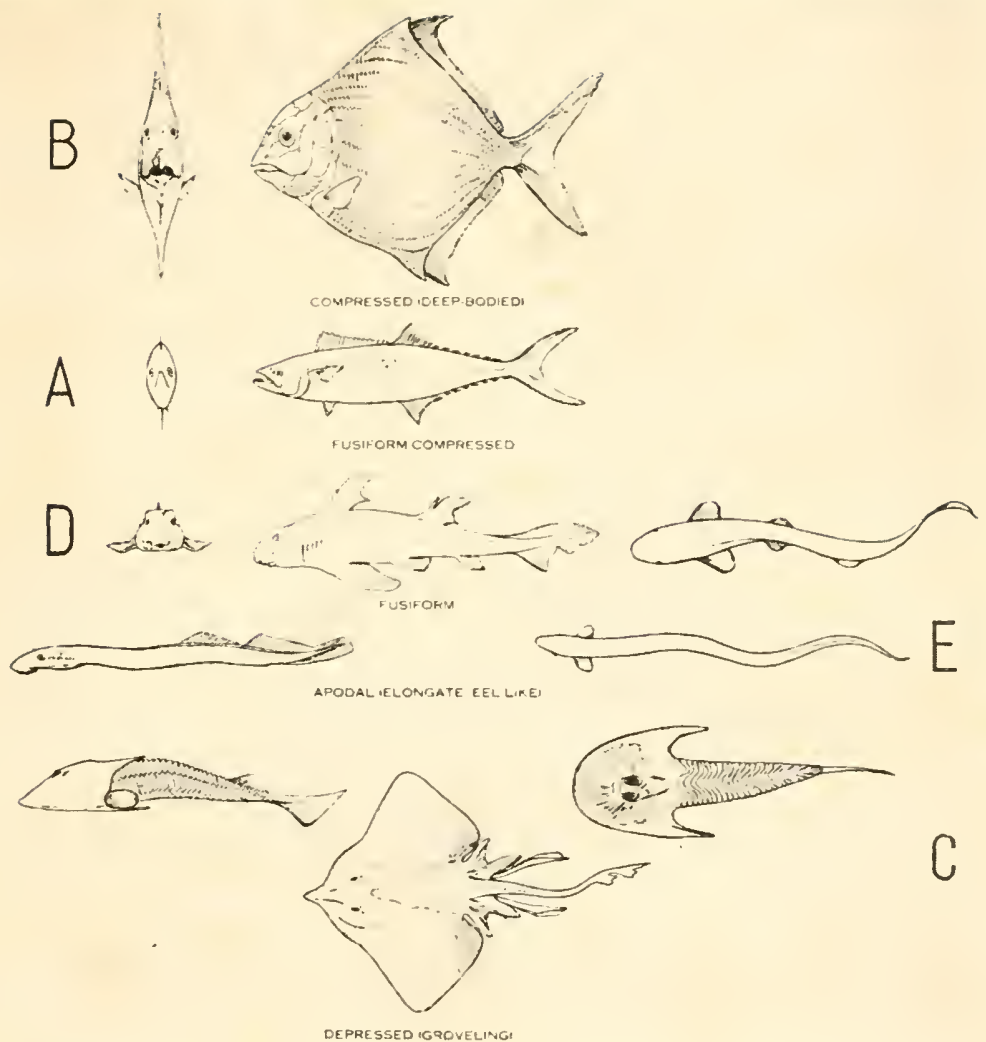

FIG. 16.-Fish forms. From "The Origin and Evolution of Life," by Henry Fairfield Osborn; copyright, 1917, by Charles Scribner's Sons. 

in the horizontal plane, as that is the direction of least resistance because of the inhibitive force of gravity. When the lamprey wishes to swim to maintain its position in the current, it simply reproduces in the active voice the motions imparted to it in the passive voice by the stream itself. More forcible action drives it ahead. Such motion, consisting as it does of a series of reversed curves, requires segmented muscles on either side, along which alternating waves of contraction may pass. An axial stiffening to resist the longitudinal compression of such muscles is also necessary. This is first a pliant cellular membrane rendered resistant by being tensely filled with liquid, next a supple rod of cartilage, and finally a bony axis, segmented for the sake of flexibility. The economic efficiency of this undulatory mode of progression as compared with the jet propulsive method of the cephalopod is evident to anyone who has observed the quick dart of a trout or the narvelously effortless progress of a school of porpoises at the bow of a ship.

As time went on, the assumption of the compact spindle shape of a swiftly swimming fish became, as we have argued, merely a speed response and not necessarily an exclusively stream-borne attribute. Depressed grovelling forms (see Fig. I6, C), or compressed highly specialized forms, are, however, either marine or static fresh-water in habitat, never stream dwellers.

It has been argued that as the most primitive existing chordates, Amphioxus, the tunicates, and the adelochordates (Balanoglossus), are marine, the ancestral chordates must have been also, but their distribution corroborates the hypothesis of fresh-water origin instead of denying it, for as Matthew ${ }^{2}$ has shown, the most ancient members of a group are not to be found at the old center of evolution, but rather

2 Matthew, W. D., "Climate and Evolution." Ann. New York Acad. Sci., vol. 24, 1915, p. 180 . 
at the periphery of their migratory area. This is certainly true of these protochordates which, save for a few pelagic forms, are all found near the continental margins in the shallow seas. They are all degenerate and more or less sedentary, and hence could not maintain themselves in their fluviatile habitat and were swept into the sea-descendants of the unsuccessful early tyros in the art of undulatory swimming.

But all of this requires as an impelling cause a change of habitat on the part of the invertebrate progenitors, either by a migration of the stock from static to dynamic waters, or by a change in the character of the waters themselves. The former view entails the necessity of some force to impel the migration, either the need for safety or food or the lack of salinity on the part of flowing waters, none of which seems adequate to compel so radical a change, and one along a line of so great resistance as the evolution of the invertebrate ancestor into the chordate implied. On the other hand, migration from the sea into sluggish terrestrial waters is more readily imagined, but affords no stimulus for chordate evolution. The picture of the Laurentian peneplain (see Fig. I7), with its low-lying lands and slow drainage, shown by glacial lakes, the result of recent choking of sluggish streams, suggests the solution, for while intermigration under such conditions would doubtless be relatively easy, it would never have stimulated chordate evolution. Geology records a great diastrophic movement toward the close of the Proterozoic, the so-called Grand Canyon revolution, partial evidence for which may be seen in the 8,000 to 12,000 feet of sediments, more or less conglomeratic, which were swept from mountains to the eastward and accumulated in the southern Appalachian region during the early part of Lower Cambrian time. This great upheaval changed the face of nature in many regions and quickened the static terrestrial waters to rapid and widespread movement over all the uplifted lands. Such inverte- 


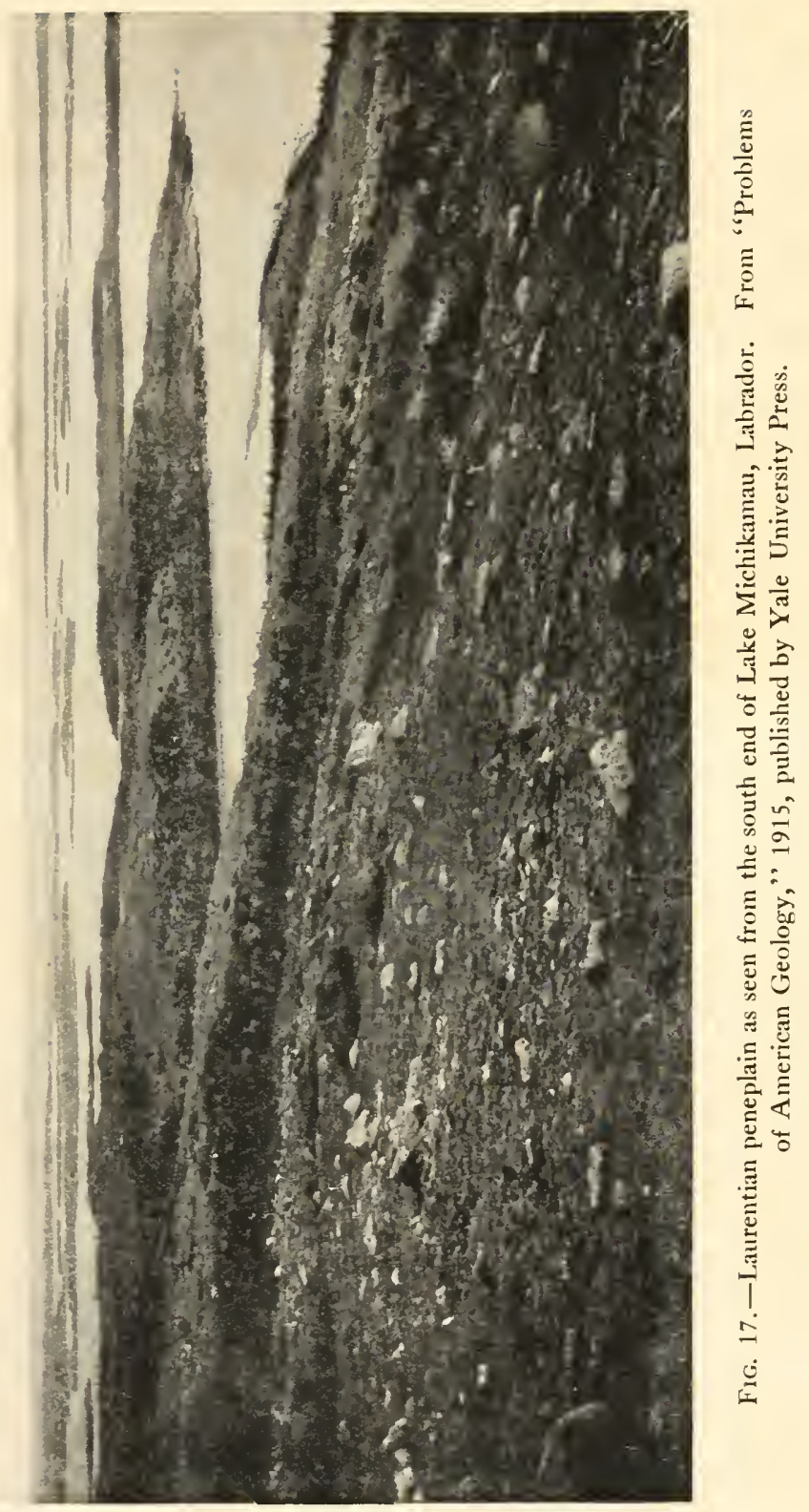



brate stocks as could neither cling to the bottom nor stem the quickening current were swept to the encircling sea and lost to the limnobiotic fauna; such as could, remained to people the fluviatile realm with creatures of a markedly higher sort.

The first recorded chordate comes from the Ordovician, but is an armored fish-like form, an ostracoderm, of grovelling habit and implied quiescent habitat (see Fig. I6, C). Such types, Patten ${ }^{3}$ to the contrary, can hardly be considered as the first expression of chordate evolution, much less annectant forms between the vertebrates and the higher arthropods which they so closely resemble; but they were rather a highly specialized offshoot of the primitive chordate stem, derived after the physical stimulus of quickened drainage had spent its force and times of quiescent waters had again appeared.

The evidence points, therefore, to Chamberlin's conclusion, that the place of chordate origin was the flowing land waters, to which may be added as the impelling cause a diastrophic movement which quickened the drainage, and, as the time of its inception, the Epi-Proterozoic interval. This crisis is therefore the direct outcome of earth movement without the intervention of the climatic factor.

Emergence of terrestrial vertebrates. The waters, while a very necessary stimulus to early chordate evolution, afford too restricted an environment for the evolution of higher forms, and as a consequence all vertebrates whose ancestry can be traced back through an unending line of water inhabitants since the beginnings of life on earth are but fishes, and no matter to what degree they may have been specialized, they could not have risen nor can they ever rise to a higher plane. The emergence from the limiting waters to the limitless air was absolutely essential to further development and constituted one of the greatest crises in organic evolution.

To know the route of such migration is of the utmost im3 Patten, W., "The Evolution of the Vertebrates and Their Kin," 1912. 
portance if we would find a cause. In search of this, the mind turns at once to the land-encircling strand or tidal zone, stretching as it does over the many thousands of miles of the coast, the omnipresent frontier between land and sea. Here the conditions are varied, here there is food and light, and here the stimulus to double-breathing is enforced by the twice daily baring of the zone and its consequent transition from aquatic to terrestrial condition and back again with monotonous regularity. But in spite of its convenience, few indeed have been the stragglers of the vast army of aquatic life which have ever essayed its passage-land crabs and other crustaceans, certain molluscs, a few of the higher fishes such as the mud-skippers Periophthalmus and Boleophthalmus, all of which are impelled to a temporary or permanent migration shoreward by the need of food. And while they have developed accessory respiratory devices, the latter are merely spongy or other extensions or modifications of the water-breathing gills, and in no instance is there developed anything comparable in structure or ultimate efficiency to the terrestrial vertebrate's lung. Such structures as the latter have been developed only in fresh waters, all fishes which show it or its homologue, the swim-bladder, being either fresh-water or the descendants of fresh-water forms. The sharks forsook their ancestral waters before or when the need of such a structure was felt and have never developed it; on the other hand, all other fishes except the cyclostomes either have it or have lost it through specialization. In the modern fish, the swim-bladder has a hydrostatic function in that it serves to alter the specific gravity of the creature and thus enables it to maintain any given level in the water without further effort. As such, it is analogous to the water ballast tanks in a submersible ship, although the mechanism whereby the effect is produced naturally varies.

The lungs of higher vertebrates are therefore identical with the swim-bladder of the fish and have retained and vastly im- 
proved the primal function of air breathing. This function is inconceivable as a prime requisite to marine life, and could only have arisen in terrestrial waters beyond the limits of the tidal zone, ${ }^{4}$ where, due to increasing aridity of climate, the waters became reduced to stagnant pools which had neither sufficient flowage nor wave action to renew the supply of respirable air exhausted by the contained life. Such conditions prevail today in Australia, where the recurrent droughts cause the rivers to dwindle until only isolated pools are left. Within certain of these rivers, the Mary, Burnett, and Dawson, dwells an ancient relic form, the lung-fish or dipnoan Neoceratodus, which in times of habitat stagnation rises to the surface, gulps

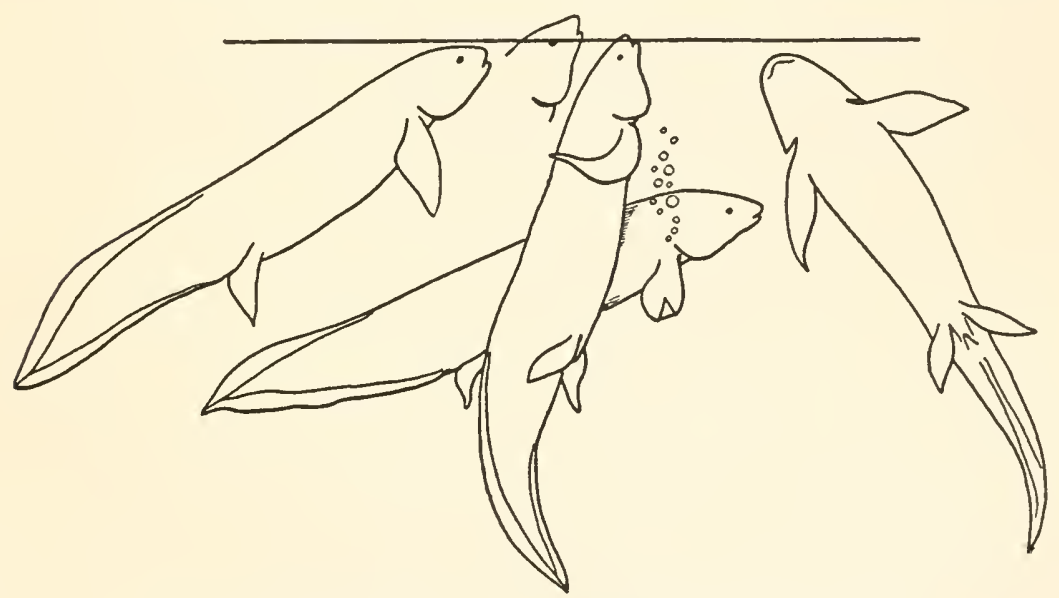

Fig. 18.-Lung-fish, Neoceratodus, breathing. After Dean.

air (Fig. I 8) into its lung, a highly vascular outgrowth or diverticulum of the alimentary canal, and thus aerrates the contained blood. Other dipnoans also exist, as the African lung-fish, Protopterus, of the Nile, which, during times of drought, forms for itself a cocoon-like case of slime-hardened

4 See Barrell, J., "Influence of Silurian-Devonian Climates on the Rise of Airbreathing Vertebrates." Bull. Geol. Soc. America, vol. 27, 1916, pp. 387-436. 
mud in the river bottom and æstivates therein; and the South American lung-fish, Lepidosiren, of the Amazon River and its affluents, which lives near the margin of the water, using its lung almost with the regularity of a mammal, and also forming a burrow for its habitation during the dry season. Of these dipnoans the latter two belong to a group of which we have no fossil record; Neoceratodus, on the other hand, is a relic of what was formerly a large and widespread group. Yet another order of fishes in which the air-bladder has a respiratory value is the Crossopterygii, or fringe-finned ganoids, again an important and numerous group in the geologic past but now

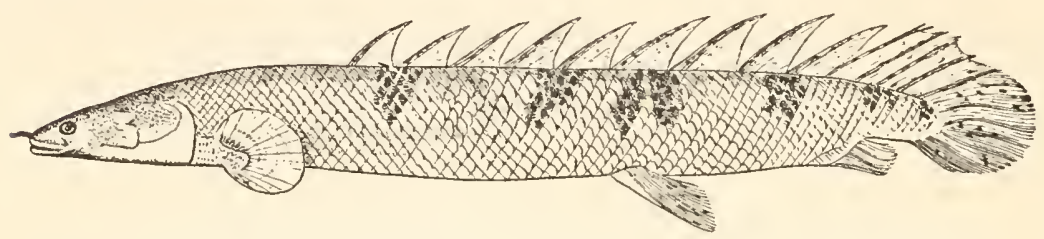

FIG. 19.-African fringe-finned ganoid, Polypterus delhezi. After Jordan, from Lull's "Organic Evolution," published by the Macmillan Company.

represented by but two genera, Polypterus (Fig. I9) and Erpetoichthys, both tropical African in distribution. While these living genera have not so effective a respiratory device as the dipnoans, nevertheless they present fewer anatomical difficulties to stand in the way of relationship with the amphibia. Without rehearsing the technical arguments, it may suffice to say that the generally accepted view is that the terrestrial vertebrates were derived either from ancient crossopterygians or from a group ancestral to both them and dipnoans.

The geologic cause which lies back of the emergence is apparent. Diastrophic movement during the Silurian period (see Fig. I4) initiated a widespread aridity which culminated in the latter part of the period, continued with varying intensity into and through Devonian time, and rose again to greater 
severity in the latter part of that period. This meant, as in Australia today, the reduction of rivers and other bodies of fresh water and the entailed concentration of their fauna, which is borne out by the mode of occurrence of the Lower Devonian (Old Red Sandstone) fishes-innumerable specimens in very restricted areas. Add to this the diminution of aerration of these waters and it will be seen that a high premium would be placed upon powers of air breathing or of æstivation. Still further desiccation would necessitate some sort of activity during the increasingly long droughts, for the periods of torpor would otherwise bear too great a ratio to the creature's life span. Thus a premium would be placed upon ability to crawl ashore and maintain an active life, while the less fit would sleep the sleep that knows no waking, to their racial extinction.

Aridity, therefore, would place a premium, first upon lung breathing, the first recorded lung-breathing fish appearing in the Lower Devonian, although they must have existed in the Silurian; and later upon emergence, the entire process up to the perfection of the terrestrial limb covering more than the whole Devonian period, as the earliest known footprint of a terrestrial vertebrate is found in Upper Devonian rocks.

Evolution of the terrestrial foot. The question of the evolution of the pentadactyl hand and foot, which is the vertebrate standard, from the ancestral fish fin is not fully solved, but much light is thrown upon it by the above-mentioned footprint, known to science as Thinopus antiquus and preserved in the Peabody Museum at Yale. The slab of sandstone bears a single track (Pl. III), that of a right foot having two welldeveloped digits with distinct phalangeal impressions. On the outer side of the second digit is a budding third, while lower down on the side of the foot may be seen the rudiment of a fourth. Rabl ${ }^{5}$ has shown that the developing foot of the

5 Rabl, C., "Gedanken und Studien über den Ursprung der Extremitäten." Zeits. für wiss. Zoologie, vol. 70, 1901, pp. 474-558. 
$\overbrace{A}^{1}$<smiles>CCCC</smiles>

B<smiles>CCCCCCCCCCCCCCCCCCC</smiles><smiles>C=CC(=O)C=C</smiles><smiles>CCCCCC</smiles>

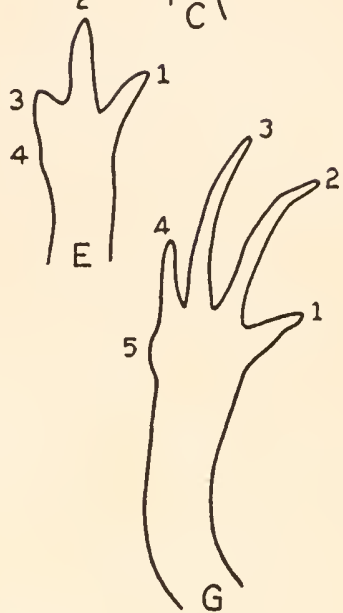

FIG. 20.-Development of the hind foot of a salamander, Triton taniatus. After Strasser, from Lull's "Organic Evolution," published by the Macmillan Company.

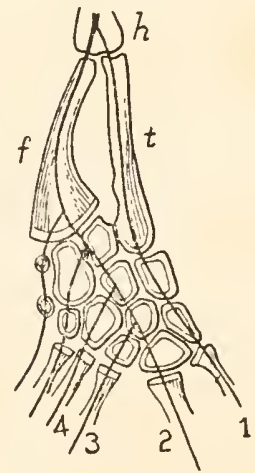

FIG, 21.-Foot of a reptile, Ranodon sibericus: $f$, fibula; $h$, femur; $t$, tibia; I, II, III, IV., digits 1-5. After Wiedersheim, from Lull's "Organic Evolution," published by the Macmillan Company. 


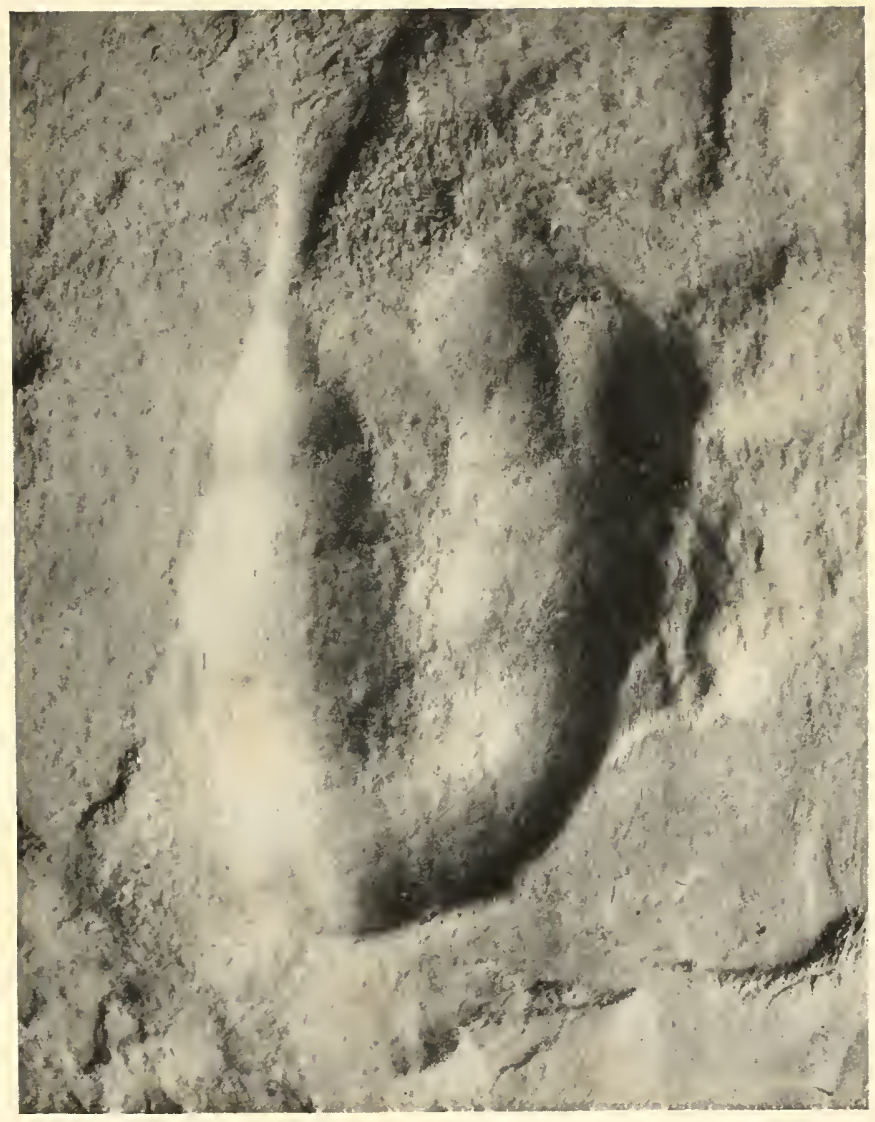

Plate III. - Cast of the oldest known fossil footprint, Thinopus antiquus, from the Upper Devonian of Pennsylvania. Original in the Yale University Museum. 

embryonic amphibian, Triton (Fig. 20), passes through a series of stages of which one corresponds precisely to the degree of development of the Devonian track, which, from its size, is probably that of an adult although yet in the adolescence of its race. Comparative anatomy corroborates this belief and completes the tale of evidence (Fig. 2I), in that the principal axes of the foot, as shown by the distribution of nerves and blood-vessels, lie in the first and second digits, the lesser axes of digits III, IV, and V arising as lateral branches from that of digit II.

With the opening of Mississippian time came increased moisture and in the succeeding widely extended swampy forests of the coal period, amphibia throve mightily and developed into the many sorts of so-called Stegocephalia or armored forms. That they still returned to their ancestral waters to bring forth their young, and that the latter bore gills upon the neck for aquatic respiration is evidenced by the actual traces of such structures in many fossil forms.

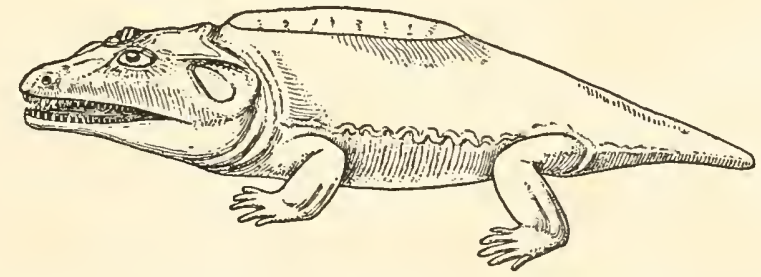

FIg. 22.-Restoration of the Permian stegocephalian, Cacops aspidephorus. After Williston, from the Pirsson-Schuchert "Text-book of Geology," published by John Wiley \& Sons, Inc.

Origin of reptiles. During the latter half of the Mississippian, however, came a diastrophic movement with a wave of aridity, making the return to the natal waters increasingly difficult until many forms were forced to abandon it forever, and the reptiles came into being. There are today wellrecognized criteria whereby a reptile may be distinguished 
anatomically from an amphibian, but with certain forms, such as Cacops (Fig. 22) from the Permo-Carboniferous red beds of Texas, the distinction is by no means so clear, for such as this were transitional, Cacops being yet on the amphibian side of the frontier.

The change of habit induced by this aridity meant a radical change in the character of the vertebrate egg, with the development of certain membranes (Fig. 23) whereby the contained young could respire air, unnecessary in the water-laid egg. Thus the terrestrial egg, typified by that of bird or reptile, is large, with an abundance of nutrient "yolk" for the developing embryo, and enclosed in a protective though porous shell. Two membranes are developed, the first of which, the amnion, is merely protective, in that the cavity between its two layers contains a fluid which serves to absorb mechanical shocks and to guard the embryo against too rapid temperature changes. The other membrane is known as the allantois (see Fig. 23). This, when fully developed, lines the inside of the shell and is abundantly supplied with blood-vessels, veins, arteries, and capillaries, which connect with the embryonic circulation. This is the respiratory device, for the blood coursing through the allantoic capillaries is thus in close osmotic relationship with the air which penetrates the porous shell, and thus the blood is purged of its carbonic acid gas and other volatile impurities and receives its life-sustaining supply of oxygen. Such an egg must be laid on land or retained within the mother until it hatches, for the contained young would drown if the egg were submerged, as surely as would the adult.

But the development of these membranes has a still deeper significance, because the allantois through an added function becomes the intermediary between the unborn young and its mammalian mother, and hence its development, due to that far-off climatic change, has rendered possible the higher (placental) mammal with all which that implies to humanity. 
Origin of warm blood. Toward the close of the Pennsylvanian commenced that series of earth movements which was to culminate in the Appalachian revolution and the passing of the Paleozoic, and as attendant phenomena came increasing aridity and, early in Permian time, glaciation, which, in the southern hemisphere, exceeded in intensity and extent the so-called glacial period of the Pleistocene.

Aridity has its influence upon terrestrial types, at any rate upon the more progressive of them, in that it places a premium upon traveling powers, especially upon speed, for not only are food and water scarce and far between, but the strife between the pursuer and pursued becomes intensified-neither can afford to be outdistanced by the other. This means increased metabolism, which in turn generally implies not only greater motive powers but higher temperature. With increasing cold a premium would be placed upon such creatures as could maintain their activity beyond the limits of the shortening summers, and this could only be accomplished by the development of some mechanism whereby a relatively constant temperature could be maintained within the animal regardless of external conditions; in other words, warm, as opposed to cold (really variably temperatured or poikilothermous) blood.

This crisis means much, for the cold-blooded reptile has its most decided limitations. On the other hand, the evolution of the bird and mammal, the latter particularly, was rendered possible by the concurrence of these two factors, aridity and cold. Thus while actual recorded mammals (Upper Triassic) and birds (Upper Jurassic) are younger in time, their inception could hardly have been later than the Permian. Not that warm blood was at once attained, for that we believe to have been a relatively slow process, just as was the emergence. Indeed, in the existing egg-laying monotreme mammals the blood still ranges in temperature through at least $30^{\circ} \mathrm{F}$., so with them the mechanism is not yet perfected. 
Origin of mammals. These forms are clearly derived from a reptilian stock known as the cynodonts or theriodonts (Fig. 24 ), in which the dentition has become differentiated as in the mammals into incisor, canine, and molar teeth. The reptiles differ from the mammals in that the lower jaw is still a complex of several bones, while in the mammal there is but one on either side. Many cynodonts were long of limb and must have traveled with the body well off the ground, which seems to have been a prerequisite to the development of warm blood. These cynodonts are widespread, but the evidence points to certain of those of Africa as nearer the direct ancestors of the mammals; the record of the actual transition, however, is as yet unrevealed.

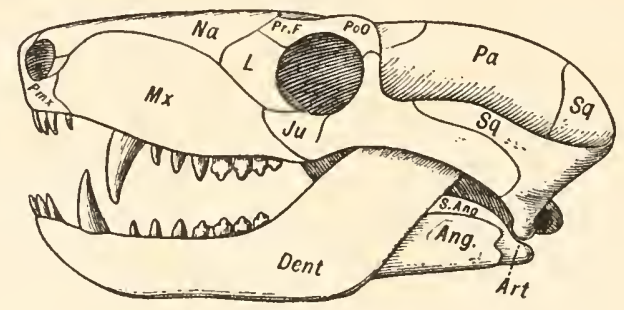

FIG. 24.-Skull of cynodont reptile, Nythosaurus larvatus. Note the mammal-like tooth differentiation, but complex reptilian jaw. After Broom, from the Pirsson-Schuchert "Textbook of Geology," published by John Wiley \& Sons, Inc.

Origin of birds. Birds, on the other hand, came from another, unrelated reptilian stock, that which also produced the dinosaurs. True flight, such as that which the birds developed, has been thrice evolved among the vertebrates and once among the invertebrates. In the two other vertebrate groups, however, the flying mechanism involves not only the fore limbs, as in the bird, but also the hinder pair. With the birds, moreover, the hind limbs, as in dinosaurs, show a dis- 

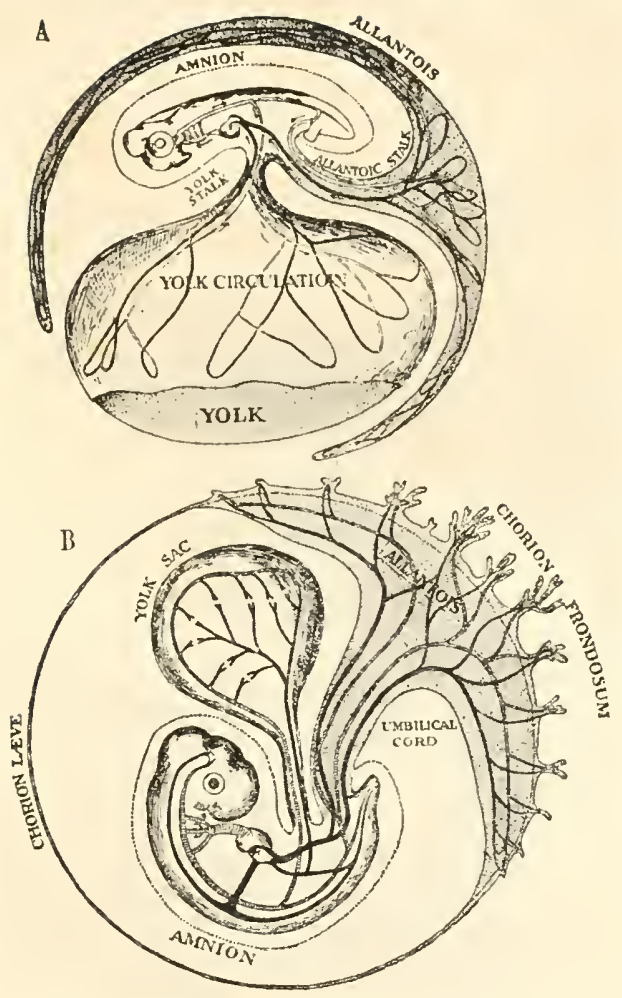

F1G. 23.-Diagram showing the relation of the extraembryonal membranes. A, bird or reptile, with functional yolk-sac and respiratory allantois; B, mammal with functionless yolk-sac and with the allantois converted into an umbilical cord and placenta. From Wilder's "History of the Human Body," published by Henry Holt \& Company. 
- 
tinct adaptation of another sort, that for swift movement, hence the bird-like hind limbs of the dinosaur-or perhaps the converse of this statement would be more nearly true. Swift movement, which in this instance implies bipedality, evidently preceded flight, and its impression on the bird was so great that it has never been entirely relinquished despite the attainment of the higher faculty. Whether birds passed through an arboreal condition or whether they arose direct from cursorial types is unknown. It hardly seems probable, however, that more than one evolution occurred. We may conceive of a proavian as being at least partially arboreal and launching itself into the air from a convenient tree, sustained for a brief soaring glide on motionless fore limbs and tail, the scales of which had metamorphosed into buoyant feathers (see Frontispiece, A). But the first recorded instance, Archaopteryx (Frontispiece, B), of the Upper Jurassic, while still retaining the long lizard-like tail of its reptilian forebears, had already attained the power of sustained flight, though by no means so efficiently as the birds to come. There is again no fossil record of actual transitional forms.

Origin of dinosaurs. The same primal influence-ariditywhich produced the bird also gave rise to the dinosaur. Whether the latter came within the further influence of glacial cold and evolved a constant temperature of blood is not known; the total absence of any heat-retaining clothing in the dinosaurs, such as hair or feathers, is against such a supposition. That their temperature rose decidedly during their periods of activity is, however, a reasonable assumption. Possibly the early dinosaur-like forms which dwelt within the influence of the Permian cold became the birds, while those beyond its influence remained dinosaurs and as such were destined to dominate the lands as no creatures before them had ever done.

One is impressed by the influence of aridity in the evolution of bipedal dinosaurs in studying the Upper Triassic footprints 
of the far-famed Connecticut Valley, ${ }^{6}$ for here there is a profusion of trails of creatures great and small, quadrupeds and bipeds, may of which were long of limb, compact of foot, and impress one as being concerned with weighty matters-questions of food or safety which would brook no delay. In several instances the quadrupedal resting posture is clearly indicated by a creature whose normal gait is that of a biped, but in no instance is the impressed hand that of a carnivorous or theropod dinosaur, whose sharply curved grasping talons borne on the fore limbs would have left a highly characteristic impression such as is never seen. That carnivores were present is an irresistible conclusion, and the inference is that certain numerous footprints made by the hind feet only, in which the claws, including that of a grasping hallux, were comparatively sharp, are attributable to such forms. That aridity does give rise to bipedality is evidenced by the present existence of several bipedal lizards, notably in our own Southwest, and in Australia where the frilled lizard, Chlamydosaurus, reaches a length of five feet and is exceedingly swift of foot.

Rise of sauropod dinosaurs. Climatic oscillation during the Jurassic gave rise to humid conditions and this, coupled with extensive low-lying delta lands along the shores of shallow seas, tempted certain of the increasingly large Theropoda to forsake the strenuous life of a carnivore for the slothful ease of an amphibious herbivore. These huge creatures, because of the increased burden of the flesh, had reacquired a quadrupedal gait as had the armored dinosaurs (stegosaurs). They suffered no very great alteration in their dental battery, the teeth of which became spoon-like (Brontosaurus) or, collectively, rake-like (Diplodocus), fit only for securing some sort of abundant vegetation, not for the rending of flesh. The fate of these forms and that of the armored Stegosaurus were

'See Lull, R. S., "Triassic Life of the Connecticut Valley." Connecticut State Geol. Nat. Hist. Survey, Bull. 24, 1915. 
curiously linked together, for although unrelated, their habitat and habits seem to have been very similar and their extinction was apparently simultaneous. What was the physical cause of this extinction, which is believed to have occurred in the Comanchian, we do not know, for there is little evidence of climatic change. It may have been a temporary restriction of habitat, but curiously enough, these dinosaurs managed to survive the uplift at the close of the Jurassic, but are apparently unknown, with a possible exception in Patagonia, after the much less extensive Comanchian movement.

All of the most impressive characteristics of both Sauropoda and Stegosauria, huge size, small brain, deficient teeth, and, in the latter, huge upstanding plates and spines, are to the paleontologist indications of the overspecialization which he interprets as racial senility. With such forms these characteristics, when coupled with a long period of adolescence and the consequent slow breeding which may safely be inferred, render their extinction imminent.

Gadow, ${ }^{7}$ in speaking of the habits of recent crocodiles, says:

"In cooler countries they hibernate in the ground; and in hot countries, which are subject to drought, some kinds æstivate in the hardened mud; or they migrate. When, during a prolonged drought on the island of Marajo, at the mouth of the Amazon, the swamps and lakes were dried up, the alligators migrated towards the nearest rivers, and many perished in the attempt. On one farm were found 8,500 dead, and at the end of Lake Arary more than 4,000. Such occurrences in bygone times may perhaps explain the masses of bones found here and there in a fossil state."

From this it will readily be seen how small a climatic change might account for the serious depletion of an army of huge forms, perhaps never very numerous as to individuals, and

7 Gadow, H., "Amphibia and Reptiles." Cambridge Natural History, vol. 8, 1909 , p. 447. 
this may have been just enough to give the final death blow to an expiring race.

Final extinction of dinosaurs. In the later Cretaceous the amphibious habitat was again widespread, if indeed it was ever seriously diminished after its first expansion in the Jurassic, for here we find the final efflorescence of dinosaurs. The Sauropoda and Stegosauria had gone, but in their place were unarmored duck-billed dinosaurs or trachodons, fairly rapid runners ashore but, judging from webbed feet and compressed tail, as quick as crocodiles when circumstances forced their retreat to the waters. Heavily armored dinosaurs, the nodosaurs (ankylosaurs) were present, as were the horned Ceratopsia, some of which were highly grotesque beings. And to maintain the balance of power there were carnivores, both small and great, the latter the mightiest beasts of prey which ever walked the earth. Then comes their dramatic extinction, the world over, although they may have lost their world-wide dominance some time before, as we only know these late Cretaceous forms, doubtful Patagonia excepted, from a few European localities and from western North America; but there they were in the climax of their grandeur and there is little save the tendency to overspecialization once more to warn the observer of their coming dissolution. But so far as our records go, not one dinosaur of all the hosts that were survived the Mesozoic, for undoubted post-Cretaceous rocks have not yielded a fragment of their remains.

Why they became extinct no one knows. Our chart shows a lowering of temperature toward the close of the Cretaceous, and to such climatic changes reptiles are highly sensitive. However that may be, the great Laramide revolution which marks the close of the Mesozoic must have brought in a long chain of attendant events in consequence of which the dinosaurs perished. Of all factors of which we have knowledge, the draining of the low-lying coastal lands, with a consequent 


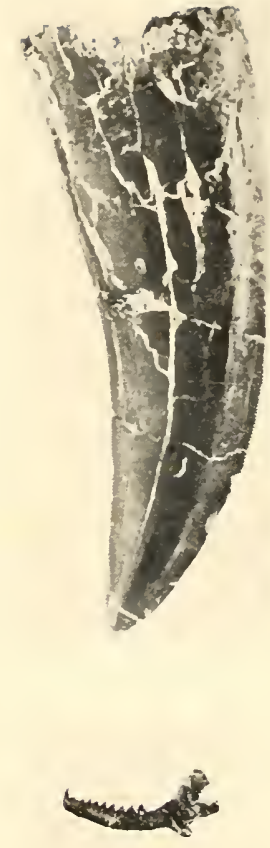

FIG. 25.- Tooth of a carnivorous dinosaur, Allosaurus, and (below) jaw of a contemporary mammal, Diplocynodon. Originals in Yale University Museum. From Lull's "Organic Evolution," published by the Macmillan Company. 
- 
obliteration of the amphibious habitat, seems to have been the most significant. Dinosaurs have been spoken of as associated with peneplanation and the times of their expansive evolution seem to be coincident with periods of degradation rather than with diastrophism, the latter having a restrictive influence.

Rise of mammals. Perhaps the most remarkable thing which the history of the Mesozoic brings forth is the immense period of evolutionary stagnation on the part of the mammals. They are first actually recorded in the Upper Triassic rocks of three rather remote localities, North Carolina, Germany, and South Africa, and are already differentiated in dietary habits. During the Mesozoic, they develop in numbers and to a certain extent in tooth specialization. They do not, however, increase markedly in size, but are humble folk, so far as our records have revealed them, until the extinction of the dinosaurs has been accomplished. One cannot but associate the idea of mammalian suppression with that of dinosaurian dominance in the relation of cause and effect, unless it shall some day be revealed that the mammals were undergoing a marked evolution beyond the temperature-limited habitat of the reptiles. That the former showed no marked evolutionary advance in the place where the dinosaurs actually occurred is an attested fact, and the significance of the dinosaurian check is no more graphically shown than by two specimens in the Yale Museum. These are both of Morrison age, from what is known is our records as Quarry 9 at Como Bluff, Wyoming, a locality which has produced a number of the rare mammalian specimens. The striking thing, however, is the association of these jaws, especially the type of Diplocynodon Marsh, with the tooth of a carnivorous dinosaur, possibly Allosaurus. The figure here reproduced (Fig. 25) is from a simultaneous photograph of these two specimens, which are therefore on exactly the same scale. The single dinosaurian tooth greatly exceeds not only the tooth of the mammal, but the containing 
jaw or even the entire creature as the imagination conjures it up.

The archaic mammals. Dinosaurian extinction heralded the expansion of the mammals, and thus the basic cause of the overthrow of the reptilian dynasty, the Laramide revolution, was the enabling act in the evolution of the higher race. Nature now began once more to people land and sea with beasts of diverse sorts, both small and great; but it was only the warm-blooded furry forms whose privilege it was thus to expand.

The first attempt, following hard upon the dinosaurian extinction, proved to be brief of duration, as though Nature took the stock she had at hand without waiting for the coming of more plastic types. These creatures of the first mammalian expansion have been called archaic, in that while capable of a certain degree of specialization, they were more or less static in three very essential structures, feet, teeth, and brain. Certain of them were herbivores, some light-limbed, fairly speedy, suggestive of the later cursorial ungulates, although never attaining perfection as speed-adapted types. These were the condylarths (Pl. IV, A). Others were slow-moving, ponderous forms relying upon weapons rather than upon fleetness for defense. Among these latter, the amblypods, were the swampdwelling Coryphodon (P1. IV, B) and the later Dinocerata (Pl. IV, C), with conservative molar teeth and feet and absurdly small brain, coupled with elephantine bulk and proportions of body and limbs, but with what was superficially a highly specialized skull having many horn-like prominences and sabre-like canine teeth-a veneer of specialization over a primitive type.

The flesh-eaters were in some respects better equipped than their plant-feeding contemporaries, but they, like the others, were, if one may judge from skull capacity, notoriously dull and 
stupid compared with the shrewdness of their modern supplanters (Fig. 26).

Incursion of the modernized mammals. The archaic mammals barely survived the Eocene, only one group, the hyænodonts, being found in Oligocene rocks. Early in the Eocene, however, are seen the vanguard of an army of invaders, none of which seem directly related to the native mammals. Their

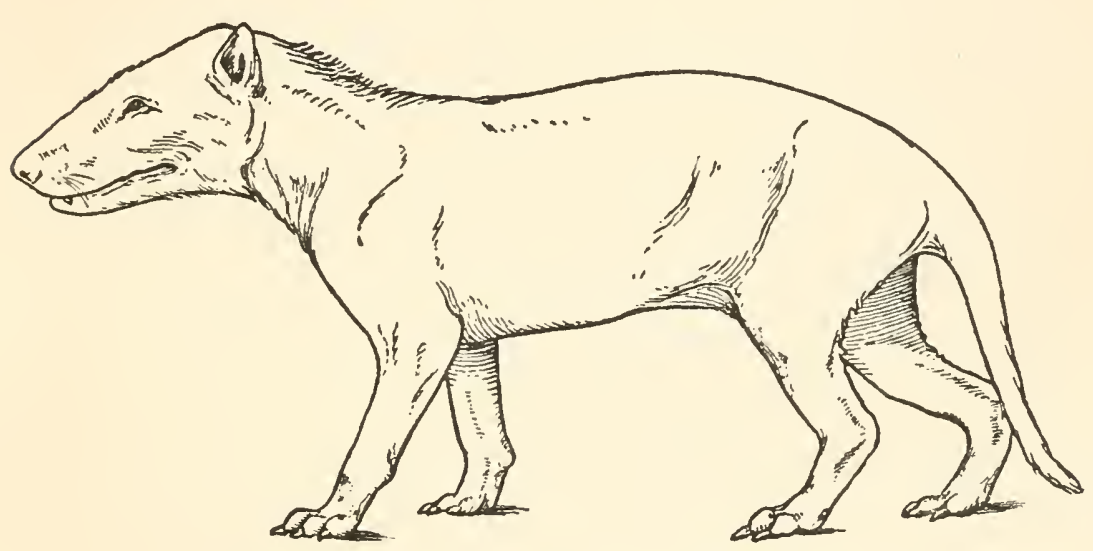

Fig. 26.-Restoration of the creodont, Dromocyon. After Osborn, from Lull's "Organic Evolution," published by the Macmillan Company.

simultaneous appearance in North America and Europe points to a contiguous center of evolution somewhere to the north, either a circumpolar land or the northern part of what is now Asia. Here they underwent their primal evolution and here they were endowed with the highest potentialities along the three directions wherein the archaic mammals failed. Climatic oscillation in the north in the early Tertiary drove these modernized mammals south along the three continental radii, not all at once, but in a series of drives, until the competi- 


\section{I36 EVOLUTION OF THE EARTH}

tion became too severe for the native inhabitants to endure. Assimilation of the native stocks by such an invading army is impossible among animals, however it may be with mankind. The archaic mammals, therefore, had but little choice. Some lingered on, enduring the competition until it became greater than they could bear, others may have migrated still farther south to find asylum, which served to postpone their inevitable fate. Yet others, a very few, may have evolved into higher types, such as the family Miacidæ of the archaic carnivores, although whether they deserve the stigma of genetic relationship with the other archaics in view of this potentiality is somewhat doubtful.

Rise of grazing mammals. The modernized invaders are now established in their kingdom; they are the early oddtoed ungulates-horses, rhinoceroses, tapirs; the even-toed ungulates, such as camels, deer, and swine; the rodents; the carnivores, insectivores, and primates; and in the Old World the proboscideans or elephants and mastodons. Continental elevation in Europe and more especially in Asia during the Miocene brought in its train a marked increase in aridity which in turn had a more or less profound effect upon the flora of the temperate zones, for it meant a diminution of shrubby and herbaceous plants and a wide expansion of the harsher grasses, which now become the dominant note in the world's flora.

This could not but affect the mammals most profoundly, especially the hoofed forms. Floral differentiation during the Oligocene had already made its impress upon certain groups, such as the horses, so that they in turn were differentiating along several lines, some with short-crowned teeth suited to tender herbage, others with grinders whose length and complexity forecast the grazing teeth of their successors and whose dietary choice led in the direction of the coming grasses. Then came the floral change of the Miocene and with it a rapid 


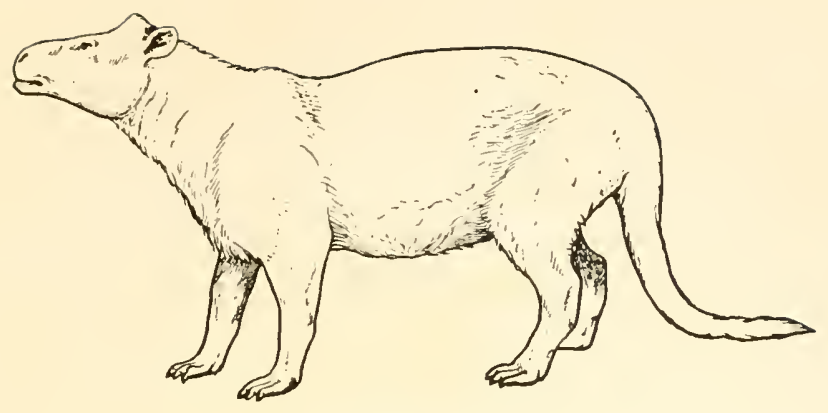

Fic. A.

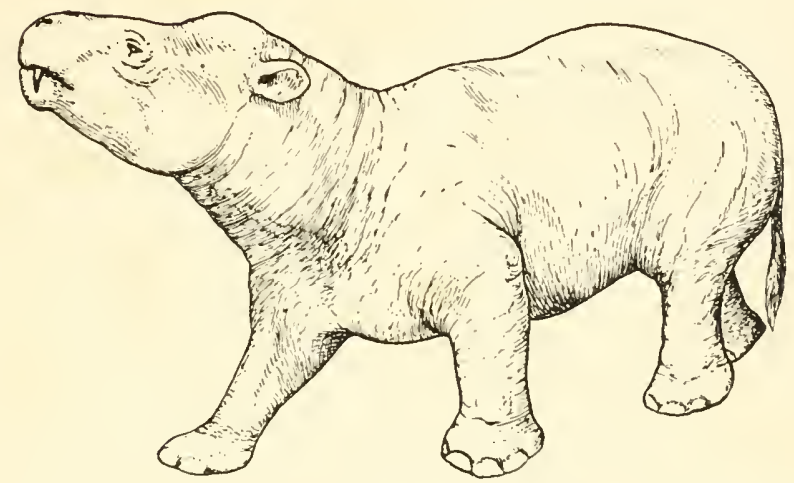

FIG. B

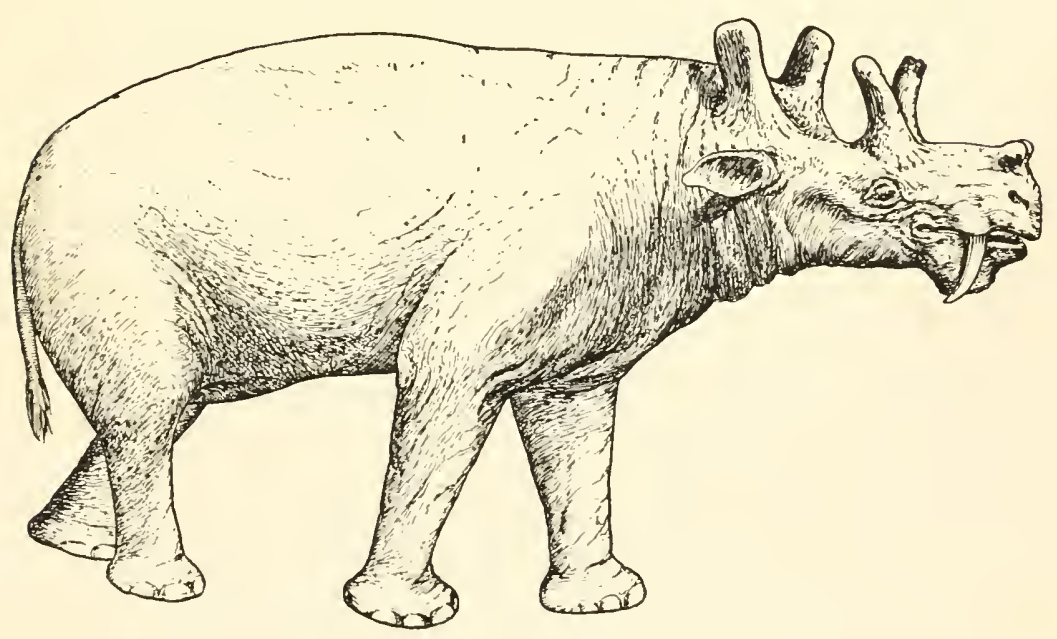

FIG. C.

Plate IV.-Restorations of archaic mammals. A, cursorial type, Phenacodus primarus; B, swamp-dwelling amblypod, Coryphodon; C, four-horned amblypod, Dinoceras, the culmination of its race. After Lull. 

expansion of grazing forms-horses, camels, deer-and the restriction and often the extinction of browsing types. It is true that browsing forms are still extant, but not in their old profusion nor in their old homes, while the grazing forms are numerous and characteristic of the widespread steppes the world over.

Origin of man. We have observed the influence of geologic change in the evolution of the brute, and we have now to inquire whether mankind in his long upward course has been amenable to those same laws or whether he has been a thing apart from other forms of life, whose development has been controlled by other influences. As the primates, the group to which mankind belongs, are to be classed with the modernized mammals, their course of evolution up to the point of their differentiation as primates must have been one with all the rest and hence the result of the same chain of causes. And their differentiation from the other mammals when they came to the parting of the ways seems to have been due to the departure of the latter from their primal mode of life and structure rather than to any special evolution of the primates themselves, for in many ways they are among the most primitive of the modernized hosts, and their tree habitations may well have been a very ancient habitat of the whole mammalian race. $^{8}$

They throve in their northern home just as did their other compatriots, and like them drove southward along the several continental radii, the rear guard drawing in toward the equator with the northern limits of the tropical forests within which they dwelt and upon which, with rare exceptions, they are dependent to this day for food and safety. They reached North America, as the map (Fig. 27) indicates, early in Eocene time (Wasatch) and became so abundant as to form a

${ }^{8}$ Matthew, W. D., "The Arboreal Ancestry of the Mammalia." Amer. Nat., vol. 38,1904 , pp. 811-818. 
high percentage of certain fossil faunas. Here they throve until the close of the Eocene, when they died out, and North America knew no more primates until the coming of man. They had, however, crossed the isthmian land-bridge or its equivalent into South America, where they still persist.

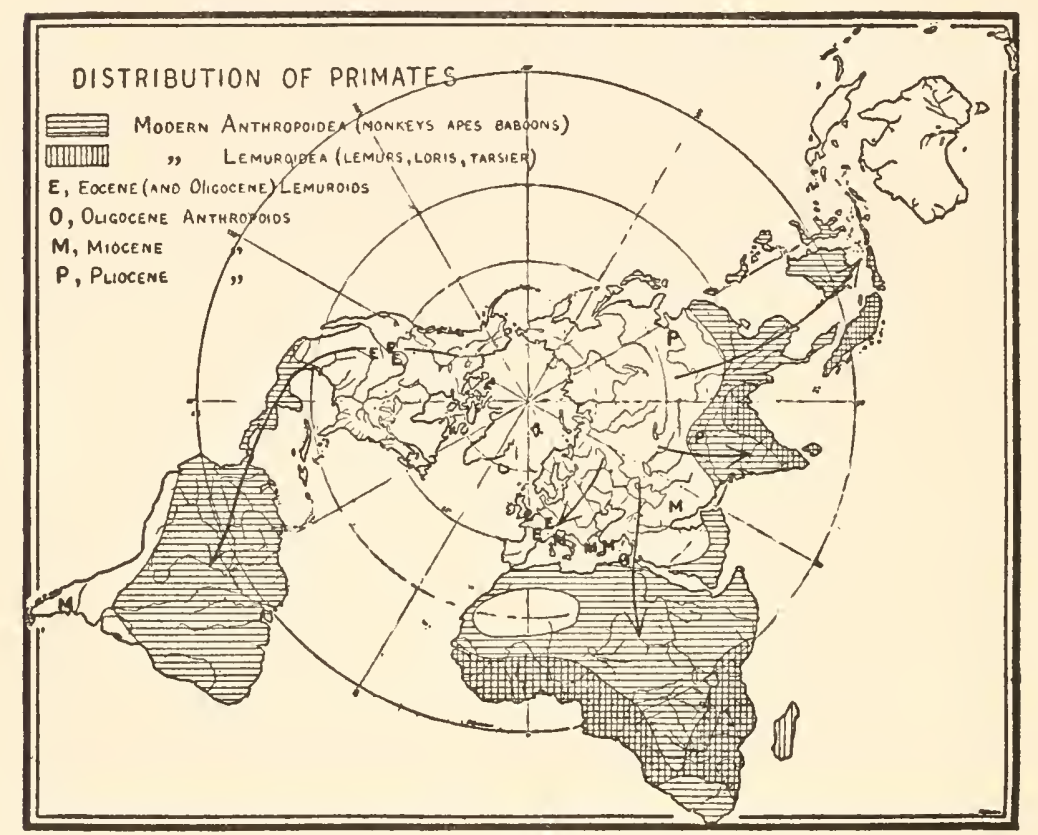

FIG. 27.-Map showing the geographical distribution of the primates, living and extinct, and their indicated dispersal from Holarctica. After Matthew, from "Problems of American Geology," 1915, published by Yale University Press.

In Europe, the history of primates below man was similar to that in North America, marked by Eocene abundance and synchronous extinction, but during the Miocene, at the time of the proboscidean migrations, they reappeared, probably from Africa, to suffer a second extinction during the Pleisto- 
cene. While the sub-human primates are now extinct on the Asiatic mainland north of the great Himalayan uplift, they still persist in tropical Asia, in India, Indo-China, the East Indies, Japan, and the Philippines. They are also extant in tropical Africa.

Anthropoid apes. Man's nearest blood relatives, whatever may be his prejudice in the matter, are the so-called anthropoid or man-like apes: the orang, chimpanzee, gorilla, and gibbon, all descendants from the same stock which gave rise to humanity and perhaps fallen to their present condition through being the victims of circumstances. That man owes his higher estate, at least in part, to his past environments we shall endeavor to show.

Of the great apes, the orang-utan is one of the most familiar, for it and the chimpanzee are the kinds most frequently seen in captivity. The orang is readily distinguished, however, by its reddish hair. It is rarely more than four feet tall but is relatively of great girth, which, together with an arm spread of upward of seven and a half feet, gives it a remarkable appearance. The jaws are powerful, with large canine teeth, but the hands are the chief weapons of defense. The great size of the orang renders it less agile than the gibbon, for instance (see page 140), and it climbs somewhat laboriously as does a man. It is highly intelligent but sluggish, stirred to action only by some powerful incentive such as hunger. Orangs are today confined to the dense somber forests of Borneo and Sumatra, but the fossil remains of their ancestors come from the Siwalik Hills on the Asiatic mainland and thus betray the course of their migration.

The chimpanzee and gorilla are both African in distribution, although also of Asiatic stock. They are perhaps the nearest to mankind in blood relationship. The chimpanzee may readily be distinguished from the orang by its black hair. It is also taller, although never exceeding five feet, and is less bulky 
and hence more active, swinging from tree to tree by the hands with great agility. They rest in the sitting posture, sometimes stand or walk, but run on all fours. Jaws and teeth are their chief defense.

The gorilla (Fig. 28) is by far the most formidable of all the great apes, for its huge size and strength and its unparalleled ferocity make it a veritable terror. An authentic recorded size makes the gorilla five feet one and one-half inches tall and 4I 8 pounds in weight. Its lower limbs, while enormously powerful, are disproportionately short. If the limbs bore a human proportion to the torso, the creatures would stand at least seven feet in height, with a weight of half a thousand pounds! The huge size of this ape has forced it to become partially terrestrial, but instead of becoming more man-like as an adaptation to ground-living, it has taken a yet more brutal aspect, more like a bear than a human being.

All of these apes, the orang, chimpanzee, and gorilla, are degenerating from the higher condition of their common ancestor with mankind, the chimpanzee least, the gorilla most of all. The gibbons (Fig. 29), however, of which there are several species, while the most remote from mankind in actual relationship, have probably retained in greater degree than any others the habits and development of the anthropoid stemform. They are wonderful acrobats, their relatively small size and immensely long and powerful arms lending themselves to the full measure of arboreal progression. The gibbons are oriental in distribution, living in the wooded regions of southeastern Asia and the islands of Sumatra, Borneo, and Java.

It were well to dwell for a moment upon the locomotive methods of these apes which, instead of running upon the upper side of the branches, as do most arboreal forms, swing beneath them by means of their hands. This method of locomotion has been called brachiation (Lat. brachium, arm) and in all probability took its rise with the earliest anthropoids, 


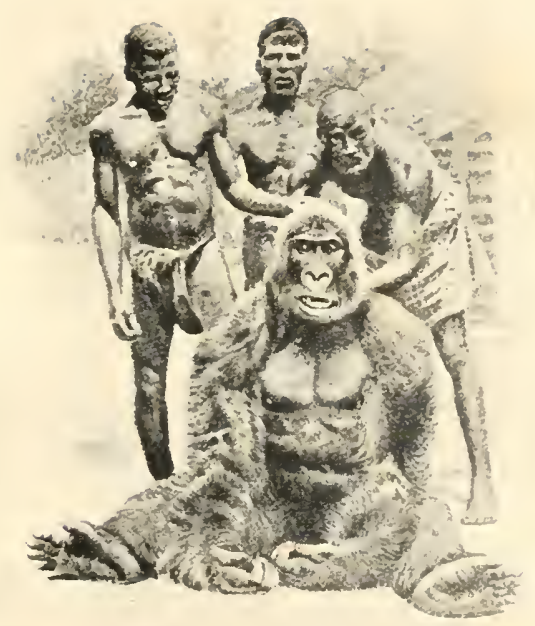

FIG. 28.-Gorilla, Gorilla gorilla. From "The American Natural History," by William T. Hornaday; copyright, 1904, 1914, by William T. Hornaday; published by Charles Scribner's Sons. 
reaching its highest development in the modern gibbon. On the ground, the gibbon walks erect, either touching the knuckles of the hands to the ground or with the arms held above the head. The gait is quick, waddling, with no elasticity of step, and they are soon overtaken. But in the trees they are virtually transformed, for their hand leaps are prodigious, twelve, eighteen, one authority says no less than forty feet being cleared, and that for hours at a time. Fully to appreciate what this means one should compare it with the precise mechanical stride of a racehorse, for whereas in the horse there is a practical uniformity of conditions stride after stride, with the gibbon no two hand leaps can be the same, and each time such a thing is essayed a problem must be solved, for in order neither to over- nor under-shoot the mark, the right amount of force must be used, and this varies with the distance and the ability of the objective branch or branches to bear the creature's weight. Thus, as with a gun pointer, the aim, distance, trajectory, windage, and in addition the varying force, all must be taken into consideration; in the present instance, moreover, the problem must be solved and its practical application brought about instantly, and the penalty for error either in solution or application may be death. Even though the process becomes automatic, the result of much experience, there is, nevertheless, a high premium placed upon mental acuteness, and the weeding out of the unfit is ruthless. Add to this the fact that the hands may be used to bring objects before the face for examination, thus inciting the powers of observation, and two great stimuli to higher mentality are attained. There is reason to believe that the human precursor, before leaving the sheltered life of an arboreal primate, progressed and acted much as do the gibbons, with a consequent quickening of intellect as time went on.

Descent from the trees. But while tree-life had much to do with the prehuman evolution of our ancestors, the arboreal 
is, after all, a limited environment and the descent to the terrestrial habitat was as necessary to further evolution manwards as was that older emergence upon land on the part of our piscine ancestry. In the former case as in the latter, the actual attainment of the terrestrial habitat is supposed to have been forced by geologic change of a very similar character. The presumption is that central Asia was the evolutionary center of the anthropoids and so far as our records go this is borne out by the fossils, the oldest of which are found in the Siwalik Hills of northern India in rocks of Lower Pliocene age. From this center of radiation these primates took their departure, the gorilla and chimpanzee southwestwardly toward the Dark Continent, although a fossil (Pleistocene) chimpanzee jaw associated with a human skull (Homo (Eoanthropus) davesoni) has recently been found in England, ${ }^{9}$ while the gibbons and orang went toward the southeast. The prehuman, on the other hand, remained in central Asia nearest the dispersal center, which, we have seen, is generally true of the latest and most highly specialized of a race. The forms which migrated southward felt the enervating languor of the tropics and remained static, if they did not actually retrogress, whereas the prehuman in the more invigorating and variable climate progressed in his evolution toward a higher type. Central Asia has proved to be the theater wherein the highest mammalian evolution could be attained, for here the forms which man has chosen for his companions, the domestic animals, almost without exception attained their evolutionary completion.

The actual descent from the trees seems to have been due to a chain of events which in many ways parallel those which impelled the emergence. ${ }^{10}$ The Miocene uplift, with the con-

${ }^{8}$ Miller, G. S., Jr., "The Jaw of the Piltdown Man." Smithson. Misc. Coll., vol. 65 , No. 12, 1915, pp. 1-31.

10 Barrell, J., "Probable Relations of Climatic Change to the Origin of the Tertiary Ape-man." Scientific Monthly, January, 1917, pp. 16-26. 
sequent aridity, has been mentioned. As a direct result, the stupendous barrier of the Himalayas began to arise, cutting off the forests of central Asia from their old-time continuity with those in India, and thereby severing the lines of communication by which the anthropoids had left the cradle of their evolution. Miocene and Pliocene aridity diminished the northern forests, as Devonian aridity had diminished the terrestrial waters, until finally there were detached wooded areas within which the contained primates were as isolated as is the orang on sea-girt Borneo and Sumatra today. Further diminution compelled the descent to the ground on the part of the larger and more intelligent forms among them and the destruction of such as could not meet terrestrial competition. Thus a man-like tree-born primate became an earth-borne creature which from sheer necessity ultimately arose to man's estate. This meant the assumption of the erect posture and the lengthening and strengthening of the lower limbs for speed, while the hands, released from the fetters of their earlier locomotive function, became the organs of the mind. Now man had to compete with the mighty carnivores, and as nature had ill endowed him with defensive weapons he had to devise crude armaments of stick or stone with which to insure his survival. The dwindling forests, especially as their tropical character had gone, no longer supplied an easily gained livelihood, and sustenance had to be sought from other sources, mainly from among the feebler of man's fellow creatures. It is probable that he also utilized the seeds of grasses which grew along the margins of the forests, the ancestors of our domesticated grains.

Increasing severity of winters, prophetic of the Glacial Period, necessitated some further means of keeping warm, and man utilized for clothing the skins of beasts which he had slain and later harnessed fire to his use. In common with the other primates, the precursors of mankind were doubtless 
gregarious, probably submitting to the leadership of such as by strength or cunning could enforce their authority, but not until the terrestrial life was attained was the higher communal life with coöperative division of labor possible.

By means of this coöperation and his individual prowess man has attained dominion over the organic world, while through his subduing of nature's forces he conquers all of her varied realms from the equator to the poles, adapting himself to environments which mold their creature denizens most profoundly and through which he passes unimpressed by the laws which compel their adaptation, for he is swifter than the eagle in his flight and he passes through the waste of the waters unscathed by nature, a victim, if such he be, only to others of his own kind (Fig. 30).

\section{SUMMARY}

As the physician, by a clever device, can record graphically the pulsations in the blood stream which are synchronous with the throbbing of the human heart, so I have drawn a curve to show the correspondence between the pulse of life and the heavings of the earth's broad breast. In this curve (Fig. I4) the evolutionary crises and periods of expansive evolution are represented by upward movements, while extinctions are indicated by the downward plunge of the racial line. This curve is broken where as yet we have no tangible evidence to validate our theory, solid when the fossil record changes theory into fact.

Thus the first recorded crisis, the origin of vertebrates, is drawn coincident with the revolution at the close of the Proterozoic era, but the actual vertebrate record begins in midOrdovician time at the numeral I. The development of lungs is connected with the disturbance at the close of the Silurian uplift, the first recorded lung-fishes appearing at the numeral 2, in the Lower Devonian, while the first footprint at 3 , in the 


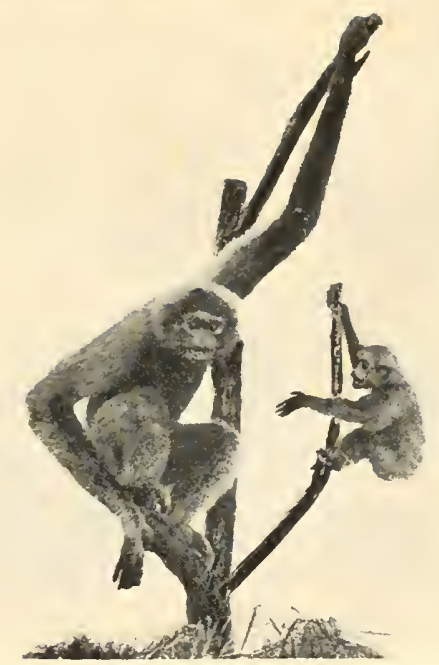

FIG. 29.-Gibbon, Hylobates lar. 


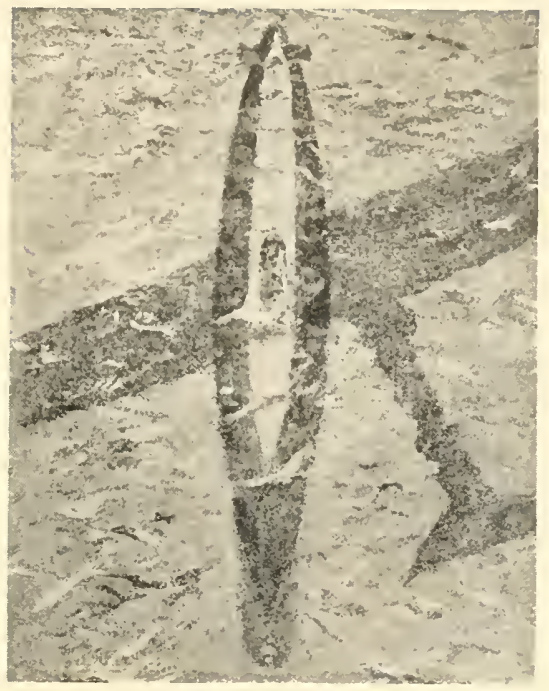

Fig. 30.-Photograph of a submarine, twenty feet below the surface, taken from the aeroplane whose shadow is shown in the picture. From London Illustrated News. 

Upper Devonian, completes the evolutionary movement. The Mississippian is a time of expansive evolution of the stegocephalians, while the establishment of the reptiles was the result of aridity toward its close, hence synchronous with the Ouachita uplift. The culmination of the wide disturbances at the close of the Pennsylvanian brought on aridity and glaciation in the early Permian, with the beginnings of the warmblooded stocks, birds and mammals, although the first recorded bird at 7 is Upper Jurassic and the first known mammals at 6 Upper Triassic. Aridity has been regarded as the chief incentive to dinosaurian evolution, the actual record at 5 beginning in the Lower Trias. The differentiation of the Sauropoda, a response to the expansion of the amphibious aquatic realm, may have been Triassic, but in greater probability the subsidence which followed the Palisade diastrophic movement late in the Triassic may be nearer to the actual time. They first appear in the Lower Jurassic, but do not culminate until early Comanchian, shortly after which they suffer extinction from unknown causes, geologically speaking. The other dinosaurs gradually increase in numbers, size, and specialization, until the close of the Cretaceous, when, with the movements which culminate in the Laramide revolution, they plunge into extinction.

The curve of mammalian evolution is perhaps the most striking of all, consisting as it does of minor fluctuations which may represent accident of preservation and recovery rather than periods of evolutionary expansion, as is equally true of the dinosaurian curve. Then with the Laramide revolution and the coincident dinosaurian extinction comes the rapid mammalian deployment, the archaic mammals, first known in the basal Eocene at 9, becoming fewer and less important, although increasing in specialization until their final extinction in the Middle Oligocene. With the fluctuating climate of the northern area come the modernized forms, first known in the Lower 


\section{I46 EVOLUTION OF THE EARTH}

Eocene at $\mathrm{I} O$, then the differentiation of browsing and grazing forms, followed by a restrictive evolution of the former and a wide expansion of the latter consequent upon the Miocene uplift and its resultant aridity. While the primate line is solid, the derived human line is broken to the point II, the first actual record of man; the descent from the trees is, however, made coincident with the Himalayan uplift and with the increasing aridity of the Miocene.

Man's intellectual and spiritual rise and his dominance over the forces of nature and over the brute creation are shown graphically by the height to which his line ascends above the highest crest of the evolutionary crises which have gone before. For this dominance the Cascadian revolution with its recurrent periods of devastating cold, out of which we are emerging, must be looked upon as a contributory cause.

Thus time has wrought great changes in earth and sea, and these changes, acting directly or through climate, have always found somewhere in the unending chain of living beings certain groups whose plasticity permitted their adaptation to the newly arising conditions.

The great heart of nature beats, its throbbing stimulates the pulse of life, and not until that heart is stilled forever will the rhythmic tide of evolution cease to flow. 


\section{CHAPTER V \\ CLIMATE AND THE EVOLUTION OF CIVILIZATION}

\section{ELLSWORTH HUNTINGTON}

RESEARCH ASSOCIATE IN GEOGRAPHY IN YALE UNIVERSITY

\section{Factors in Human Progress}

HUMAN progress depends upon three great factors. The first is inherent mental capacity, the second material resources, and the third energy. If any of these is lacking, civilization stagnates or even retrogrades. Where all are present civilization moves onward. How far do these three depend upon physical environment? How far does man's higher evolution agree with the evolution of plants and animals discussed in previous lectures? At first sight it appears as if there were a great gap between the evolution of man's body which this course of lectures has thus far considered, and of the mind which is the subject now before us. In one sense there is undoubtedly such a gap. Yet the more we study the matter, the more we see that from the lowest protozoan to the highest philosopher a marvelous unity pervades all nature.

All progress in civilization, whether material or moral, arises from ideas in the minds of individuals. Therefore the first requisite of any advance is men with unusually gifted minds. Some races seem to be capable of producing such men in far greater numbers than do others. We rightly think of ancient Greece as preëminent in this respect. Galton, the founder of modern eugenics, has said that the average Athe- 
nian in the age of Pericles was as much superior to the average Englishman of today as the Englishman is superior to the African. Although a few students still claim that all races possess equal possibilities if given equal opportunities, their conclusions lack statistical foundation. Judged by their achievements and by all the exact tests yet available, races differ as do individuals, although not to so great an extent.

What causes these racial differences? We cannot answer until the biologists give us more light on the origin of the new forms called mutants. If it be asked, however, what preserves the mutants and thus gives rise to new racial qualities, we can answer with considerable certainty. Environment by means of natural selection allows some types to perpetuate themselves indefinitely, while it rigidly exterminates others. Among the various environmental factors, climate is apparently the most important. As Professor Lull has said in a previous lecture: "Changing environmental conditions stimulate the sluggish evolutionary stream to quickened movement. Whenever it has been possible to connect cause and effect, the immediate influence is found to be generally one of climate."

Inherent mental capacity. The American Indians seem to furnish one of the best examples of the influence of climate upon mental capacities. ${ }^{1} \quad$ Practically all authorities agree that the Indian is endowed with a relatively conservative type of mind. He has great powers of observation, of patience, of endurance, and also of action when some crisis suddenly stirs him. He is lacking, however, in originality, in the power of adaptation, and in the quick insight and inventiveness which make the Japanese so competent in seizing what they want in European civilization. It seems probable that the Indians owe much of their mental status to the fact that they appar-

${ }^{1}$ For a fuller discussion of this matter see "The Red Man's Continent," Yale University Press, 1918. 
ently migrated from Asia to America by way of Bering Strait. If that is the case, they must have spent many generations in the extremely trying environment of the Far North where the January temperature averages $10^{\circ} \mathrm{F}$. below zero, and where the winter night lasts months. Such an environment is a terrible strain on the nerves. White men go crazy under it. To a man of quick, inventive mind who always wants to be up and doing, the enforced monotony of the long, icy night is torture. His mind preys upon itself and in time gives way. The type that survives is the phlegmatic man who can sit idly for weeks inside his stuffy hut, and not care whether anything happens or not. When they left the primitive home of man in Asia, the ancestors of the Indians presumably had minds like those of their neighbors who became the fathers of other races. When they emerged from their long sojourn in the Far North, however, they had lost some of their most valuable qualities.

In the same way the European Nordics possess the type of mind to be expected of a race that has always lived in a stimulating climate. The Japanese show similar characteristics to an almost equal degree. It is significant that although these two races pushed out from central Asia in opposite directions, neither was ever forced far to the north or south, and each finds its present home in one of the world's best climates. Neither race, however, has evolved in a uniform climate, for changes due to the Glacial Period, especially in Europe, have forced them to endure repeated epochs of stress. The stress, however, was of a stimulating kind because it was apparently characterized by variability and not by the monotonous uniformity of the Far North or the equator. The African negroes, on the other hand, have by no means been so fortunate. Because their migrations led them into southerly regions they suffered a repressive evolution much like that of the Indians. In tropical regions the energetic types unfortunately 
kill themselves by overexertion. Activity accelerates the processes of metabolism and generates toxic poisons. In the right kind of climate these are eliminated during periods of rest. In a warm climate, however, the high temperature appears to cause excessive chemical activity of the protoplasm just as does exercise. Hence people feel tired even without exertion. When the effects of activity and of heat a re combined the result is often fatal. The exact mechanism of the process has not yet been determined, but some such poisoning of the system and consequent elimination of unduly active types appears to be the reason why the negro has acquired a comparatively indolent character.

Among the backward natives of Australia the elimination of energetic, nervously alert people has gone farther than among the negroes. The Australians in crossing the torrid zone were subjected to all the evils which have weakened the mental powers of the negroes. They also suffered a terrible handicap because their tropical experience was the precursor of an equally strenuous repression by the desert. There sudden and intense activity is at a premium when the water dries up and a long march must be made to a new supply. The most essential of all qualities, however, is the ability to endure hunger, thirst, and heat indefinitely, a kind of endurance which is much harder on people with alert nerves than upon those of stolid disposition. Moreover, mental alertness loses much of its importance as a factor in natural selection when the environment becomes so poor that there are almost no material resources. It is by no means strange, then, that the Australian bushmen, even more than their fellow sufferers, the Hottentots of South Africa, show, as it were, the combined weaknesses of the tropical negroes and of the desert people of Arabia. One might go on to discuss this theme in relation to all the races of the earth. Such a discussion would apparently strengthen the conclusion that while the mental inherit- 
ance of an individual may show no apparent relation to his present environment, each individual is born with the indelible impress of the climatic environments through which his race has passed.

Material resources. Material resources are no less important than innate capacity in their effect upon civilization. They are, if anything, still more closely connected with climate. A Socrates with no resources except the sands of Arabia to support himself and his ideas would never have been heard of. Mohammed had to live in an oasis and not in the sand. His religion would not today dominate nearly a seventh of mankind if it had not speedily spread to places with abundant material resources. The Eskimos show the importance of material resources still more clearly. Though possessing the same power of passive, nerveless endurance which is characteristic of the Indians, these people of the snow and ice seem to have a strain of inventive ability. Their stone lamps, their drills for lighting a fire by twirling one stick upon another, their clever boats which make a man and his canoe parts of a single watertight structure, all show the earmarks of ingenious minds. Nevertheless, civilization could not make progress among the Eskimos. Even if they were not afflicted with the inertia of the North, the absence of material resources would forbid a high civilization. Here, as in so many other cases, climate is the factor which mainly determines the resources. No crops will grow and even the reindeer cannot thrive in many parts of the Eskimo coasts, hence hunting is the only possible mode of life. Hunters must be nomadic. They cannot accumulate any large amount of the material resources which are needed as aids to progress. If the white man with his claims to superiority were placed in the home of the Eskimos with no outside resources, would it be more than a few generations before his mode of life and manner of thought would be much like theirs? The retrogression of the 
white fishermen in northern Newfoundland and Labrador, where the conditions are much better than in the home of the Eskimos, is a pointed answer to this question.

The effect of climate upon material resources and of material resources upon civilization is well illustrated by a comparison of the Indians of California and Utah with their Pueblo neighbors in New Mexico. The pre-Columbian inhabitants of California and Utah were abject savages. They dwelt in flimsy brush huts, and ate rabbits, lizards, grasshoppers, acorns, and other equally poor kinds of food. Because food was so scanty they lived in very small communities, and were forced frequently to move from place to place. Because of their wandering, isolated life they had only the rudiments of social and political organization. All in all, they were well-nigh the lowest of the American aborigines. The Pueblo Indians, on the other hand, had risen far beyond mere savagery and were well along in the stage of culture known as barbarism. They had an excellent diet of corn, beans, and squashes, with enough meat to keep them in health. Not being obliged to wander, they lived in compact, well-made adobe houses. Their villages were large enough and near enough to one another so that intercourse was frequent, hence they had a highly organized social and governmental system. They had also developed a series of complex religious ceremonials that did much credit to their mental powers. Among the aboriginal people of America they stood not far from the top.

The contrast between these two neighboring types was apparently not due to racial differences. The Hopis, who were among the most advanced Pueblo people, were apparently of the same race as the Utes, who were among the lowest of the other type. Material resources seem to have been the main cause of the contrast. The Pueblos had behind them the resources of agriculture, while their savage neighbors 
could not raise crops. This difference was due to climate. At first sight the climates of the two regions appear closely similar. Both are dry. Salt Lake City, in the home of the Utes, for example, has an average rainfall of sixteen inches per year. Los Angeles, where lived some of the lowest California Indians, has the same. Santa Fé, in the center of the Pueblo district, receives a yearly average of nearly fifteen inches. Why, then, was agriculture and hence civilization so different in the two types? The answer is found in the season of rainfall. At Santa Fé the months of June, July, and August have an average of 8.4 inches of rainfall, whereas at Salt Lake City the same months average only 2.2 inches, and at Los Angeles are practically rainless.

Today the greatness of California depends upon its agriculture more than upon anything else; and the farms of Utah are also by no means to be despised. It must be remembered, however, that wheat, barley, beets, grapes, oranges, and other orchard fruits are the staples of agriculture in these regions. They are raised largely by means of elaborate systems of irrigation which utilize the winter snows upon the mountains. Where irrigation is not practised, cattle are the great agricultural resource. The other foundation of prosperity is mining. All these things are essentially European. The crops which place parts of California and Utah among the world's garden plots did not grow indigenously in America. The cattle and horses which browse on the thousand brown hillsides had no counterpart in the New World. Since iron tools were unknown, the art of mining was impossible. So far as anyone has yet pointed out, the poor Indians had no plants that would serve in place of those with which the early people of the Old World were blessed. The absence of summer rain which is typical of all subtropical climates caused the vegetation to be scanty, and hence wild animals, wild seeds, and fruits were also scarce. Thus the people were condemned to be 
nomadic hunters and to remain in the lowest stage of civilization.

Turn now to the Pueblo region. A rainfall of six or eight inches in the three summer months seems insignificant. Yet it made all the difference between savagery and barbarism. Its absence caused the Utes and the California Indians to be as much below the Hopis and the other Pueblo tribes as the Pueblos are below modern Europeans. The one great cereal of the New World is Indian corn. The two other staple crops capable of being raised in the dry regions of preColumbian America were beans and pumpkins. All of these can grow where there is moisture in summer, but not otherwise. To raise them by irrigation in places like Utah and California is practically impossible for primitive people. On all except the larger streams, whose control is beyond the power of beginners, the floods come to an end long before the time when the crops most need them. Where the Pueblos live, however, the summer rains produce floods just when the corn, beans, and pumpkins are most eager for water. Hence these crops provided the early Americans with the basis for a welldeveloped system of agriculture, and progress was assured. Even if the Utes and the Indians of California had been more inventive than the Pueblo Indians and had produced men with minds of unusual brilliancy, the lack of material resources adapted to the early stages of development would probably have kept them permanently in savagery.

The material resources thus far mentioned depend upon climate. In this they are like nine-tenths of the world's resources. All kinds of food, all kinds of clothing, and a large part of the materials used for shelter depend absolutely upon climate. Perhaps there is some exception to this statement, but $I$ have searched for it in vain. The fish of the sea, the fowl of the air, and the beasts of the field, even though they may prey upon other animals, are in the last analysis wholly 


\section{AND ITS INHABITANTS}

dependent upon the vegetation which feeds either them or their prey. Vegetation is absolutely dependent upon temperature, rainfall, winds, ocean currents, and other climatic conditions. Soil, to be sure, is of much importance, but all soils would be moderately fertile if they had never been subjected to any except a favorable climate. There would be no great wastes of sand, salt, gravel, or naked rock, for these arise only under extremes of aridity or glaciation.

In spite of the overwhelming preponderance of climate in determining the nature of material resources, certain articles, such as iron and coal, occur without reference to heat or cold, moisture or drought. Their use, however, depends largely upon climatic conditions. Iron was well known in Mediterranean lands at the time of their highest civilization. Nevertheless, its use was strictly limited by the scarcity of fuel in a subtropical climate. Only when iron was smelted in countries like England where the climate fostered dense forests did its use increase rapidly. When the value of coal was at last realized it added wonderfully to man's material resources. Yet even here the limitations of climate are strict. In Alaska today the presence of coal does little to advance civilization. It brings a group of coal miners whose chief desire is to make money enough to enable them to get home again. Because Alaska is so cold and inhospitable the regions with better climates farther south are the ones that profit by its coal. So, too, with the iron mines of Gellivara in northern Sweden. A few small towns have sprung up, but the places chiefly benefited are the cities of southern Sweden where the climate is less severe. Thus it appears that all kinds of resources are strictly limited by climate either in their occurrence or in their use.

Energy. The importance of energy in advancing civilization is not so well understood as that of inherent mental capacity and material resources. Darwin says that the latent capacities with which most men are endowed are so great 
that inherent ability is less important than the zeal and determination, or in other words, the energy with which that ability is used. In our own experience have we not scores of times had good ideas-perhaps revolutionary ideas-with which we toyed for an hour or a day, only to forget them because we had not the energy to undertake the hard work necessary to bring them to fruition? Such energy is needed not only by the individuals of unusual capacity who make the great inventions, but also by the people around them who must put the new ideas into effect. "We have but partly solved the mysteries of the progress of civilization,-when we have pointed out that each tangible stage of progress owed its initiative to a new invention or discovery of science. To go to the root of the matter we must needs explain how it came about that a given generation of men was in a mental mood to receive the new invention or discovery." ${ }_{2}$ The necessary mental mood is "alertness," which is merely a manifestation of energy. Therefore it would seem that in the march of civilization energy is quite as important as either inherent mental capacity or material resources. Energy is partly the result of proper food, clothing, and shelter, partly the result of inherited ability, and partly the result of freedom from specific disease. All these things depend in large measure upon climate. Back of all, however, lies something else. Everyone knows that he may be well fed, well dressed, well housed, of good ancestry, and free from specific disease, and yet may not feel like work even when he has no special occasion to be tired. Apparently the thing that is needed is the stimulus of the right kind of climate. Health is one thing; full efficiency is quite another.

Effect of climate upon man's efficiency. This matter is so important that we shall dwell on it at some length. Wherever we find him, man seems to be characterized by a most delicate physiological adjustment to climate quite apart from the innu-

2 Williams, H. S., Article on "Civilization" in the "Encyclopædia Britannica." 
merable indirect effects through inheritance and material resources. In this he appears to be like all other organisms. For every species of living being there is apparently a certain optimum or most favorable condition. As the temperature, humidity, or other climatic elements depart more and more widely from the optimum, the animal's reproductive rate diminishes, its general strength declines, it becomes more susceptible to disease, and its life is shortened. Between the optimum conditions and those which cause death there may be a wide range in which life and even health are possible, but in which the organism is not at its best.

One of the great lessons of biology is that man's physiological nature is essentially the same as that of the lower animals. A law which applies universally to them applies also to him. This is eminently true in respect to climate. By measuring the rate of reproduction of infusoria, the rate of growth of plants, the amount of oxygen consumed by crayfish, or the length of life of the boll weevil we can arrive at an exact estimate of the effect of climate upon these various organisms. In the same way we can measure man's response to climate and find out just what conditions are the best and how much harm is done by departures from the ideal. Thus far man's physical relation to climate has been tested chiefly in the following ways: (I) by frequent measurements of the weight of healthy persons or of those suffering from tubercular or other diseases, (2) by daily or weekly tests of people's strength, (3) by examination of the amount of work done by specially chosen subjects or by piece workers in factories day after day throughout long periods, (4) by measuring the amount of carbon dioxide given off in the breath of people who are at rest under various climatic conditions, (5) by tabulating people's estimates of their own feelings of comfort or discomfort at different temperatures and humidities, and ( 6 ) by ascertaining the number of deaths at different seasons of the 
year and comparing them with the weather. All of these methods yield substantially the same results. So far as temperature is concerned they indicate that people's health is best and their physical energy greatest when the average temperature for day and night together is from $60^{\circ}$ to $68^{\circ} \mathrm{F}$., which means when the noon temperature ranges from about $65^{\circ}$ to $75^{\circ}$.

Among the methods mentioned above the study of deaths seems to be the best thus far employed. As this method has never before been used on a large scale, it may be well to consider it somewhat fully. Death is one of the few occurrences which takes place in all parts of the world and can easily be reduced to accurate statistics. Such statistics are kept by all of the more advanced governments, so an enormous body of valuable facts is easily available, and needs only to be tabulated in order to give most significant results. Accordingly, I shall here give a résumé of the detailed study of about 9,000,000 deaths in Italy, France, and the United States, and of the more cursory but no less exact study of a much larger number in Belgium, Germany, Sweden, Finland, and Japan. The most important result of these studies is a series of "climographs" like Figures 3 I to 33. Figure $3 I$ is based on 2,500,000 deaths in the part of the United States north of the fortieth parallel and east of the Missouri River during the years I900-I9I2. Figure 32 is based on 2,200,000 deaths in France from I90I to I 910 , and I,500,000 in Italy from I 899 to I9I3. Figure 33 is based on 142,000 deaths in four California cities, namely, San Francisco, Sacramento, Los Angeles, and San Diego, from I 900 to I9I2. The diagrams show to what extent the deaths during months with any specified temperature and humidity fell short of or exceeded the normal. Temperature is indicated at the left and humidity at the top. The heaviest shading means that on an average the deaths during months having the conditions included within its area were at least ro per cent 


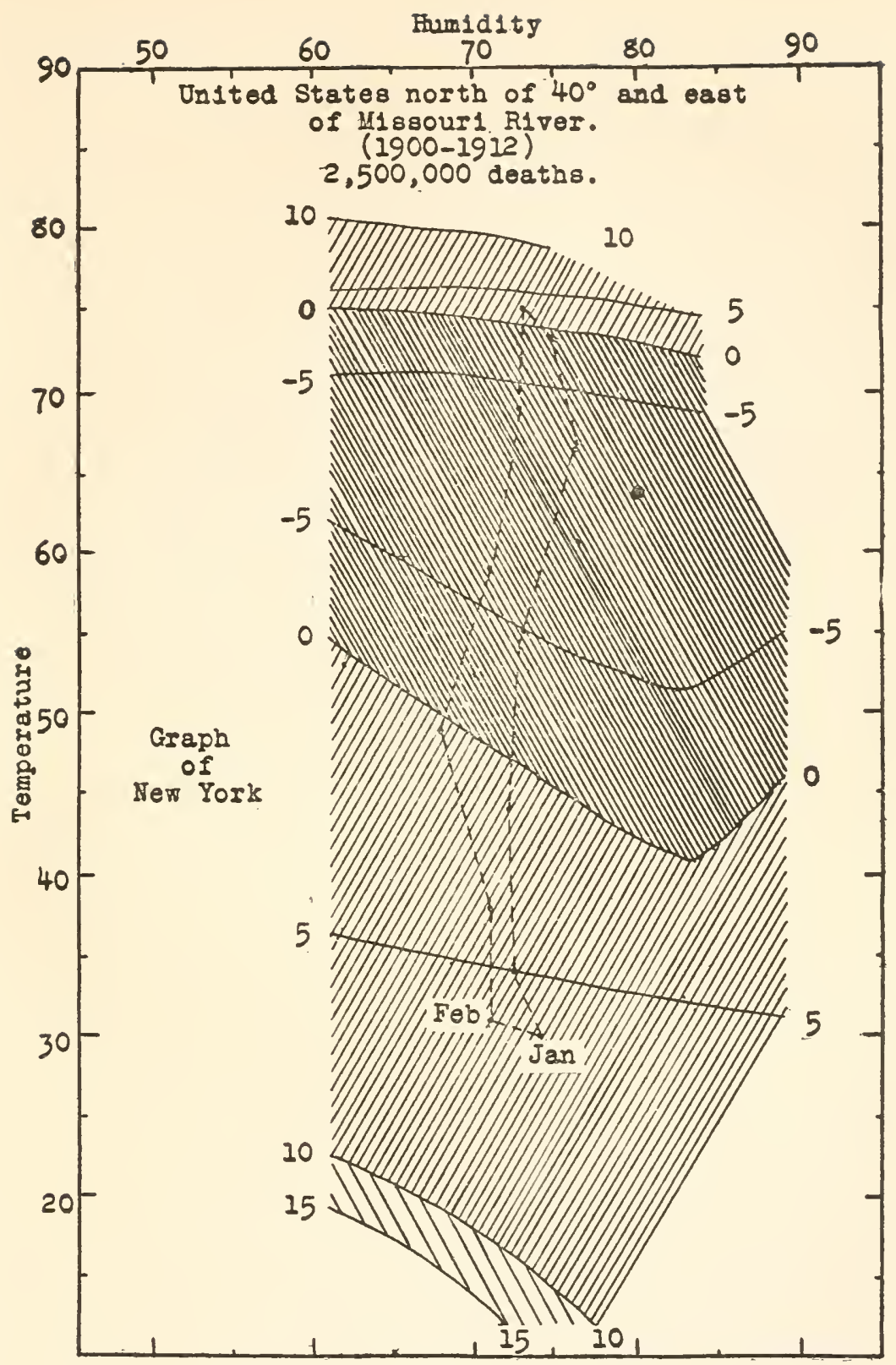

FiG. 31.-Climograph of the northeastern United States. Based on about $2,500,000$ deaths in the United States north of $40^{\circ}$ latitude and east of the Missouri River, 1900-1912. 


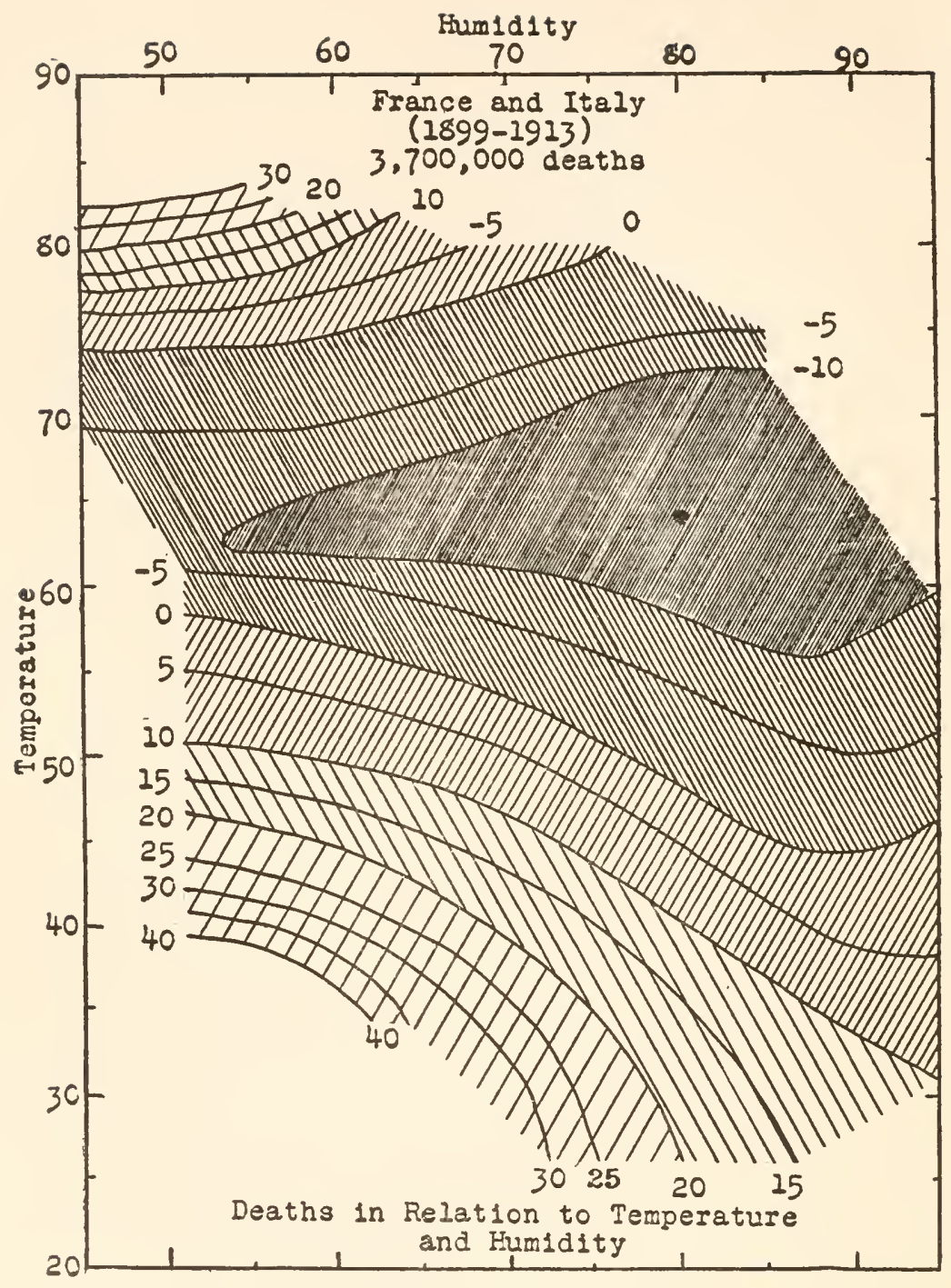

FIG. 32.-Climograph of France and Italy. Based on 3,700,000 deaths, 1899-1913. 


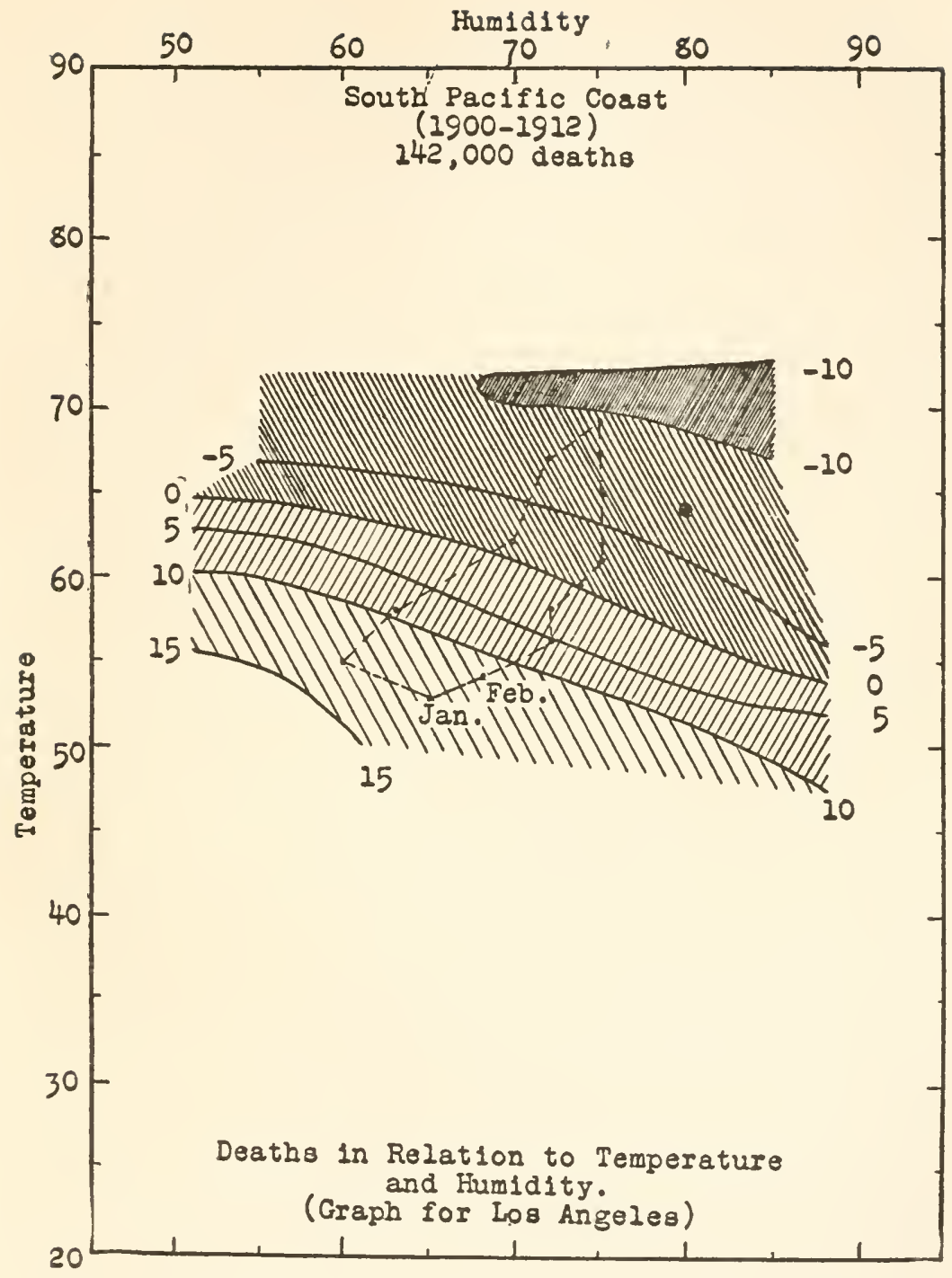

FIG. 33.--Climograph of Southern California. Based on 142,000 deaths at San Francisco, Sacramento, Los Angeles, and San Diego, 1900-1912. 
less than the normal. The less heavily shaded area between the ro per cent line and the zero line means that on an average the deaths in months having any of the combinations of temperature and humidity falling between these lines range from the normal to not more than Io per cent below it. The next lighter strip indicates conditions under which deaths range from normal to Io per cent more than the normal, and so on. The lighter the shading the greater the number of deaths, and the less the vitality and energy. The practical use of the diagrams may be illustrated by an example. Suppose, for instance, that we want to find what degree of health we may expect in a month having an average temperature of $50^{\circ}$ for night and day together and a mean humidity of 70 per cent. In Figure 31 find $50^{\circ}$ in the scale on the left. Follow this level to the right to a point in line with 70 per cent as marked at the top. This point lies a trifle above the zero line and about one-fifth of the way toward the minus 5 per cent line. Therefore we infer that on an average the months with a mean temperature of $50^{\circ}$ and a relative humidity of 70 per cent have I per cent less than the normal number of deaths. Such a month in spring after a hard winter may have ro per cent more than the normal deaths, while in the fall after a cool summer it may have 2 per cent less than the normal, but the average is I per cent below normal.

The method of preparing these diagrams is as follows. Certain cities were first selected to cover all parts of each region, namely fourteen in France, fourteen in Italy, twentytwo in the northeastern quarter of the United States, and four in California. For each place tables were prepared showing the mean temperature, mean relative humidity, and number of deaths for each month. Next the yearly deaths in the first and last halves of the period under discussion were averaged to see how rapidly the number was increasing or diminishing. On the basis of these figures, and assuming that the change in 
the number of deaths due to increasing population and to improved sanitation progresses uniformly, the normal for each month was obtained. Allowance was made for the varying number of days in different months. Then for each month the departure of the death-rate from the normal was calculated in percentages. These departures were next tabulated according to temperature and humidity. Contagious diseases were of necessity included and cause some irregularities which have been smoothed out in the diagrams here presented. It must be clearly understood, however, that the irregularities are slight, and their effect is merely to cause the lines separating the different zones to be wavy instead of smooth. As a matter of fact, contagious diseases are in general worst under the same conditions which are worst for other diseases.

By the method described above, each place is compared only with itself. This avoids the serious difficulty which arises if actual death-rates are employed, and if all places are compared with the same standard. The death-rate of one town may be high because of poor sanitation, or because a great number of people work in factories. In another it may be low because a large number of young people have migrated thither or because the occupations are unusually healthful. Therefore comparisons of the death-rate of different places are misleading. According to the method here employed, however, it makes no difference what the actual death-rate is. We deal simply with the degree to which the deaths fall above or below the normal for the particular place and period in question.

It will readily be seen that diagrams 3 I to 33 present the same general features. This would be much more evident if the range of temperature in California and of humidity in the eastern United States were not so small. Nevertheless, in each diagram the outstanding feature is a central heavily shaded area of few deaths and high physical energy. When 
the weather conditions are like those included within this area, the number of deaths averages at least ro per cent less than the normal. In Figures $3 \mathrm{I}$ to 33 and in others of similar character not here reproduced the favorable conditions when deaths are more than 5 per cent below normal range as follows: Mean Temperature at Which Deaths Are More than 5 Per Cent Below Normal

I. The northeastern quarter of the United States $5 \mathrm{I}^{\circ}$ to $7 \mathrm{I}^{\circ}$ 2. France and Italy $\ldots \ldots \ldots \ldots \ldots \mathrm{I}^{\circ}$ to $74^{\circ}$

3. California ....................... $55^{\circ}$ to $75^{\circ}$

4. The southeastern United States ....... $60^{\circ}$ to $63^{\circ}$

5. The dry interior of the United States .... $57^{\circ}$ to $73^{\circ}$

6. Colored people in the United States ..... $53^{\circ}$ to $78^{\circ}$

In each of these cases the central part of the area of high vitality lies not far from a mean temperature of $64^{\circ}$ and a mean relative humidity of 80 per cent or 85 per cent. In each case there is a tendency for the lines to converge toward the right at high temperatures, which means that hot and very damp weather is not favorable, as everyone knows. To the left is also a similar tendency toward convergence which indicates that although a certain degree of dryness may be favorable in hot weather, too much is bad. Another notable feature is that toward the top of the diagrams above the area indicating most favorable conditions the lines are closer together than they are toward the bottom. In other words, temperatures that are too high have a worse effect than those that are too low. Again it is noticeable that at lower temperatures the lines tend to swing from a horizontal position on the left to a vertical position on the right. This means that in cool weather moist conditions are decidedly better than dry. In this respect the diagrams are surprising, for it rarely realized that there is any such pronounced difference between cold damp weather and cold dry weather. In fact, the vast majority of persons, 
myself among the number, have always supposed that dry weather is the best. There is no questioning the diagrams, however, for, as has already been said, they are based on millions of deaths. Moreover, the same features appear in each of the five areas into which the United States is divided, and in France and Italy when taken separately as well as together.

One of the most striking features of the diagrams is that although their general form is alike and although they all show substantially the same optimum, the lines are far apart in Figure 3 $\mathrm{I}$, the diagram for the northeastern United States, nearer together in Figure 32 for France and Italy, and nearest of all in Figure 33 for California. This means that while people in all these regions are strongest and most energetic at essentially the same temperature and humidity, a departure from these apparently ideal conditions does much more harm in France and Italy than in the northeastern United States, and still more in California. We might add that between the northern and southern parts of France and Italy there is the same sort of difference as between Figures 31 and 32 , or 32 and 33. This at first sight seems puzzling. The climates that are generally considered best for invalids actually show greater extremes in the death rates than do the more rugged northern climates. This happens not only in southern California where there are many invalids, but in San Francisco and southern Italy where there is no influx of such people.

The explanation is apparently found in the variability of the different climates. Measurements of factory work and studies of the marks of students show that changes of temperature, especially a moderate drop, are distinctly stimulating. Other evidence also indicates that variability, both from season to season and from day to day, is much better than uniformity. Apparently people who live in variable climates acquire a power of resistance unknown among those where relative 
uniformity prevails. The effect is like that of exercise. The people whose bodies are exercised by frequent transitions from one set of weather conditions to another are more healthy and energetic than those who live where there are no changes. The benefit of a climate like that of southern California comes not from staying there year after year, but from going there. Since the temperature never departs far from the optimum, people who come from other regions usually experience a helpful change. It is like what they experience in their own homes during the favorable months of spring and fall, but it has the added advantage of rest, novelty, interesting scenery, and out-of-door life.

Since storms are the chief cause of variations of weather from day to day, they appear to be a most valuable stimulant. Hence they have much to do not only with human energy but with civilization. In the trying winters of the northeastern United States, to be sure, the most stormy months have about 6 per cent more deaths than do those with only a moderate number of storms. Months with almost no storms, however, are not so good as those with a moderate number. Even in the mild winters of California the same is true. There at temperatures below $56^{\circ}$ the following conditions prevailed from I 900 to I9I 2 :

I. In months of practically no storminess, the deaths, which numbered 27,700 , were 6 . I per cent more than the normal.

2. In months with a medium number of storms, the deaths ( I I,920) were $5 \cdot 3$ per cent more than normal.

3. In months of great storminess, the deaths $(13,200)$ were 7.3 more than normal.

In warm weather, on the other hand, the most stormy months are the most favorable. In the northeastern quarter of the United States the deaths are about 5 per cent less in such months than in those with least storms. In California for mean temperatures above $65^{\circ}$ the figures are as follows: 
I. In months having no storms ( 17,800 deaths), the rate was 8.6 per cent less than the normal.

2. In months having slight storms (3,000 deaths), the rate was 6. i per cent less than the normal.

3. In months having moderate storminess ( 1,700 deaths), the rate was 13.8 per cent less than the normal.

On the basis of these figures and of others in other parts of the country the bad effect of great storminess in cold weather appears to be balanced by the good effect in warm weather. To this, however, must be added the significant fact that storminess, as has already been explained, appears to increase people's vitality and energy at all seasons. ${ }^{3}$

What has all this to do with civilization? Much, as we shall shortly see. Thus far we have been dealing only with people of European races. We have seen that whether in France, Italy, or any one of five sections of the United States, the best health and greatest energy are found under essentially the same conditions. Less intensive studies of Belgium, Finland, Germany, and Sweden indicate that so far at least as temperature is concerned the response is the same as in France, Italy, and the United States. This is evident from the following table:

\section{Optimum Temperature on the Basis of the Death-Rate} in Foreign Countries

Place

Belgium,

Finland,

Germany,

Japan,

Stockholm,
Years

I 86 I - I 9 I O

I $900-19$ I 2

I 9 I 2

I 899-I 908

I 906-I 9 I 4
Optimum

Temperature

above $63^{\circ}$

above $6 I^{\circ}$

$64^{\circ}$

$64^{\circ}$

$60^{\circ}$

Average,

3 For a further discussion of this matter see the author's volume on "Civilization and Climate," 1915, published by Yale University Press. 
Humldity

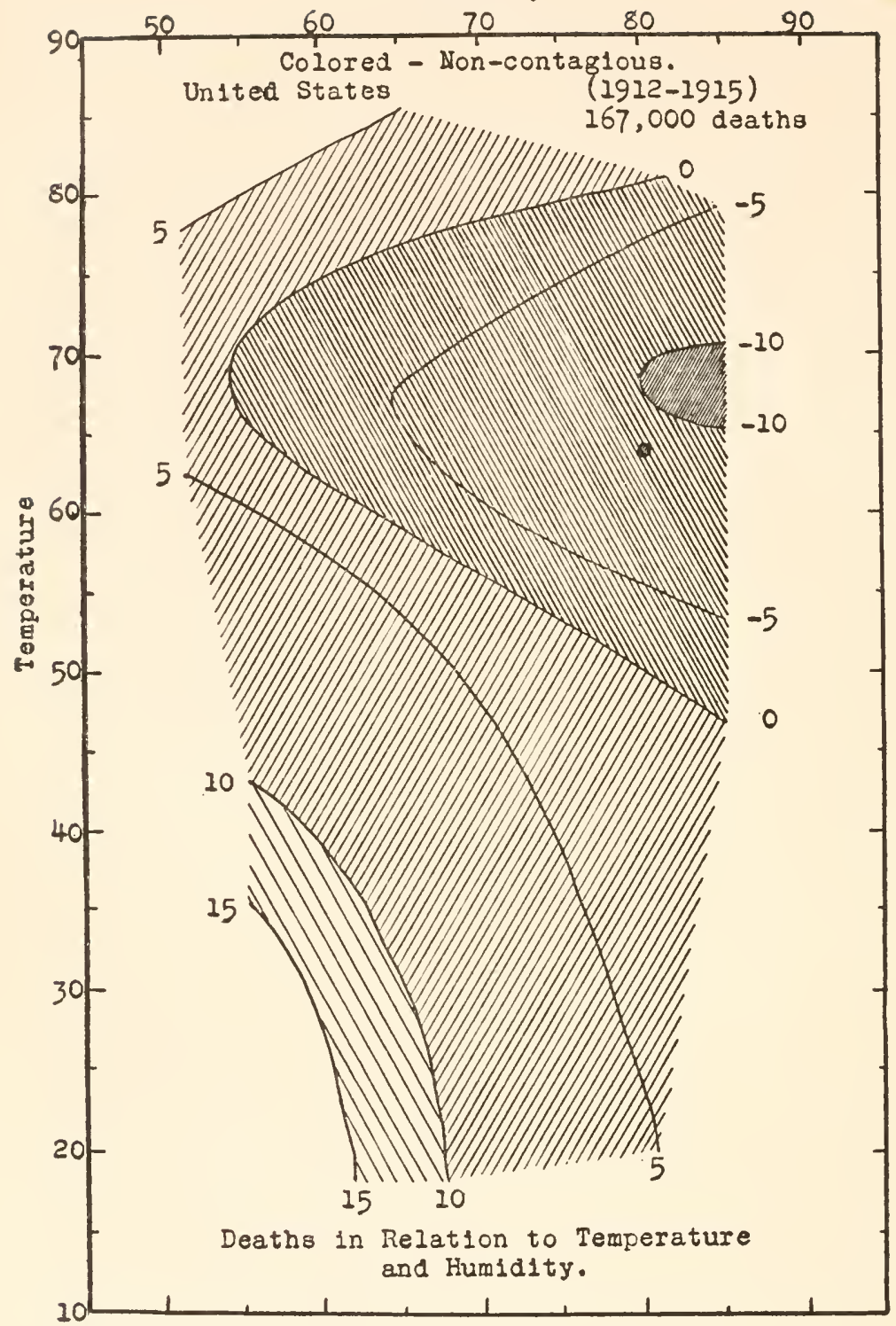

FIG. 34.-Climograph of deaths of colored people in the eastern United States, 1912-1915. Non-contagious diseases. Departures from normal in percentages of normal. Based on 167,000 deaths in all cities and states for which separate figures for whites and negroes are given in the Census Reports, with the exception of New Orleans. 
Buraldity

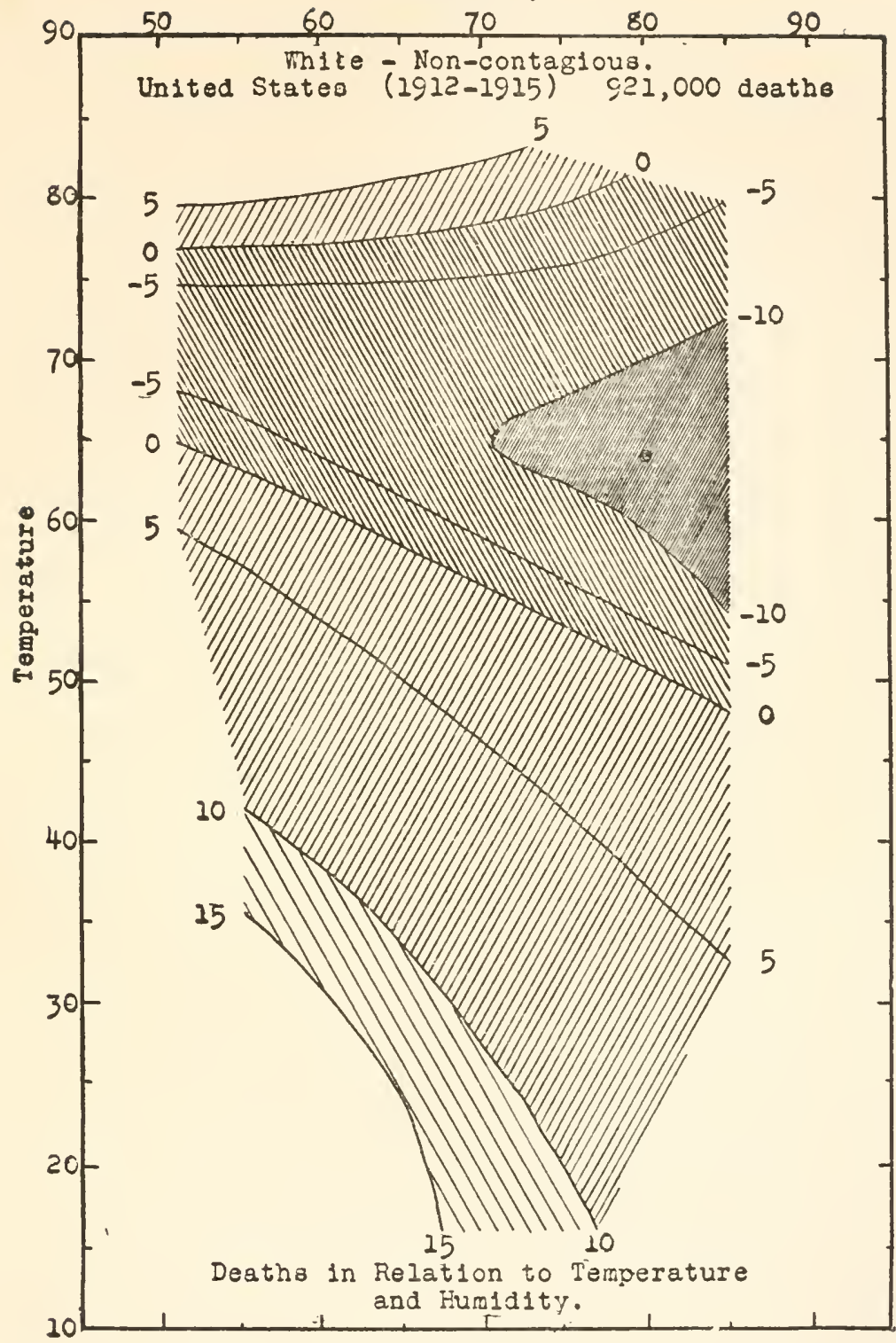

FIG. 35.-Climograph of deaths of white people in the eastern United States, 1912-1915. Non-contagious diseases. Departures from! normal in percentages of normal. Based on 921,000 deaths in all cities and states for which separate figures for whites and negroes are given in the Census Reports, with the exception of New Orleans. 
Belgium and Finland are so cool that no entire month has a mean temperature as high as the optimum. Stockholm happens to show a low optimum, but this is not significant, for accidental circumstances such as epidemics may cause the figures for a single city to depart from the true normal. ${ }^{4}$

From the facts now before us it appears to make little difference whether we are dealing with Finns of semi-Mongoloid stock in the Far North, with Nordics in central Europe and America, with people of Mediterranean stock in southern Italy and Sicily, or with Japanese in the Far East. In all cases, the highest energy is found where the average temperature for day and night together is between $58^{\circ}$ and $71^{\circ} \mathrm{F}$. In general it varies only a little above or below $64^{\circ}$. It is surprising enough to find such an agreement among all these races of Europe and Asia. It is still more surprising to find that in the United States the deaths of whites and of negroes, so far as they are available in the figures of the United States Census from I9I2-I9I5, show essentially the same response. This is illustrated in Figures 34 and 35. Figure 34 is based on all the reported deaths of colored people from noncontagious diseases in the states of Maryland, Virginia, North Carolina, and Kentucky, together with all the cities, both north and south, where deaths of negroes are reported in the Census tables. The negro deaths number only I 67,000, or so few that accidental and local circumstances cause great irregularities. Nevertheless, it is clearly evident that the zone of fewest deaths ranges from about $53^{\circ}$ to $78^{\circ}$, which is essentially the same as in Figures 3 I to 33 . Light areas indicating many deaths are increasingly prominent at low temperatures and low humidities, and also at high temperatures and high humidities.

Figure 35 is based on exactly the same places as Figure 34,

4 For a further discussion of this subject see Huntington, Ellsworth, "Temperature Optima for Human Energy." Proc. Nat. Acad. Sci., vol. 3, 1917, pp. 127-133. 
but it illustrates white deaths instead of colored. It differs from Figure 34, however, because the number of deaths is much greater, being about 921,000. Moreover, the relative importance of different places varies much. For instance, in New York City there are only about 2,500 colored deaths per year, while white deaths number nearly 70,000. In North Carolina, on the contrary, the white and the colored deaths in the towns for which statistics are available each amount to about 4,000 per year. In spite of this, the two diagrams show the same general features. This is highly significant. It shows that in spite of the great outward difference between whites and negroes, the two races are fundamentally alike in their climatic response. The negro does not seem to have acquired any especial adaptation to a hot climate, even though his ancestors lived in Africa for thousands of years. His case is even more striking than that of the Finn, who has lived in a cold climate for many generations. The average temperature in the places where these two races have spent most of their lives differs by about $40^{\circ}$. Nevertheless, the temperature at which each is most healthy and energetic differs by no more than $4^{\circ}$. Thus it appears that not only the Nordic, Mediterranean, and Mongoloid races are alike in their response to climate, but even the negro joins them. It seems scarcely going too far to conclude that all mankind probably shows nearly the same adjustment to one special kind of climate. Men may have black skins to protect them from the heat of the tropics, or fair skins adapted to a cloudy, northern home, but so far as actual temperature and humidity are concerned they are not essentially different. It looks as if man's adjustment to climate were like the temperature of the blood, which is the same in all races, and does not change, no matter in what climate man may live. Perhaps such a universal adaptation to the same climate indicates that the conditions under which man is now at his best are those under which he took the most important 
steps in his final physical evolution, and acquired his present invariable inner temperature.

In this connection it is important to note that among white men the best conditions for mind and for body do not appear to be quite the same. Variability seems, if anything, to be even more stimulating to mental than to physical activity. Tests of school children made by Lehman and Pedersen in Copenhagen and my own study of the marks of about 1,600 students at West Point and Annapolis indicate that mental activity is greatest at a temperature decidedly lower than the optimum for physical energy. For negroes the difference, as indicated by daily tests of twenty-two students at Hampton Institute for sixteen months, is much less. Perhaps this indicates that after the separation of the white and negro races there came a period of low temperature and of climatic stress which modified the white man's mental response, but did not affect the negro because he had gone too far south.

If the conclusions here presented are sound, a knowledge of the temperature, humidity, and variability of any region enables us to determine what effect its climate would have upon the physical and mental energy of all mankind. It is thus possible to prepare a map showing the distribution of either kind of energy or of the two combined. Such a map, in which physical and mental energy are regarded as of equal importance, is shown in Figure $36 .^{5}$ The map is subjest to correction when fuller data are available, but that will not change its main outlines. The heavily shaded areas are those of great energy. The agreement of these areas with the places where civilization is highest is too marked to escape notice. In order to bring the matter more clearly before us, Figure 37 has been prepared. This is a map showing the distribution of civilization according to the opinion of fifty competent judges in fifteen different countries. The judges have been grouped in

${ }^{5}$ The map is fully discussed in "Civilization and Climate." 


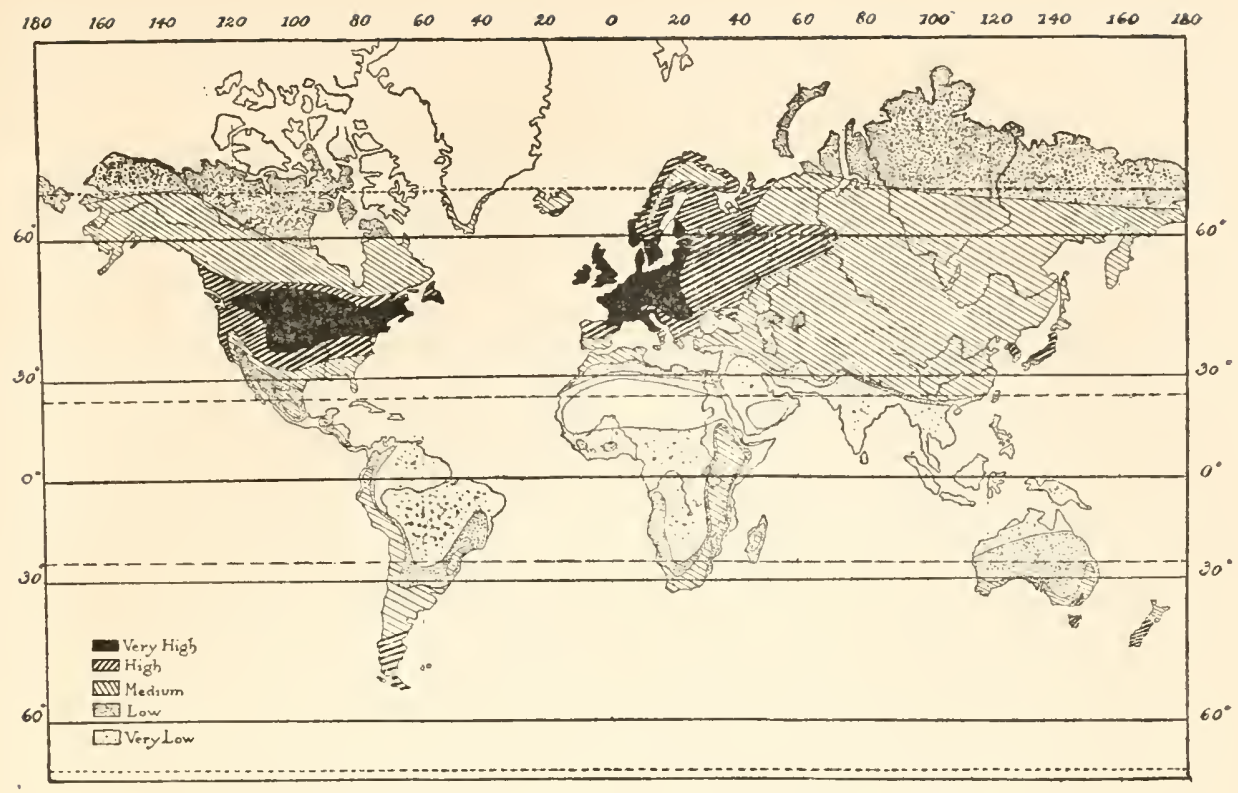

FIG. 36. - The distribution of human energy on the basis of climate.

From "Civilization and Climate."

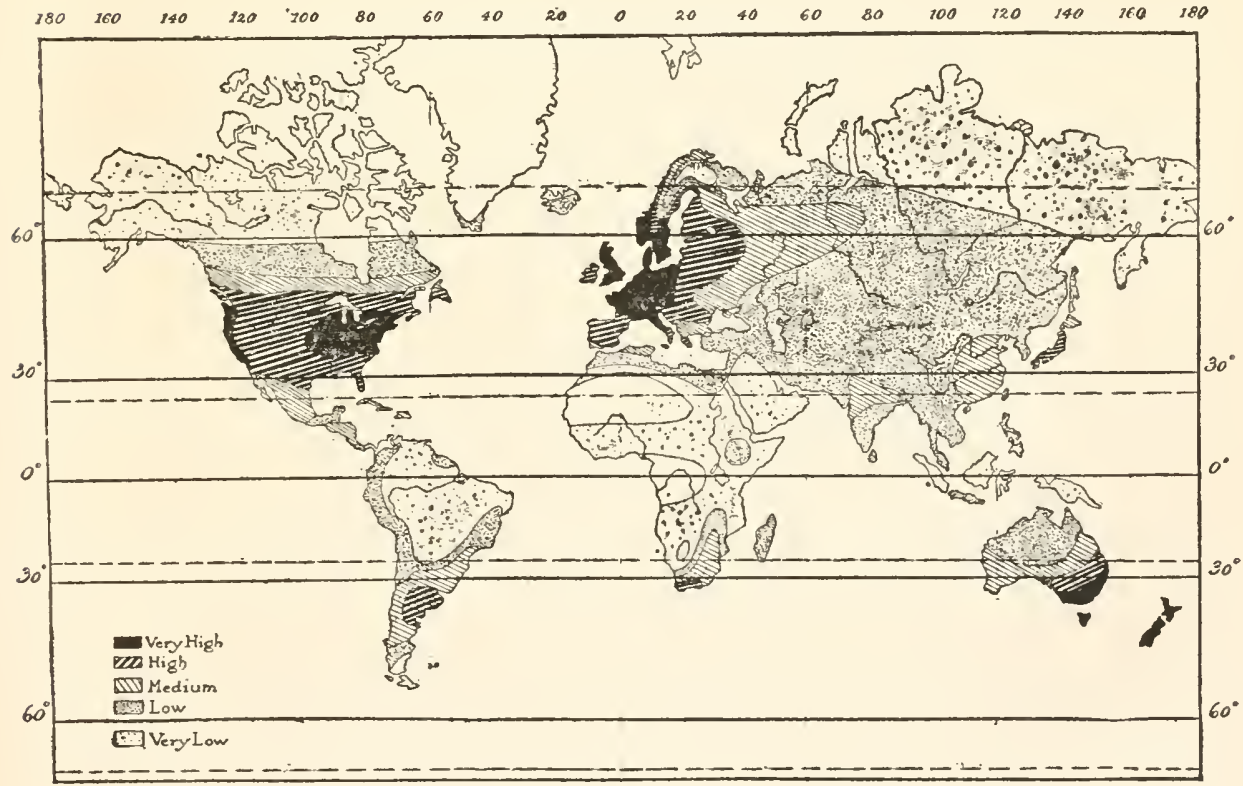

FIG. 37.-The distribution of civilization. From "Civilization and Climate." 
such a way that the opinion of each of five groups, namely Americans, British, Teutonic Europeans, Latin Europeans, and Asiatics, has equal weight. The agreement of the two maps is surprising. It indicates that at the present time the distribution of climatic energy and that of civilization are almost identical. Such differences as are discernible occur almost wholly where exact information is lacking or where the presence of Europeans as colonial rulers raises the apparent standard of civilization.

This brings us to the climax of our discussion. At the beginning of this lecture we saw that human progress, that is, the growth of civilization, depends in apparently equal measure upon inherent mental capacity, material resources, and energy. We then saw that although inherent capacity has no relation to present climatic conditions, it is closely intertwined with those of the past. We also saw that although some resources like the metals and coal occur without respect to climate, their utilization is largely controlled by climatic conditions, while the vast majority of resources depend directly upon climate through its effect on vegetation. Finally we have seen that human energy, even more than either of the other conditions, appears to be dependent directly upon the physiological effect of climate upon man's body. Thus in the evolution of civilization, as in the broader field of the evolution of life, the most obvious controlling factor, although by no means the only one, appears to be climate.

\section{Steps in the Evolution of Civilization}

Invention of tools and speech, and discovery of use of fire. In the light of this conclusion let us briefly examine some of the great steps in the evolution of civilization. Three of the earliest and greatest steps were the invention of tools, the invention of speech, and the discovery of the use of fire. As to the relation of tools and speech to climate, nothing definite 
can be said. They probably became a part of man's cultural inheritance so early that he still lived in his primeval home, and had perhaps not begun to differentiate into races. If that is the case, the climate was presumably of the kind which we have found to be most stimulating. That is, it had a temperature about like that of modern Greece, but with much more variability from day to day. As to fire, the conditions of its discovery were probably like those of the first use of tools and of speech. In this case, however, we can go farther. Undoubtedly after man discovered that he could produce fire artificially he first employed it primarily as a source of heat. Only in a climate which had a distinct cold season would the incentive to its use be great. Only in a climate where there was plenty of wood and also a dry season to prepare the wood for fuel would he find it easy to use the new discovery. Moreover, only in a relatively stimulating climate would early men probably have had the energy to develop the highly laborious art of fremaking, for few things require greater determination and persistence. When some happy accident taught man the value of heat in cooking food, the discovery doubtless spread to warm regions, but it seems no great stretch of the truth to infer that tropical man, if left to himself, would never have become a user of fire.

Discovery of use of iron. One of the next great steps in human progress was the discovery of the use of iron. This discovery required the concurrence of four important conditions, all of which are much less likely to occur within the tropics than without. First, there must be bits of ore lying about where fires are likely to be made. Of course this may occur in any part of the world, but it is far less likely to happen within the tropics than farther north because the tropical soil is generally so deep that rocks are rare. In the next place the fires must be hot enough and of long enough duration to melt the ore. This, too, may occur within the tropics, but is much 


\section{I76 EVOLUTION OF THE EARTH}

less common there than in colder climates. In warm regions cooking is apt to be done over small fires that do not make people uncomfortable, or else in pits dug in the hot ashes; and the temperature is rarely high enough to melt iron ore. Farther north, however, where the winters are chilly, huge fires must have been common from the earliest times. There, too, in the fairly dry areas many stones lie on the surface almost everywhere. The next necessity is that when some bits of ore happened to be in a particularly hot fire a man of unusual genius should be present and observe the molten metal. This might occur anywhere, but we have already seen reasons for believing that quickness of intellect is fostered in some climates more than in others. Finally, the fourth requisite, and much the most important, is that the man of genius have the zeal and determination, as Darwin puts it, to bring to fruition the ideas engendered by his observations. A single mind, however, was not enough to consummate the great discovery. It was necessary that the generation of men who lived with the genius should be "in a mental mood to receive the new invention or discovery." That mood, together with the necessary energy on the part of the genius, is rarely found within the tropics. It is common in regions blessed with a stimulating climate. Thus each of the conditions controlling the discovery of the art of smelting is so much stronger outside the tropics than within them that it seems highly probable that the art arose in a stimulating extra-tropical climate. It is generally supposed that the use of iron originated in North Africa perhaps 6,000 years ago. This is eminently consistent with our conclusions. At that time, as is almost universally admitted by geologists, the climate of the world was intermediate between that of the Glacial Period and the present. Therefore North Africa was then a decidedly more stimulating place than it is today. This same line of reasoning applies to other great steps in the early development of civilization, 
for many of them were influenced by the glacial stages or minor epochs which succeeded the last glacial epoch.

Taming of wild animals. The taming of wild animals was one of these steps. The dog was apparently the first domestic animal. His contribution to civilization, however, is slight, for instead of lifting man out of the hunting stage, he preserves it. If the hunter becomes a tiller of the soil he does not want dogs, for he no longer has a frequent surplus of meat which will spoil if the dogs do not eat it. While he remains a hunter, however, the dogs not only help their master to find wild animals, but serve as a reserve supply of food in times of scarcity. Among the American Indians no delicacy was formerly more esteemed than a fat young puppy. The taming of the dog was in itself no great feat. It was easy to bring home a wild puppy, which grew up as tame as though its ancestors had long been domesticated. This, however, was the step which apparently led to the domestication of other and more useful animals. It probably did not occur within the tropics, for today the wolf-like creatures from which the dog is supposed to be descended do not appear to be found within twentyfive degrees of the equator.

Other domestic animals far surpass the dog in utility. Lowest among these stands the pig. This creature is highly useful as a source of food, but cannot easily be domesticated unless the art of agriculture is well developed, for it is not readily herded, and its food is primarily the products of agriculture rather than grass. Therefore, though the pig might have helped civilization, it never had the chance, because before it was kept in large numbers the tillage of the ground had already done all, and more than all, that the pig could do in this line. So far as climate goes it might have been domesticated almost anywhere from the equator to the temperate zone.

The horse, the ox, and the sheep stand in a different cate- 
gory from the $\mathrm{dog}$ and the pig. Aside from agriculture nothing did more than their domestication to give man that sense of ownership and feeling of responsibility which are among the most essential prerequisites of high civilization. As soon as herds were in his care, man was compelled to watch them day by day. Carelessness was fatal. He must defend them from wild animals, drive them to new supplies of grass and water, and plan to sustain them through the winter. Not only did man thus become a property owner by reason of his beasts, but he himself was able to increase in numbers to a degree utterly impossible while he still depended on the chase. Therefore the contact of family with family greatly increased. That necessitated either war and destruction, or some kind of mutual agreement whereby was laid the basis of a rudimentary social and political organization. As to the climate under which domestication of the grass-eating animals took place, it is almost certain that the horse, ox, and sheep all were first tamed in the subtropical grasslands of central Asia thirty or forty degrees from the equator. Since this occurred during the change from the last glacial epoch to the present, it presumably took place in a climate closely resembling that which we have found to be ideal. Two other animals, the llama and the camel, have been domesticated under less favorable circumstances, but neither is truly tropical. The llama of Peru lives where it is decidedly cool. The camei may frequent the hot desert, but the only known wild camels are in the deserts of central Asia where the winter temperature may be $20^{\circ}$ below zero. Neither of these animals can vie with the horse, ox, and sheep as contributors to civilization. In the case of the llama this may be due to small size, but probably in both cases a more important factor is the fact that neither animal flourishes in the kind of climate in which man is at his best.

Rise of agriculture. During the whole course of human history probably no one thing has had a greater influence upon 


\section{AND ITS INHABITANTS}

civilization than has the art of agriculture. It is impossible to say exactly where agriculture arose. Perhaps it developed in different ways in many different regions. The great staples of agriculture are the cereals-wheat, barley, rice, millet, maize, rye, and oats. The majority of these are of subtropical origin. Rice, however, which supports more people than any other one kind of food, is probably of tropical origin. The same may be true of maize. This conclusion, however, is mere guesswork, for that grain has never been found in its indigenous form. Millet, which well-nigh rivals maize in the number of people it supports, is of great importance within the tropics, but apparently it originated farther north in a subtropical climate, such as that of Egypt. The other grains all appear to have originated in regions well beyond the limits of the tropics.

Whatever may be said of the origin of agriculture, it needs little demonstration to show that its effect in advancing civilization has been far greater in relatively cool climates than in those that are warm. It is a commonplace of history that the great civilizations of early times arose in fertile plains where agriculture was carried on by means of irrigation. These were located more than twenty-five degrees from the equator, as we see in Egypt, Mesopotamia, northern India, and China. It is hard to overestimate the effect of irrigation upon the early progress of civilization. Because of the necessity of making ditches and reservoirs, and of having everything ready when the water is turned on a field, the power to prepare consciously for the distant future is enormously stimulated. The man who depends on irrigation cannot neglect his fields, for a week of carelessness may cost his whole crop. He must learn, too, to live at peace with his neighbors. If men who use the same stream for their water-supply quarrel with one another and break down one another's dams and ditches the chances are that all will suffer famine. They must 
agree, and therefore must organize a well-regulated system of government. The fact that in irrigated regions many people live close together on a small area also tends to cause society to be thoroughly and wisely organized. Moreover, the mere fact that water is precious leads to economy in its use and to intensive agriculture. Hence man's faculty for planning and for devising new schemes to increase his crops is constantly stimulated. The Hopis, whom we have already cited, are an admirable example of this. Could there be any higher development of agricultural science than their way of putting a seed into the midst of a ball of wet clay and burying it in the dry sand? The stalk of corn that grows from such a seed may be only a foot or two high, but it bears an ear with a hundred grains to replace the one grain that was planted. Irrigation, it need hardly be said, is rarely practised in tropical countries. So far as it exists there it is either a relatively late development as in Java, or is confined to the highlands as in Peru, or to certain dry regions as in India. Everywhere it is a direct response to special types of climate.

So it is with all agriculture. Its type depends upon the kind of climate. After man has reached a fairly high stage of culture the most stimulating of all kinds of agriculture appears to be that which prevails in temperate regions where there is rain at all seasons. There each farmer lives on his own independent farm. He may not have the stimulus of close contact with his neighbors which is found in irrigated subtropical regions, but he has the great stimulus of being wholly independent and of being constantly urged to meet his own needs. Moreover, he must be industrious and alert to a degree demanded of no other kind of farmer. The constant variety of weather to which he is subjected demands that he shall be ready to cut or harvest his hay instantly when the right time comes. He cannot put off cutting his grain as can the subtropical farmer, for when once it is ripe the rain may come 
and ruin it. In the fall, no matter how tired he is, he is forced to gather his crops before a sudden frost comes and spoils some of them. Thus while tropical agriculture is a help toward civilization, that which prevails in subtropical regions is far more helpful, while that of the stormy temperate zone is still more so.

Invention of ariting. We come now to the invention of writing, the great step which marks the boundary line between barbarism and civilization. Twice at least this step has been taken, once among the Mayas in Guatemala, and once in Asia. Perhaps the writing of the Chaldeans may be of different origin from that of the Chinese, although we cannot speak with certainty. At least the line of development of the western forms of writing in Mesopotamia, Egypt, and the adjacent lands, has been very different from that on the eastern side of the continent. However this may be, it seems certain that writing was invented in regions with a variable and stimulating climate, as will soon appear more fully. The invention marks an era in man's development as truly as does the discovery of the use of fire or the invention of the art of smelting iron. When man learned to speak, the individual thereby became able to avail himself of the experience of all the people around him and of many people whose experiences had been handed down in memory. When he learned the art of writing he no longer needed to trust to memory. The minds of all the ages became available to the mind of today. During the hundreds of thousands of years of the previous existence of the human race many a great man must have lived in vain, because among his immediate associates there was none to comprehend and carry out his ideas. When writing was invented, it enabled such men to spread their thoughts a hundred times more widely both in place and time. Who knows how greatly our modern discoveries are influenced by thoughts recorded by the ancient Greeks and Egyptians? 
Contribution of tropical countries. In these later days since historical records have been kept, the contribution of tropical countries to civilization has been as meager as appears to have been the case in the remote past. So far as we are aware, no truly great man except Mohammed has arisen within twentyfive degrees of the equator. Gautama, the founder of Buddhism, lived north of this limit. Moreover, his home was among the mountains where the climate is more stimulating than in the lowlands. Mesopotamia had its great men whose names are still known, but that country, though hot in summer, lies from thirty to thirty-five degrees north of the equator. So too with Egypt, for its great men almost without exception lived from Thebes northward, and the latitude of Thebes is more than twenty-five degrees north. In modern times it is even harder than in the past to find great men who lived in tropical or even in warm countries. Diaz in the high, cool, but nevertheless tropical plateau of Mexico may be cited as an example, but a hundred years from now only the special student will have heard of him, while men like Lincoln, Pasteur, and Humboldt will still be admired by thousands, yea, millions of people. Even if we go back to Mohammed as an example of a truly great man arising within the tropics, we find that his ideas came to fruition only when they were carried northward to a place where the minds of that generation were more alert than in southern Arabia.

We have now seen that civilization is today highest in places where climatic energy is also high. We have likewise seen that in the past no great steps in human progress seem to have been taken in tropical countries, nor do great men appear to have sprung up there in appreciable numbers. These considerations apparently lead to the conclusion that when the progress of human civilization is viewed in the broadest light its great movements depend upon climate almost as closely as do the pulsations of the evolutionary stream in geological times. One 
great objection, however, has hitherto seemed to controvert any such conclusion. Tropical countries may indeed have made no appreciable contribution to civilization at any time, but no later than two or three thousand years ago many countries where climatic energy is now comparatively low were the seats of the highest civilization. How was this possible? The answer is that a great mass of evidence seems explicable only on the hypothesis of pulsatory changes of climate during historic times. This evidence has been discussed so fully in other publications that it seems unnecessary to repeat it here. ${ }^{6}$ It will be enough to state the main conclusions with almost no details of proof. With these in mind we can apply them to concrete instances and see how climate appears to have been related to historic crises.

\section{Historical Changes of Climate}

During the past few decades the opinion of geographers as to historical changes of climate has followed a course almost identical with that of geologists as to earlier and greater changes. Formerly climatic uniformity was supposed to be the "normal" condition and variations were supposed to be rare and exceptional. Today geologists universally believe that glacial periods have occurred irregularly from the earliest times to the most recent, and that these have been broken into alternate glacial and interglacial epochs, while other less extreme changes have been frequent. Coming to historical times a belief in similar but smaller climatic pulsations is now almost universal among American geographers, as is indicated by

'See "The Pulse of Asia," 1907; "Palestine and Its Transformation," 1911; and "The Climatic Factor," 1914. Briefer treatments embodying further modifications of the original hypothesis, together with replies to certain criticisms, are found in "The Solar Hypothesis of Climatic Changes," Bull. Geol. Soc. America, vol. 25, 1914, pp. 477-590; in "Civilization and Climate," 1915, ch. XI ; and in "Climatic Change and Agricultural Decline as Elements in the Fall of Rome," Quart. Jour. Econ., vol. 31, 1917, pp. 173-208. 
the answer to a series of questions recently sent out by the writer. As Dr. W. D. Matthew, one of the most careful students of the matter, says, "I should demand proof before I would admit that there has been no change within 2,000 years."

The weakness of the hypothesis of climatic uniformity is indicated by a consideration of the strongest argument in its favor. It runs thus: The palm and the vine grow together only within a most limited range of temperature. Today they grow together in essentially the same places as 2,000 or 3,000 years ago. Hence no change of temperature and no change of climate. This argument is weak in two respects. In the first place, students of the Glacial Period agree that at the height of the last epoch of advancing ice, perhaps 30,000 years ago, the mean temperature of the earth was only about $10^{\circ}$, or at most $20^{\circ} \mathrm{F}$, lower than now. On that basis an historic change of climate one-tenth as great as the enormous change since the height of glaciation would mean a change of only one or two degrees in temperature, an amount too small to detect by means of vegetation. In the second place, the fact that there has been no appreciable change of temperature in historic times does not mean that there has been no change in the distribution of rainfall. The records of the United States Weather Bureau show that during the years I 875 to I 884 the region from Galveston to New Orleans had 40 per cent more rainfall than during the ten years from I 890 to I 899 . The difference in temperature between these two periods was only $0.42^{\circ} \mathrm{F}$. Curiously enough, the wet period was the warmer, although in other cases the reverse has been true. If such important changes in the distribution of rainfall can occur in our own day with almost no change in temperature, there is no reason why much larger changes may not have occurred similarly in the past. That such changes have occurred is indicated by almost innumerable waterless ruins like those which 
everywhere dot the country from Mongolia through Turkestan and Persia to Turkey and North Africa, and also in our own Southwest. In the deserts, roads too dry for caravans, but known once to have been much used, also point to a change in rainfall. So, too, do abandoned springs and the scanty supply of water in many aqueducts. One of the most significant pieces of evidence is the amount of salt dissolved in the waters of Owens Lake in southern California, and of Pyramid and Winnemucka lakes in Nevada. This, as Gale has shown, indicates that from 2,000 to 4,000 years ago these lakes must have been so high that they overflowed and were fresh. About 2,000 or 2,500 years ago Owens Lake appears to have been two and one-half times as large as now and to have stood 180 feet above its present level.

It is not enough to conclude merely that the climate of the present is different from that which prevailed 2,000 or 3,000 years ago. We must know the nature of the change. Geologists formerly thought that climatic changes proceed very slowly and uniformly in one direction. They now believe that they are highly irregular. Even when the general change during thousands of years is decidedly in one direction, it is marked by great irregularities. There is now a general conviction that the same is true of historic times. Pulsatory changes have apparently occurred whereby certain centuries have been moister than the present and others drier. No other hypothesis seems adequate to explain the fact that lakes whose waters are known to have stood many feet above their present level also contain ruins buried beneath their waters. Equally strong evidence is afforded by the fact that the growth of the big trees of California indicates constant pulsations whose main features agree with those inferred from other kinds of evidence in Mediterranean regions and central Asia. In our own day exact records show an unmistakable harmony between spring rainfall and tree growth in California on the 


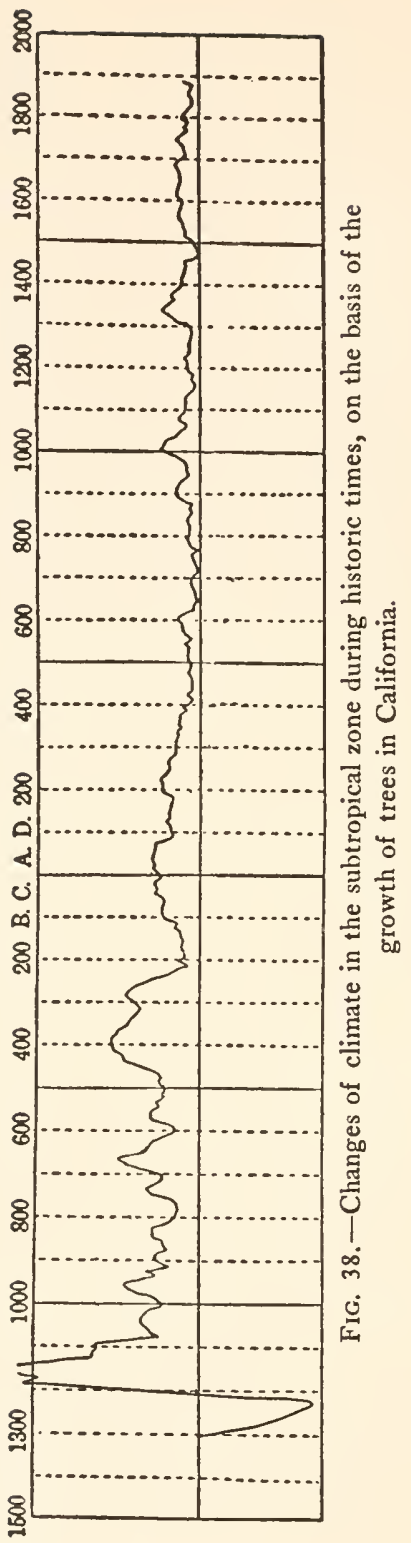


one hand, and Mediterranean rainfall on the other. Hence it seems legitimate to infer that the main fluctuations in tree growth, which are portrayed in Figure 38 , represent climatic pulsations of world-wide extent.

Even yet we have not fully explained the nature of climatic changes. They appear to have been not only pulsatory, but to have produced different effects in different parts of the world. It is an interesting coincidence that independently and on wholly different lines of evidence the German glaciologist, Penck, and the writer at almost the same time announced the conclusion that climatic changes are the result of an alternate equatorward and poleward shifting of the climatic zones. The matter seems to be even more complicated than this, however, for changes in the interior of continents seem to be different from those on their borders or over the oceans. The net result is that when such regions as the subtropical zone which embraces California and the Mediterranean lands enjoy unusually abundant rainfall, the northern border of the zone of equatorial rains becomes drier. The chief basis for this conclusion, so far as historic times are concerned, is the fact that the Maya ruins in the dense forests of Central America seem to indicate periods of relative dryness at the times when tree growth in California indicates unusual moisture, and vice versa.

One more point needs emphasis if we would understand the nature of these pulsatory shiftings of the climatic zones. Apparently the most essential feature is a change in the tracks of storms. At certain periods the total number of storms appears to increase. Of even greater importance, however, is the fact that at such times the storms show a tendency to follow two belts instead of the one to which they are now largely confined. The present belt of storms is well known. From British Columbia it runs as a band hundreds of miles wide centering along the international boundary line, but with a 
southward tendency. Its center sweeps across the Great Lakes, and then swings northeastward down the St. Lawrence River to the Atlantic south of Newfoundland. It crosses the Atlantic to Europe, where it splits up, and almost dies out in Siberia and central Asia. On the eastern border of Asia it is joined by an important and vigorous branch from Japan, and then skirts the Pacific coast of North America to British Columbia. Its course may be judged from Figure 34, where in general the dark areas of high energy are also stormy areas. The other, or minor storm belt, appears to start in California, cross Arizona and New Mexico to the Gulf of Mexico, and then swing northeastward into the Atlantic Ocean. In the Old World its course lies along the Mediterranean, beginning apparently east of Spain. Beyond the Mediterranean it passes across Syria to Mesopotamia and Persia, and then in an attenuated form to India. It probably revives again in China and joins the strongly developed Japanese area of storms. In the past, at times when rainfall has been abundant in Mediterranean lands, many storms appear to have followed this southern belt. Thus increased rainfall and increased variability occurred during certain centuries, while the opposite occurred in others. The centuries which saw increased rainfall in the subtropical belt saw decreased rainfall farther south in places like Yucatan, on the northern border of the torrid zone, but with this decreased rainfall also went greater variability because of the storms whose centers passed a little farther north. Hence it appears that not only in our own day, but throughout historic times the highest civilization has been found in the regions of greatest climatic energy.

The possible exceptions to this conclusion are the areas of high civilization within twenty-five degrees of the equator. These include Central America, the highlands of Peru, Yemen and Rhodesia, Indo-China, and some of the East Indies like Sumatra and Java. None of these places, however, made any 
great impression on the world. In the plateaus of Peru, Yemen, and Rhodesia, civilization took a few steps and then halted. This corresponds closely with their climate. In mean temperature and humidity they are admirable. Therefore to that extent they are stimulating. A competent race migrating to any one of them would be invigorated and would be led to make important advances. There is no evidence, however, that any of them ever enjoyed any great degree of climatic variability due to strong seasonal changes and frequent storms. Therefore they lacked the stimulus needed to keep them steadily progressing.

The only tropical center of civilization which developed any really remarkable ideas was Central America, where the Mayas evolved a decidedly high type of architecture, a remarkably accurate calendar based on extensive astronomical knowledge, and a system of writing more advanced than that which the Chinese have even yet attained. It is perhaps significant that the center of Maya culture in Yucatan and Guatemala lies in the longitude where storm tracks today swing farthest south and where they apparently swung much farther south in the past. To this day the Yucatecan descendants of the Mayas say that they work fastest when the temperature is lowered by the "northers" which follow in the wake of storms whose centers pass farther north. In the past such northers were apparently much more frequent than now. Hence it looks as if the relatively active Maya civilization were associated with variability just as are the high civilizations of today. ${ }^{7}$

As to the cultural center in southeastern Asia, we cannot speak with much certainty. It never showed anything like the originality of the Central American center, for most of its ideas were borrowed from places farther north. It did not

'This subject is fully discussed in the author's volume, "The Climatic Factor." Pub. No. 192, Carnegie Institution of Washington. 
last so long as the other. It is worth noting, however, that its relation to the continent of Asia is almost the same as the relation of the Maya civilization to the continent of America. There is some reason to think that when the southern storm belt was intensified even this region, like its American counterpart, may have had a more variable climate than at present.

Effect of climate upon Roman history. The history of Rome furnishes a good example of the way in which climatic changes appear to influence the march of history. ${ }^{8}$ The golden age of Rome occurred 400 or 500 years B. C. In the fourth century B. C., as appears in Figure 35 , storms and rainfall seem to have been abundant in subtropical lands like California and Italy. In Rome five acres of land was then considered enough to support an average family, although this presumably does not include the land used for pasturage. Cultivation, as we know from numerous classical accounts, was highly intensive, so that the most advanced methods of agriculture were developed. The crops rarely failed and there was widespread prosperity. The farmers were independent and sturdy, and the difference between rich and poor was slight. The towns were small and the conditions were all highly favorable to a strong democratic form of government.

Turning back to Figure 35 we see that during the third century B. C. there was a marked diminution of rainfall. In Rome this was accompanied by two occurrences of sinister omen. One was a serious decline in agriculture. The small tracts of land which had hitherto been the rule were no longer large enough to furnish a living for the farmer and his family. Crops that had previously been profitable ceased to be worth while. Hence there arose much discontent and the agrarian troubles with which the names of the Gracci are closely asso-

${ }^{8}$ See Simkhovitch, V. G., "Rome's Fall Reconsidered," Pol. Sci. Quart., June, 1916; and Huntington, Ellsworth, "Climatic Change and Agricultural Exhaustion as Elements in the Fall of Rome," Quart. Jour. Econ., vol. 31, 1917, pp. 173208. 
ciated. The other sinister event was an increase in malaria, which Jones $^{9}$ has shown to have played an important part in diminishing the vigor of both the Greeks and Romans. Its increase was apparently due to the fact that the decline in rainfall caused a diminution in the amount of vegetation on the mountains. Hence the streams washed down an undue amount of silt which filled up their beds in the lowlands and caused them to wander widely and form great swamps. These were ideal breeding places for the anopheles mosquito which is the carrier of malaria.

After the period of depression in the second century B. C., Rome recovered somewhat during a period of favorable climate culminating about the time of Christ. Yet she never was quite restored to her former energy and glory. A century or two later, in the early part of the Christian era, there began a climatic decline which culminated in the seventh century. Since crops were no longer profitable, the land was used for grazing purposes, the methods of agriculture became slipshod and unprofitable, and the farms fell into the hands of a few large owners. The great number of sheep and goats not only added to the difficulties of agriculture by their ravages upon the fields, but ate up the seedling trees and thus prevented the growth of new forests. Hence the soil was washed away from the hillsides, with distressing consequences.

With this agricultural decline there arose political diffculties. Taxes which had previously been easily paid became onerous. Agrarian reforms were even more necessary than in the days of the Gracci, but they were much harder to make. The people flocked to the city in order to get work and thereby share in some of the wealth which came to Rome because of her conquests. This, however, only increased the evils. Democracy gave place to plutocracy, and thus to despotism. At this same time the nomads in the drier parts of the lands

9 Jones, J. H. S., "Malaria, a Neglected Factor in History." 
surrounding the Roman Empire were also suffering from drought and famine. Therefore they began to make raids, which set more prosperous people also into motion, and soon barbarian invasions threatened the very existence of the Roman Empire. If the climate had remained favorable there might have been an occasional raid, but there is no reason to think that there would have been the great disasters which finally became so terrible.

Worst of all, the climatic changes seem to have had a sad effect upon the energy of the Romans themselves. We have already seen how close is the connection between climate and energy. As the variability of the Italian climate decreased because the storms diminished in number, the energy of the people seems also to have declined. This was particularly unfortunate because special energy was needed to resist the ravages of malaria, to overcome the agricultural difficulties, to engender the self-control and patience which are essential when political difficulties arise because of undue taxation or other causes. Most of all, energy was needed to resist the invasions of barbarians, but instead of this the people's energy declined. They became prone to sit still and wait for someone to feed them, prone to think only of pleasure, and hence ready for the disaster which finally overtook the Roman Empire.

It would be interesting to carry this discussion farther and see how these same principles apply to almost every country. It is easy to attribute too much to climate, and I am well aware that many of my hearers will think that $I$ have done so in this lecture. It must be remembered, however, that this is merely a brief attempt to show the importance of one of the great factors in the evolution of civilization. The fact that the importance of climate is here emphasized does not mean that I deem it a whit more important than the other factors. So far as inherent mental capacity is concerned climate is in one sense a minor factor. It is more important as regards material 


\section{AND ITS INHABITANTS}

resources, but is far from being the sole factor. Even where energy is considered, the effect of climate may readily be neutralized by several other factors such as lack of resources or lack of ability. The point to be emphasized is that climatic energy is one of the great factors which must be reckoned with in any attempt to understand the evolution of civilization. Hitherto, its importance has not been realized. Therefore today we must emphasize it until it takes its true place with inherent mental capacity and material resources. It is not a determiner of civilization, but a condition which prevents civilization from advancing in some places and stimulates it to the greatest activity in others. Without an understanding of its part in human evolution we cannot rightly comprehend our own present development in any of the great branches of human progress. 



\section{INDEX}

Activity, mental, optimum temperature for, 172

physical, optimum temperature for, 172

Adelochordates, 117

Africans, 148, 149

Agriculture, 153, 154, 177, 178, 180

Air currents, changes in, 73

Alaska, coal in, 155

Alchemists, 82, 95

Algæ, 63, 113

Allantois, 126, 128

Allen, F. J., 101

Allosaurus, 133

a Centauri, 7, 8

Alps, rise of, 74

Alumina, 100

Alveolar substance, of protoplasm, 83

Amblypods, 134, 136

American Indians, 148, 151, 153, 177

Amino acids, 85

Ammonia, 99, 102

Ammonites, 73

Ammonium carbonates, 107

Amnion, 126, 128

Amphibia, 125

origin of, 65,111

Amphioxus, 117

Animals, domestic, 177, 178

lime-secreting, 113

wild, taming of, 177

Ankylosaurs, 132

Annelids, 113

Apes, anthropoid, 139, 141

origin of, 111

Appalachian Mts., 78

revolution, 111, 127

trough, 78

Arabians, 150
Arboreal habitat, forsaking of, for terrestrial, 142

Archæocyathinæ, 113

Archaopteryx, 129, frontispiece

Archean, beginning of, 43

Archeozoic era, 46, 49, 50, 56, 63

era, time ratio of, 69

sediments, thickness of, 63,67

Arctic climate, effect of, on man, 149

Aridity, 123, 126, 127, 129, 136

Devonian, 143

Miocene, 143, 146

Mississippian, 145

Permian, 145

Pliocene, 143

Aristotle, 86, 89, 91

Arrhenius, S., 97, 98

Arthropods, 114

Asia, as home of domestic animals, 178 as primitive home of man, 149

as theater of mammalian evolution, 142

Asteroids, see planetoids

Asthenosphere, 41

Athenians, 147

Atmosphere, 54, 57, 75, 80

in Archeozoic, 63

of growing earth, 51

of water-gas, 35

origin of, 50

primordial, 34

Atmospheric blanket, of earth, 54

Atoms, 100, 101, 102

Australians, native, 150

Azoic era, time ratio of, 69

Bacteria, 96, 97

Baker, H., 91

Balanoglossus, 117 
196

Barbarism, 152, 154

Barrell, J., 47, 49, 50, 56, 67, 69, 110

Beans, 154

Bees, 90

Beetles, 90

Belgium, optimum temperature in, as shown by death-rate, 167-169

Bichat, M. F. X., 86

Biochemists, 85,95

Biogenesis, history of, 89

Biology, 82

Bipedality, cause of, 129, 130

Birds, evolution of, 127

first recorded, 111, 129

origin of, 111, 128, 145

toothed, 65,129 , frontispiece

Blainville, D. de, 86

Boleophthalmus, 120

Brachiation, 140

Brachiopods, 113

Breaks, geologic, 70, 71

Brontosaurus, 130

Browne, Sir Thomas, 90

Browsing mammals, origin of, 111

Buffon, Comte de, 92

Butterflies, 90

Cacops, 125, 126

California, agriculture of, 153

deaths in, 158, 161, 164, 165

Indians of, 152, 153, 154

rainfall in, 187

rate of growth of big trees in, 185, 186

southern, climate of, 166

storms in, 166

Cambrian period, 46, 79, 111, 113, 118

Camels, 74, 136, 137, 178

Campbell, W. W., 11, 21

Canadian period, 76

Carbohydrates, 84

Carbon, 75, 102

compounds, 100
INDEX

Carbon dioxide, 34, 35, 38, 44, 50, 51, $52,54,57,102,104,105$ dioxide, as climate regulator, 52 dioxide, in Archeozoic, 63 dioxide, resupply of, through volcanoes, 52

monoxide, 34, 35

Carbonic acid, 99

Cardan, G., 89

Carnivores, 136

Cascadian revolution, 110, 111, 146

Catalysis, 104

Cells, 87, 94, 102, 105, 106

potential immortality of, 98

Cenozoic era, 46, 65, 73, 74, 76, 79, 110,111

era, time ratio of, 69

sediments, thickness of, 65,67

Central America, 187, 188, 189

Cephalopods, 114, 115

Ceratopsia, 132

Cereals, 179

Cetacea, 115

Chaldeans, 181

Chalks, 58

Chamberlin, T. C., 21, 24, 25, 47, 51, 116,119

Chamberlin and Moulton, on the nebular hypothesis, 12 planetesimal hypothesis of, 13,46

Chazyian period, 76

Chemical elements, essential to life, 105

Chimpanzee, 139, 140, 142

China, 179

Chinese, 181

Chlamydosaurus, 130

Chordates, evolution of, cause of, 116 first recorded, 119

origin of, according to Chamberlin, 119

Cincinnati uplift, 62

Cincinnatian period, 76 
Civilization, distribution of, 173

evolution of, 147, 174

high, a reas of, 188

Civilizations, early, 179

Clarke, F. W., 52, 54, 56

Climate, arctic, effect of, on man, 149 as factor in racial differences, 148 changes in, $53,78,80,111$

changes in, as cause of extinction, 131

changes in, causes of, 187

changes in, effects of, 187

changes in, evidences for, 184, 185

changes in, historical, 183, 186

Cretaceous, 55, 132

effect of, on clothing, 154

effect of, on death-rate, 158

effect of, on discovery of use of fire, 175

effect of, on energy, 156

effect of, on food, 154

effect of, on man, 153

effect of, on materials for shelter, 154

effect of, on Roman history, 190

Eocene, 55

Liassic, 55

Permian, 51, 55, 127, 129, 145

Pleistocene, 55, 66, 110

Proterozoic, 51, 55

Silurian, 55

Triassic, 55

tropical, effect of, on man, 149

Climates, ancient, 51, 52, 55

glacial, $55,66,73,110,127,143$

Climographs, 159-161, 168, 169

Clothing, dependence of, on climate, 154

effect of, on energy, 156

necessitated by Glacial period, 143

Coal, 65, 66, 155, 174

Colenterates, 113, 114

Cold, increase in, influence of, 127
Collisions, among planetary nuclei, 33 among stars, 23

Colloidal suspension, life elements in, 106

Colloids, 100, 101

characteristics of, 101

Comanchian period, 46, 76, 79, 111, 131,145

Communal life, 144

Complexification, in matter, 100

Complexity, law of, 101

Condylarths, 134, 136

Conglomerates, 58

Conifers, 65, 73

Connecticut Valley footprints, 130

Continents, areal variability of, 78

elevation of, 71, 73, 75, 136

in Archeozoic, 63

origin of, 49

permanency of, 50

when largest, 73,76

Convection currents, 35,37

Coördination, biochemical, 106

Corals, 114

Coryphodon, 136

Cosmic time, 46, 47

Cosmozoa theory, 95

Crabs, land, 120

Creator, 108

Creodonts, 135

Cretaceous period, $46,76,79,111,132$, 145

period, climate of, 55,132

period, in North America, 77

Critical periods, 73, 81

Crocodiles, 131

Croixian period, 76

Crops, of early Americans, 154

Crossopterygii, 122

Crust of earth, granitic, 34

Crustaceans, 120

Crustal density, relation of, to ocean basins, 39

Crystallization, fractional, 37 
I 98

Crystalloids, 101

Crystals, basic, 37

Culture, centers of, 188, 189

Cyanogen, 99

Cycads, 65, 73

Cyclostomes, 120

Cynodonts, 128

Cysts, 96, 97

Daly, R. A., 32

Dana, J. D., 50, 69

Darwin, C. R., 108, 155

Death-rate, cause of differences in, 163 effect of storms on, 166 effect of temperature on, 164

Deaths, statistics of, $158,159,160,161$

Deer, 136, 137

Denudation, 58 rates of, 59

Deposition, rate of, 68

Deposits, cycles of, 58 glacial, 54, 56

organic, 58 salt, 32

Derham, W., 91

Deserts, 73, 185

effect of, on man, 150

Devonian, Lower, 123, 144

period, 46, 76, 79, 111, 122

period, aridity in, 143

period, diastrophism in, 122

Upper, 145

Diastrophism, 50,110, 118, 133

Devonian, 122

Miocene, 146

Mississippian, 125

Pennsylvanian, 127, 145

Silurian, 122, 144

Diaz, 182

Dinocerata, 136

Dinosaurs, 73

ankylosaurs, 132

armored, 130, 132

associated with peneplanation, 133

\section{INDEX}

Dinosaurs, bipedal, 129

carnivorous, 130, 132

Ceratopsia, 132

duck-billed, 132

effect of, on mammals, 133

evolution of, 145

expansion of, 145

extinction of, 131, 132, 134

nodosaurs, 132

origin of, 111, 129

Sauropoda, 111, 130, 132, 145

Stegosauria, 130

Theropoda, 130

trachodons, 132

una rmored, 132

Diplocynodon, 133

Diplodocus, 130

Dipnoans, 121, 122

Disruption hypothesis, of Chamberlin and Moulton, 46

Disturbances, 70

Dog, 177

Double-breathing, 120

Dromocyon, 135

Earth, 105

age of, 57

as a planet, 5

atmospheric blanket of, 54

crustal readjustments in, 78

diameter of, 48

effect of moon on, 28

effect of, on moon, 30

evolution of, 45,94

granitic crust of, 34

growing, atmosphere of, 51

-growth, by rapid infall of planetoids, 25

-growth, by slow accretion of planetesimals, 24

-growth, in Formative era, 47

internal heat of, 48,49

-moon knot, 19

negative areas in surface of, 50 
Earth, origin of, 46

outer shell of, 40

passage of, from molten into rigid state, 36

place of, in universe, 4

positive areas in surface of, 50

primordial molten state of, 26, 33

readjustments in, 70,71

shrinkage of, 48, 70,71, 80, 109

sub-crustal shell of, 40

tidal strains in, 30

warping of, 70, 109

Echinoderms, 114

Eels, 90

Efficiency, effect of climate on, 156

Eggs, 126

Egypt, 90, 97, 179, 181, 182

Elephants, see Proboscidea

Energy, as factor in human progress, $147,155,173,174,192$

distribution of, on basis of climate, 173

electric, of chemical elements, 105 heat, 105

to what due, 156

"Energy traffic," 85, 102

England, iron in, 155

Englishmen, 148

Environment, changes in, 73

fitness of, 88

Enzyme theory, of Troland, 103

Enzymes, autocatalytic, 103

catalytic power of, 104

evolution of, 106

Eocene time, 46, 111, 137, 138, 145, 146 time, climate of, 55

Eopaleozoic time, 79

Epi-Proterozoic interval, 119

Eras, duration of, 67, 68

Erosion, 32, 40, 54, 56, 57, 58, 60, 70, $76,78,110$

Erpetoichthys, 122

Eskimos, 151

Europeans, modern, 154
Evolution, 73, 98

crises of, 112

cycles of, 80,81

organic, 101

Fats, 84

Finland, optimum temperature in, as shown by death-rate, 167, 169

Finns, 169, 171

Fire, discovery of use of, 174,175

life derived from, 99

Fish forms, 116

Fishes, 81, 89, 119, 123

Age of, 46

origin of, 65

Flight, true, evolution of, 128

Floras, origin of, 65

Flying dragons, 73

Food, dependence of, on climate, 154, 155

effect of, on energy, 156

use of fire in cooking, 175

Foot, reptilian, 124

terrestrial, evolution of, 123

terrestrial, origin of, 111

Footprint, earliest known, 123, 124, 144

Footprints, Connecticut Valley, 130

Upper Triassic, 129

Formative era, 46, 47, 49, 50

era, earth-growth in, 47

era, volcanism in, 48

Fossils, 59

living, 81

France, deaths in, 160, 164, 165

Gabbro, 39

Gadow, H., 131

Galaxy, see Milky Way

Gale, H. S., 185

Galton, F., 147

Ganoids, 122

Gautama, 182 
200

Geikie, A., 76

Generation, æquivocal, 91

spontaneous, 90, 91

Geologic column, 60, 67

history, 108

record, 70

time, eras of, 63

time, length of, 80

time, ratios of, 69

time-table, 45

Geosynclines, 61, 62

Germany, optimum temperature in, as shown by death-rate, 167

Gibbon, 139, 140,141, 142, 144

Gills, 120

Glacial deposits, 54, 56

period, 46,184

period, effect of, on man, 149

periods, 55, 183

Gorilla, 139, 140, 142

Grand Canyon revolution, 111, 118

Granite, 37, 40, 49, 75

Graphite, 63, 113

Grasses, expansion of, 136

used for food by man, 143

Gravitation, 97

Grazing mammals, expansion of, 137 mammals, origin of, 111 mammals, rise of, 136

Greece, 147, 175

Greeks, 89, 191

Habitats, organic, variability in, 78

Hands, as organs of the mind, 143

Haughton, S., 69

Health, best climatic conditions for, 158

effect of storms on, 166

Helmholtz, H. L. F. von, 10, 96, 98

Helmont, J. B. van, 90

Henderson, L. J., 88

Herds, 178

Himalayan uplift, 146

Himalayas, 74
INDEX

Holmes, A., 52, 57, 60, 61

Homo (Eoanthropus) dawsoni, 142

Hopi Indians, 152, 154, 180

Hornets, 90

Horses, 74, 136, 137, 177, 178

Hottentots, 150

Human progress, factors in, 147

Humboldt, A. von, 182

Hunters, 151, 154, 177

Huxley, T. H., 54, 107

Hydrogen, 102

Hydrosphere, 50, 51, 55, 63, 75

Hylobates lar, 144

Ice age, Permian, 51

age, Proterozoic, 51

Igneous rocks, 43, 75

rocks, as source of oceanic salts, 56

rocks, erosion of, 32

Imagination, scientific, 106

Impact, effects of, 28

India, 179

irrigation in, 180

Indian corn, 154

Indians, American, 148, 151, 153, 177

California, 152, 153, 154

Hopi, 152, 154, 180

New Mexico, 152

Pueblo, 152, 154

Utah, 152

Ute, 152, 153, 154

Indo-China, 188

Infusions, organic, 93

sterilization of, 92

Insectivores, 136

Insects, 73,89

Intervals, time, 71, 73

Invertebrates, distinguished from vertebrates, 114

evolution of, 114

Iron, 155

compounds of, 102

discovery of use of, 175

limits to use of, 155 
Irrigation, 153, 154, 179, 180

Irritability of living matter, 95

Isostasy, 40, 41

Italy, deaths in, 158, 160, 164, 165

Japan, optimum temperature in, as shown by death-rate, 167

Japanese, 149, 169

Java, 188

irrigation in, 180

Jefferson, Thomas, 74

Jelly-fishes, 114

Johnston and Williamson, 52

Jupiter, 5, 6, 31

Jurassic, Lower, 145

period, 46, 76, 79, 111, 130, 131

Upper, 127, 129, 145

Juvenile waters, 38,75

Kankakee uplift, 62

Kant, hypothesis of, concerning evolution of solar system, 10

Kelvin, 96

Kircher, 90

Labrador, fishermen of, 152

Lamprey, 116

Land-bridges, 73, 74, 138

Land waters, as place of chordate origin, 119

Lands, contributions of, to oceans, 61 elevation of, 70,109,110, 111

Lane's law, 15

Laplace, P. S. de, 10, 50

Laramide revolution, $111,132,134,145$

La Tour, C. de, 93

Laurentian peneplain, 118

Lava, 2, 38, 44, 75

Lavas, of moon, 43

Proterozoic, 64

Law of Complexity, 101

Lehman and Pedersen, 172

Leith and Mead, 60

Lepidosiren, 122
Leverrier, U. J. J., 27

Lewes, 86

Lias, climate of, 55

Life, 88

ancient, 59

Archeozoic, 63

as manifestation of protoplasmic activity, 82

changes in, 73

chemical elements essential to, 105

chemical elements of, grouping of, 105

communal, 144

cycles in, 73

definitions of, 85

dormant, 97

elements, coördination of, 105

elements, grouping of, 105

elements, in colloidal suspension, 106

evolution of, 64

fresh-water record of, 59

land record of, 59

marine, increase in, 78

marine, record of, 59

materials at basis of, 51

origin of, $63,82,94,112$

paleontological record of, 93

pulse of, $81,109,111,144,146$

scientific explanation of, 95

thermometers, 55

transportation of, through space, 96

vehicle of manifestations of, $\$ 5$

Light, radiation pressure of, 97

Lightning, 102, 103

Limbs, change in, in primates, 143

Lime-secretion, establishment of, 113

Limestones, 58, 60, 61, 67, 68

Lincoln, A., 182

Lithosphere, 41, 49, 50, 75, 76

density differences in, 41

Lizards, bipedal, 130

frilled, 130

Llama, 178

Locusts, 90 
202

Loeb, J., 98

Loligo, 115

Los Angeles, deaths in, 158, 161 rainfall at, 153

Lucretius, 89

Lull, R. S., 148

Lung-breathing, first recorded, 123 place of origin of, 121

Lung-fishes, 121, 122 first recorded, 144

Lungs, development of, 144 of higher vertebrates, 120 origin of, 111

\section{Maggots, 90}

Magmas, 2, 34, 37, 38, 39, 40, 42, 43, 44 Maize, 179

Malaria, 191

Mammals, 65, 73, 81

Age of, 46

archaic, 111, 134, 135, 136, 145

browsing, origin of, 111

evolution of, 127, 145

expansion of, 134

fate of, 136

first recorded, 111, 127

grazing, rise of, 111, 136, 137

modernized, 135, 145

modernized, origin of, 111

modernized, source of, 135

origin of, 111, 128, 145

placental, 126

rise of, 133

Man, Age of, 45

best climatic conditions for, 158

brute-, 74

dominance of, over organic world, 144,146

increase of, dependent on domestic animals, 178

origin of, 111,137

physiological adjustment of, to climate, 156

reasoning, 74
INDEX

Man, response of, to climate, 157, 171 rise of, 146

Mars, 5, 27, 31

Material resources, as factor in human progress, 147, 151, 152, 154, 155, 174,193

resources, limited by climate, 155

Matter, complexification in, 100

evolution of, 106

living, irritability of, 95

Matthew, W. D., 117, 184

Mayas, 181, 187, 189

Mediterranean lands, iron in, 155

lands, rainfall in, 187, 188

peoples, 169, 171

Membranes, extra-embryonal, 126, 128

Mental activity, optimum temperature for, 172

alertness, a manifestation of energy, 156

alertness, effect of lack of material resources on, 150

capacity, as factor in human progress, $147,148,174,192$

Mentality, 81

Mercury, 28

Mesopotamia, 179, 181, 182

Mesozoic era, 46, 65, 73, 76, 78, 79, 111, 132,133

era, time ratio of, 69

sediments, thickness of, 65,67

Meteorites, 33

Meteors, 27, 97

Miacidæ, 136

Mice, 90

Microcosm, organism as, 88

Milky Way, 8

Millet, 179

Mining, 153

Miocene time, 46, 111, 136, 138 time, a ridity in, 143,146

time, diastrophism in, 142, 146

Mississippian period, 46, 76, 79, 111, 125,145 
Mississippian period, aridity in, 145 period, diastrophism in, 125

Mohammed, 151, 182

Mohawkian period, 76

Molecules, 84, 100

Molluscs, 114, 120

Molten stage, in earth's history, 26, 33

Mongolia, 185

Mongoloid races, 171

Monotremes, 127

Moon, 2, 5, 13, 28, 30, 33, 43

effect of earth on, 30

effect of, on earth, 28

in Archeozoic, 63

Moon-knot, 47

Moore, B., 100

Moulton, F. R., 12, 18, 19

Mountain-making, 53, 70, 78, 109

Mountains, 71

cycles of, 60

origin of, 48

Muds, 58, 60

Mud-skippers, 120

Mudstones, 58, 61, 67, 68

Mutants, 148

Nature, uniformity of, 45

Nebulæ, 8

irregular, 8

planetary, 8

ring, 9

solar, 21,47

spiral, 8, 9, 13, 18, 20, 21, 47

stellar, 9

Nebular hypothesis of Laplace, 10

hypothesis of Laplace, modifications of, 11

Needham, T., 92

Negative areas, in earth's surface, 50

Negroes, American, adaptation of, to climate, 171

death-rate of, $164,168,169,171$

effect of tropical climate on, 149

Neoceratodus, 121, 122
Neogene time, 79

Neopaleozoic time, 79

Neptune, 4, 5, 6

Neutral medial area of North America, 62

New Mexico, Indians of, 152

New York City, death-rate in, 171

Newfoundland, fishermen of, 152

Nitrogen, 44, 102, 103

compounds, 104, 105

in primordial atmosphere, 34

Nodosaurs, 132

Nome land-bridge, 74

Nordics, 149, 169, 171

North America, in Paleozoic time, map of, 62

North Carolina, death-rate in, 171

Nuclei, planetary, 19, 33

Nythosaurus larvatus, 128

Oceanic basins, 43

basins, in Archeozoic, 63

basins, increase in volume of, 39

basins, origin of, 39,49

basins, relations of crustal density to, 39

currents, 54

currents, changes in, 73

floodings, 61, 71, 75, 76, 79

floodings, Cretaceous, 77

floodings, Pennsylvanian, 66

floodings, Silurian, 72

level, inconstancy of, 76

salts, 31, 50, 56

waters, gathering of, 37

waters, increase in volume of, 50

waters, origin of, 55

Oceans, carbon dioxide in, 52

increase in area of, 78

origin of, 37

when smallest, 73

Oligocene time, 46, 111, 135, 136, 145

Orang, 139, 140, 142

Orbits, planetary, 5, 19 
Ordovician period, 46, 79, 111, 113, 119,144

Organic deposits, 58

habitats, areal variability in, 78

Organism, 105

Organisms, bionomic relations of, 108 individuality of, 87

origin of, 106

Orion, 8

Osborn, H. F., 104

Ostracoderms, 119

origin of, 111

Over-specialization, indications of, 131

Owens Lake, 185

Ox, 177, 178

Oxalates, 107

Oxides, 100

Oxygen, 44, 51, 102

importance of, for life, 92

in primordial atmosphere, 34

Ozark uplift, 62

Paleogene time, 79

Paleogeography, 66, 72, 77

Paleozoic era, 46, 64, 65, 76, 78, 79, 111,127

era, North America in, 62

era, time ratio of, 69

sediments, thickness of, 65,67

Palms, 184

Panama land-bridge, 74

Pasteur, L., 93, 182

Patten, W., 119

Peabody Museum of Yale University, 123,133

Penck, A., 187

Peneplanation, 76

Pennsylvanian period, 46, 66, 76, 79, 111,127

period, diastrophism in, 127, 145

period, North America in, 66

Periodicity, 70, 75

Periophthalmus, 120
Permian period, 46, 76, 79, 111, 127

period, aridity in, 145

period, climate of, $51,55,127,129$, 145

Persia, 185

Peru, 180, 188, 189

Petromyzon, 116

Pflüger, E., 99

Phasic activity, 100

Phenacodus primcevus, 136

Phosphates, 107

Physical activity, optimum temperature for, 172

Pig, 177

Planetary nuclei, 19, 33

system, 47

Planetesimal dust, 25 hypothesis, 13, 101

hypothesis, outstanding difficulties of, 20

material, 32

Planetesimals, 35, 47 earth-growth by slow accretion of, 24

Planetoids, 4, 5, 26, 28 earth-growth by rapid infall of, 25 significance of, 26

Planets, 4, 5, 13, 18, 19, 24, 28, 31 relations of, 5,6

Plants, flowering, 65, 73 herbaceous, 136 lime-secreting, 113

Pleiades, 8

Pleistocene time, 46, 111, 138 time, climate of, $55,66,110$

Pliocene time, 46, 111 time, aridity in, 143

Polypterus delhezi, 122

Positive areas, in earth's surface, 50 areas, in North America, 62

Posture, erect, assumption of, 143

Primates, 136, 137, 143

American, 137

descent of, from trees, 143, 146 
Primates, distribution of, 138, 139

Eocene, 137

European, 138

evolution of, 146

origin of, 111

radiation of, 137, 138, 142

Proavian, 129, frontispiece

Proboscidea, 74, 136

Proteins, 84, 85, 99, 100

Proterozoic era, 46, 113, 118, 144 era, climates of, 51,55

era, time ratio of, 69

lavas, 64

sediments, thickness of, 64,67

Protochordates, 118

Protoplasm, 82, 88, 99, 100, 105

alveolar substance of, 83

chemical characteristics of, 84

combinations of elements in, 84

lability of, 85

living, evolution of, 107

physical characteristics of, 83

variation in, 87

Protopterus, 121

Protozoa, 96, 97, 113

Psychozoic era, 45, 66

Pueblo Indians, 152, 154

Pulse of life, 81, 109, 111, 144, 146

Pumpkins, 154

Pyramid Lake, 185

Rabl, C., 123

Racial differences, causes of, 148

Radioactive elements, 42

minerals, rate of disintegration of, as basis for computing geologic time, 67, 68

Radiola ria, 113

Rain, 54

first, on earth, 37

Rainfall, 153, 154, 184

Ranodon sibericus, 124

Recrystallization, 40

Redi, F., 90, 91, 92
Reptiles, 65, 73, 81, 132, 145

Age of, 46

foot of, 124

origin of, $65,111,125$

Revolutions, 71

Rhinoceroses, 136

Rhodesia, 188, 189

Rhythms, in solar energy, 109

Rice, 179

Richter, 96, 98

Rivers, 54, 57, 76

Rocks, acidic, 49

basaltic, 49

basic, 49

granitic, 49

sedimentary, 57, $61,67,68$

stratified, composition of, 60

Rodents, 136

Roman history, effect of climate on, 190

Ross, 90

Sacramento, deaths in, 158,161

Salamander, foot of, 124

Salt deposits, 32

evidence of, for climatic change, 185

oceanic, derivation of, 32

oceanic, significance of, 31

Salt Lake City, rainfall at, 153

San Diego, deaths in, 158, 161

San Francisco, deaths in, 158, 161

Sandstones, 58, 60, 61, 67, 68

Santa Fé, rainfall at, 153

Satellites, 6, 19

Saturn, 5, 6, 31

Sauropoda, 111, 130, 132, 145

characteristics of, 131

Savagery, 152, 154

Schäfer, E. A., 98

Schuchert, C., 110

Schwann, 93

Scorpions, 90

Sea-anemones, 114 
Sedimentary rocks, distribution of, 61 rocks, origin of, 57 rocks, thicknesses of, 61, 67, 68

Seeds, 97

Selection, natural, 106

Sharks, 120

Sheep, 177,178

Shellfish, 90

Shelter, dependence of, on climate, 154 effect of, on energy, 156

Silica, 100

Silurian period, 46, 76, 79, 111, 122, 123 period, climate of, 55

period, diastrophism in, 122, 144

' period, North America in, 72

Sloths, fossil, 74

Snails, 90

Snow, 54

Socrates, 151

Soil, 155

Solar energy, 102

energy, rhythms in, 109

prominences, 16

system, elements of, 5

system, Kant's hypothesis of evolution of, 10

system, Laplace's theory of origin of, 10

system, plantesimal hypothesis of origin of, 13

Sollas, W. J., 60

Space, interstellar, transportation of life through, 96

Spallanzani, L., 92

Speech, invention of, 174

Spencer, H., 86

Sponges, 113, 114

Spontaneous generation, 90, 91

Spores, 96, 97, 98

Squids, 73, 114, 115

Star streams, 7

Stars, 6, 13, 15, 23

chances of close approach among, 22
Stars, mode of tidal disruption in, 15 new, 9

Wolf-Rayet, 9

Static forms, 81

Stegocephalia, 125, 145

Stegosauria, 130, 132

characteristics of, 131

Stegosaurus, 130

Stellar system, sun a member of, 6 Stockholm, optimum temperature in, as shown by death-rate, 167,169

Storms, changes in track of, 187 effect of, on human energy, 166 present belt of, 187

Strand-line, 76, 120

Stratification, density, 36

Struggle for existence, 73, 81

Suess, E., 38

Sulphur, 102

Sumatra, 188

Sun, 4, 10,12,13,19,20,44, 98, 105 ancestral, tidal disruption of, 16 as life factor, 54 as member of stellar system, 6 critical velocity of, 17 origin of, 46 prominences shot out from, 16 rotation of, 20

Sunshine, 102

Surface processes, in earth, 43

Swan, 89

Sweden, iron in, 155

Swim-bladder, 120

Swine, 136

Tapirs, 136

Tartrates, 107

Temperature, changes in, effect of, 165,172

effect of, on death-rate, $163,164,165$ optimum, 167

Terrestrial foot, evolution of, 123 foot, origin of, 111 types, influence of aridity on, 127 
Terrestrial types, influence of increasing cold on, 127

vertebrates, eggs of, 126

vertebrates, emergence of, 119, 122 waters, as place of chordate origin, 119

waters, as place of origin of lungbreathers, 121

Tertiary, climatic oscillation in, 135

Theriodonts, 128

Thermal springs, 56, 75

Theropoda, 130

Thinopus antiquus, 123, 124

Thorium, 42

Tidal disruption, forces of, 13, 14 disruption, in ancestral sun, 16, 17 disruption, mode of, in stars, 15

force, of earth on moon, 30 retardations, 28

strains, in earth, 30

Tide-generating force, 16

Tides, body, 29

in Archeozoic, 63

loss of energy due to, 29

Tools, invention of, 174

Trachodons, 132

Trees, growth of, as evidence of climatic change, 185,186

Triassic period, 46, 76, 79, 111

period, climate of, 55

Upper, 127, 129, 133, 145

Triton, 124, 125

Troland, L. T., enzyme theory of, 103

Tropical climates, effect of, on man, 149

Tropics, contribution of, to civilization, 182

Tunicates, 117

Turkestan, 185

Turkey, 185

Tyndall, J., 93

Underhill, F. P., 84

Ungulates, 136
Uniformitarian trend, of biologic thought, 106

United States, eastern, deaths in, 158, $159,161,164,165,168,169,170$, 171

northeastern, storms in, 166

southwestern, ruins in, 185

Weather Bureau, $18+$

Uranium, 42, 67, 69

Uranus, 4, 5, 6, 31

Utah, 152, 153, 154

Indians of, 152

Ute Indians, 152, 153, 154

Vadose water, 75

Vegetation, dependence of, on climate, 155

Venus, 5, 28

Vertebrates, distinguished from invertebrates, 114

egg of, change in, 126

evolution of, 113

first recorded, 144

origin of, $111,114,144$

terrestrial, emergence of, 119, 122

Virgil, 89

Vitalism, 94

Volcanic activity, as source of earth's water, 56

activity, times of, 74

ashes, 75

Volcanism, in Formative era, 48

Volcanoes, as source of carbon dioxide, 52

Walcott, C. D., 69

Warm blood, origin of, 111, 127, 145

Wasps, 90

Water, precipitation of, 100

Water-va por, 54, 98

-vapor, as climate regulator, 52

-vapor, in primordial atmosphere, $34,35,38$

Waters, juvenile, 38, 75 
208

\section{INDEX}

Waters, land, as place of chordate Winds, 54 origin, 119 oceanic, gathering of, 37 vadose, 75

Waucobian period, 76

Weathering, 32, 33, 80

Whales, 81

Williams, H. S., 69

Wilson, E. B., 94

Winnemucka Lake, 185

Worms, 89, 90, 113, 114

Writing, invention of, 181

Yemen, 188, 189

Young, C. A., 5

Yucatan, rainfall in, 188 



\section{$-$}



$v$

$\infty$

$\vartheta$

h 
